Summary of Failure Analysis Activities at Brookhaven National Laboratory

Prepared by

M. G. Cowgill, C. J. Czajkowski, E. M. Franz

Brookhaven National Laboratory

RECEIVED

Hov 121996

OSTI

Prepared for

U.S. Nuclear Regulatory Commission 


\section{AVAILABILITY NOTICE}

Availability of Reference Materials Cited in NRC Publications

Most documents cited in NRC publications will be available from one of the following sources:

1. The NRC Public Document Room, 2120 L Street, NW., Lower Level, Washington, DC 20555-0001

2. The Superintendent of Documents, U.S. Government Printing Office, P. O. Box 37082 , Washington, DC 20402-9328

3. The National Technical Information Service, Springfield, VA 22161-0002

Although the listing that follows represents the majority of documents cited in NRC publications, it is not intended to be exhaustive.

Referenced documents available for inspection and copying for a fee from the NRC Public Document Room include NRC correspondence and internal NRC memoranda; NRC bulletins, circulars, information notices, inspection and investigation notices; licensee event reports; vendor reports and correspondence: Commission papers; and applicant and licensee documents and correspondence.

The following documents in the NUREG series are available for purchase from the Government Printing Office: formal NRC staff and contractor reports. NRC-sponsored conference proceedings, international agreement reports, grantee reports, and NRC booklets and brochures. Also available are regulatory guides, NRC regulatlons in the Code of Federal Regulations, and Nuclear Regulatory Commission Issuances.

Documents avallable from the National Technical Information Service include NUREG-series reports and technical reports prepared by other Federal agencies and reports prepared by the Atomic Energy Commission, forerunner agency to the Nuclear Regulatory Commission.

Documents available from public and special technical libraries include all open literature items, such as books, journal articles, and transactions. Federal Register notices. Federal and State legislation, and congressional reports can usually be obtained from these libraries.

Documents such as theses, dissertations, foreign reports and translations, and non-NRC conference proceedings are available for purchase from the organization sponsoring the publication cited.

Single copies of NRC draft reports are available free. to the extent of supply. upon written request to the Office of Administration, Distribution and Mail Services Section, U.S. Nuclear Regulatory Commission, Washington, DC 20555-0001.

Coples of industry codes and standards used in a substantive manner in the NRC regulatory process are maintalned at the NRC Library. Two White Flint North. 11545 Rockville Pike, Rockville, MD 20852-2738, for use by the public. Codes and standards are usually copyrighted and may be purchased from the originating organization or, if they are American National Standards. from the American National Standards Institute. 1430 Broadway, New York, NY 10018-3308.

\section{DISCLAIMER NOTICE}

This report was prepared as an account of work sponsored by an agency of the United States Government. Neither the United States Govemment nor any agency thereof, nor any of their employees, makes any warranty, expressed or implied, or assumes any legal liability or responsibility for any third party's use, or the results of such use, of any information, apparatus, product, or process disclosed in this report, or represents that its use by such third party would not infringe privately owned rights. 


\section{DISCLAIMER}

Portions of this document may be illegible in electronic image products. Images are produced from the best available original document. 


\section{DISCLAIMER}

This report was prepared as an account of work sponsored by an agency of the United States Government. Neither the United States Government nor any agency thereof, nor any of their employees, makes any warranty, express or implied, or assumes any legal liability or responsibility for the accuracy, completeness, or usefulness of any information, apparatus, product, or process disclosed, or represents that its use would not infringe privately owned rights. Reference herein to any specific commercial product, process, or service by trade name, trademark, manufacturer, or otherwise does not necessarily constitute or imply its endorsement, recommendation, or favoring by the United States Government or any agency thereof. The views and opinions of authors expressed herein do not necessarily state or reflect those of the United States Government or any agency thereof. 


\section{Summary of Failure Analysis}

Activities at

\section{Brookhaven National Laboratory}

Manuscript Completed: May 1996

Date Published: October 1996

Prepared by

M. G. Cowgill, C. J. Czajkowski, E. M. Franz

Brookhaven National Laboratory

Upton, NY 11973

\section{Prepared for}

Division of Enginering

Office of Nuclear Reactor Regulation

U.S. Nuclear Regulatory Commission

Washington, DC 20555-0001

NRC Job Code E2089 


\begin{abstract}
Brookhaven National Laboratory has for many years conducted examinations related to the failures of nuclear materials and components. These examinations included the confirmation of root cause analyses, the determination of the causes of failure, identification of the species that accelerate corrosion, and comparison of the results of nondestructive examinations with those obtained by destructive examination. The results of those examinations, which had previously appeared in various formats (formal and informal reports, journal articles, etc.), have been collected together and summarized in the present report. The report is divided into sections according to the general subject matter (for example, corrosion, fatigue, etc.). Each section presents summaries of the information contained in specific reports and publications, all of which are fully identified as to title, authors, report number or journal reference, date of publication, and FIN number under which the work was performed.
\end{abstract}





\section{TABLE OF CONTENTS}

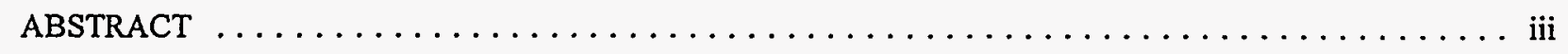

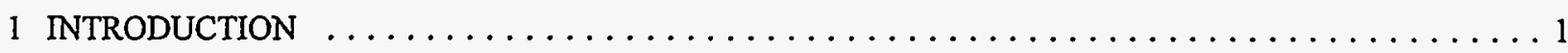

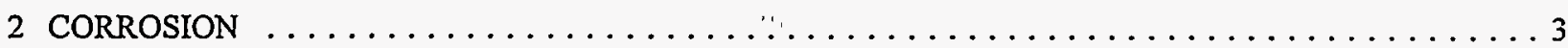

2.1 Corrosion of Structural and Poison Material in Spent Fuel Storage Pools . . . . . . . . 3

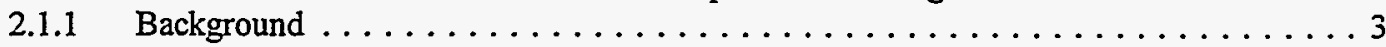

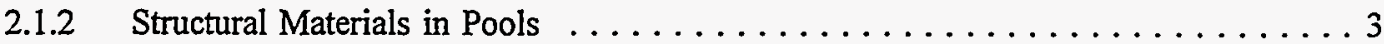

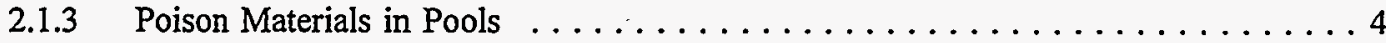

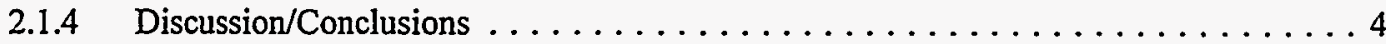

2.2 Boric Acid Corrosion of Ferritic Reactor Components $\ldots \ldots \ldots \ldots \ldots \ldots \ldots \ldots$

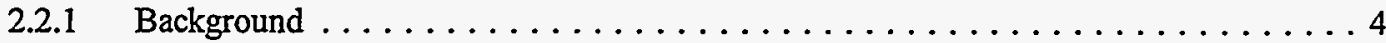

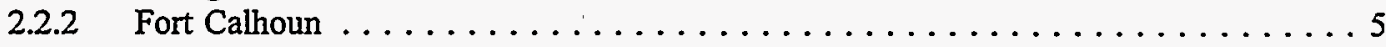

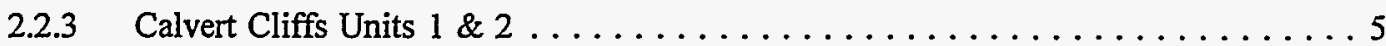

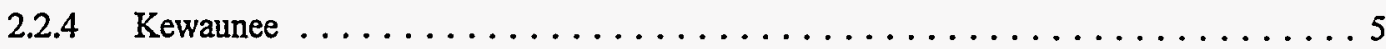

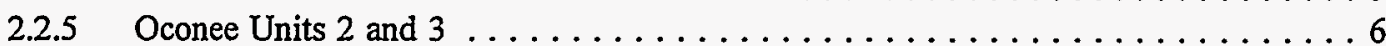

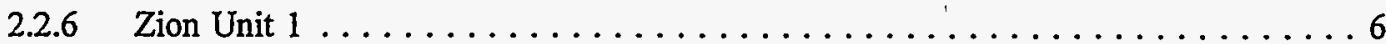

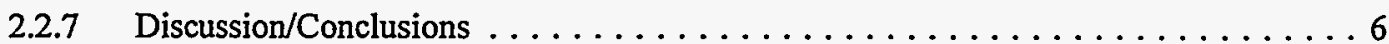

2.3 Investigation of a Reactor Head Bolt from Turkey Point No. $3 \ldots \ldots \ldots \ldots \ldots \ldots \ldots$

2.3.1 Background ....................... 7

2.3.2 Visual Examination/Dye Penetrant Examination $\ldots \ldots \ldots \ldots \ldots \ldots \ldots \ldots$

2.3.3 Hardness . . . . . . . . . . . . . . . . . . . . . . 7

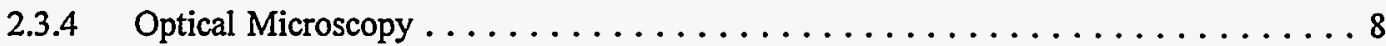

2.3.5 Discussion/Conclusions . . . . . . . . . . . . . . . . . . 8

2.4 Evaluation of Dealloying in Aluminum Bronze Components at the South Texas Project . . . 8

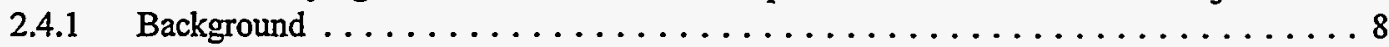

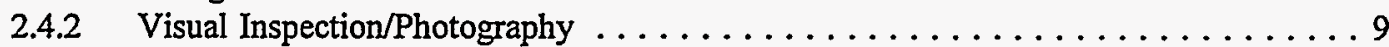

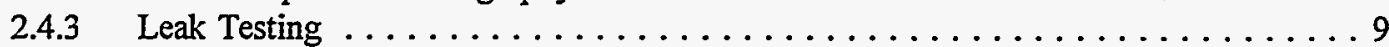

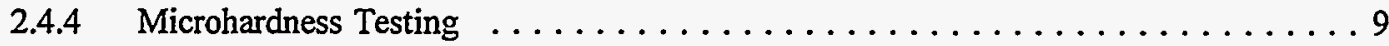

2.4.5 Chemical Analysis of Flux ..................... 9

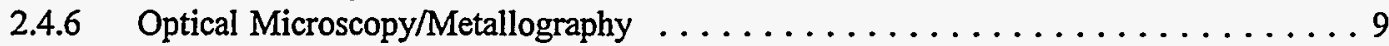

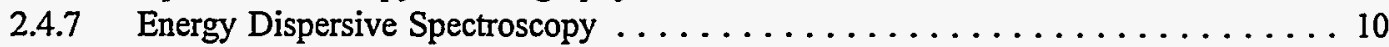

2.4 .8 Discussion/Conclusions . . . . . . . . . . . . . . . . . 10

2.5 Survey of Boric Acid Corrosion of Carbon Steel Components in Nuclear Plants . . . . . 10

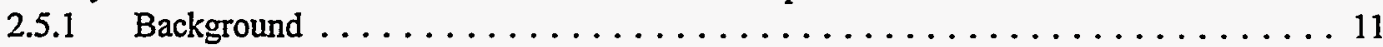

$2.5 .2 \quad$ Audit Results . . . . . . . . . . . . . . . . . . . . . . 11

2.5 .3 Discussion/Conclusions . . . . . . . . . . . . . . . . 12

2.6 Corrosion Testing of Thermal Shield Support System - San Onofre Nuclear Generating

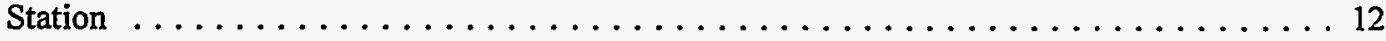

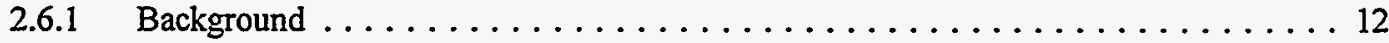

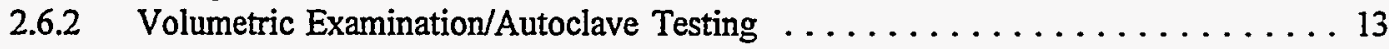

2.6 .3 Dye Penetrant Testing . . . . . . . . . . . . . . . . . . 13

2.6 .4 Discussion/Conclusions . . . . . . . . . . . . . . . . . . . 13

2.7 Examination of a Bolt with Boric Acid Attack from Three Mile Island Nuclear Generating

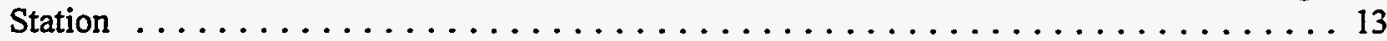

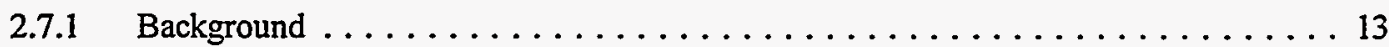

2.7.2 Visual Examination/Dimensional Characteristics $\ldots \ldots \ldots \ldots \ldots \ldots \ldots \ldots$

2.7.3 Hardness Measurements . . . . . . . . . . . . . . . . . 14 


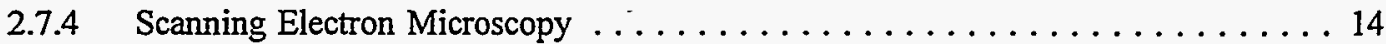

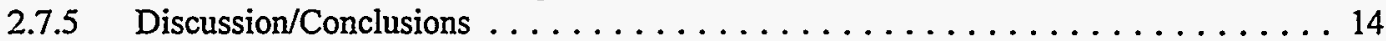

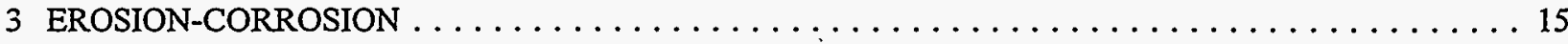

3.1 Metallurgical Evaluation of an 18-inch Feedwater Line Failure at the Surry Unit 2 Power

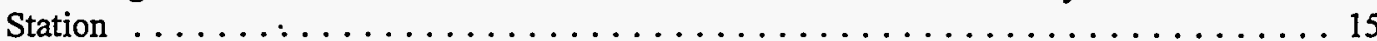

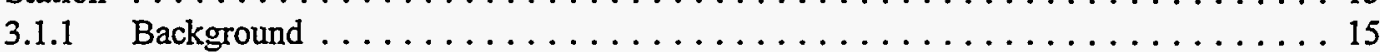

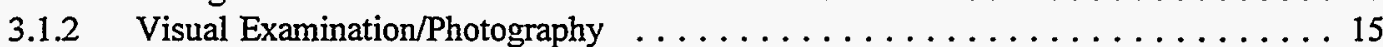

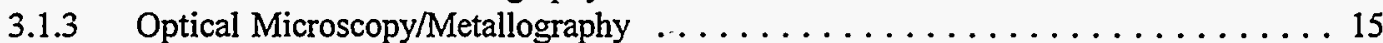

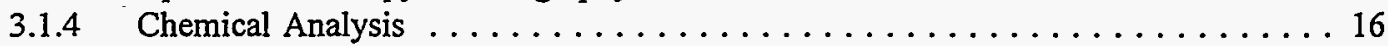

3.1.5 Impact Testing/Bend Testing/Hardness Testing/Tensile Testing . . . . . . . . 16

3.1.6 Scanning Electron Microscopy/Energy Dispersive Spectroscopy $\ldots \ldots \ldots \ldots \ldots 16$

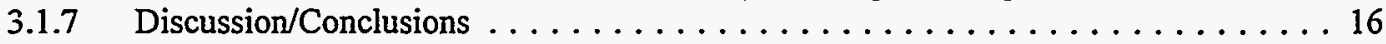

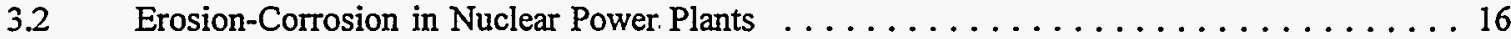

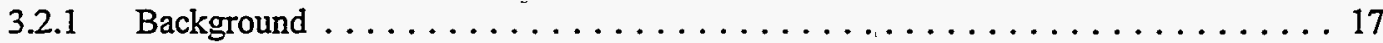

3.2.2 The Erosion-Corrosion Phenomenon $\ldots \ldots \ldots \ldots \ldots \ldots \ldots \ldots \ldots \ldots \ldots$

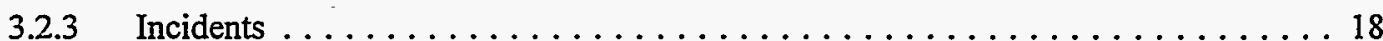

3.2.4 Discussion/Conclusions . . . . . . . . . . . . . . . . . . . . 19

3.3 Evaluation of Pipe Samples from the Trojan Nuclear Power Station . . . . . . . . . 19

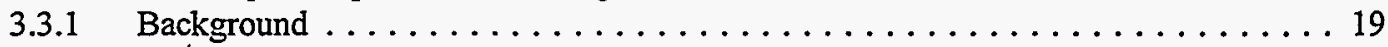

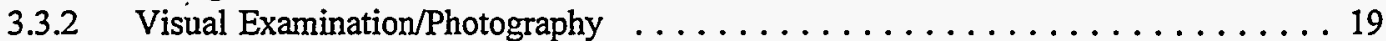

3.3.3 Chemical Analysis . .......................... 20

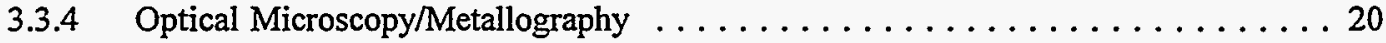

3.3.5 Scanning Electron Microscopy/Energy Dispersive Spectroscopy $\ldots \ldots \ldots \ldots 20$

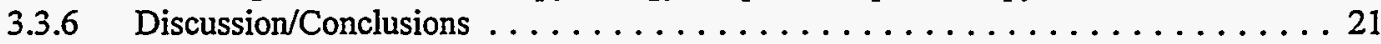

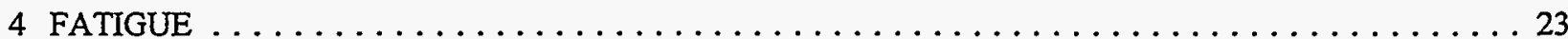

4.1 Metallurgical Examination of Steam Generator Feedwater Pipe Cracks . . . . . . . . . 23

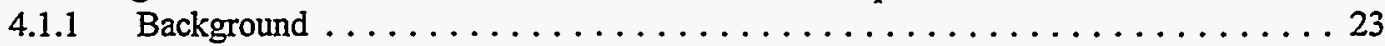

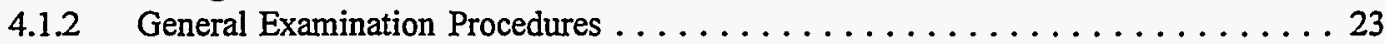

$4.1 .3 \quad$ Results . . . . . . . . . . . . . . . . . . . . 24

4.1.4 Discussion/Conclusions . . . . . . . . . . . . . . . . . . . 26

4.2 Metallurgical Examination of Cracked Feedwater Pipes from Nine Pressurized Water

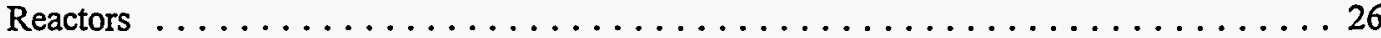

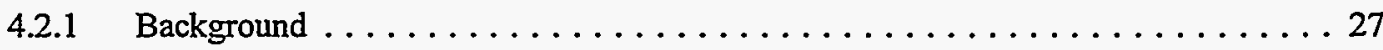

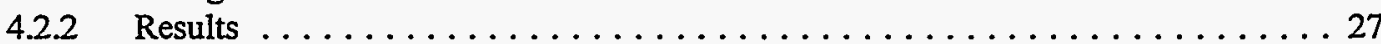

4.2.3 Discussion/Conclusions .......................... 27

4.3 Evaluation of the Transgranular Cracking Phenomenon on the Indian Point No. 3 Steam

Generator Vessels . . . . . . . . . . . . . . . . . . . . . . . . . . . . . . 29

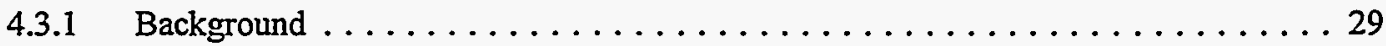

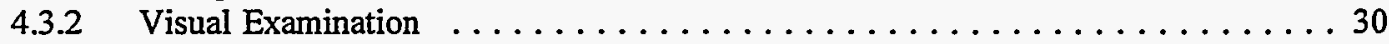

4.3.3 Hardness Measurements/Heat Treatments . . . . . . . . . . . . . 30

4.3.4 Optical Microscopy . . . . . . . . . . . . . . . . . . . . 30

4.3.5 Scanning Electron Microscopy/Energy Dispersive Spectroscopy $\ldots \ldots \ldots \ldots .30$

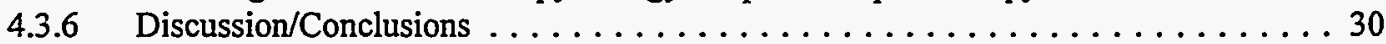

4.4 Evaluation of Boat Samples from the Steam Generators at Indian Point No. $2 \ldots \ldots \ldots 31$

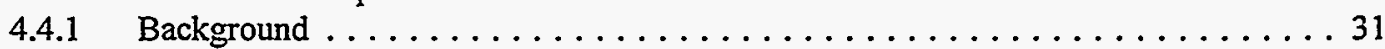

4.4.2 Visual Examination/Hardness Measurements/Heat Treatment ............. 31

4.4 .3 Optical Microscopy . . . . . . . . . . . . . . . . . . 31

4.4.4 Scanning Electron Microscopy/Energy Dispersive Spectroscopy . . . . . . 32

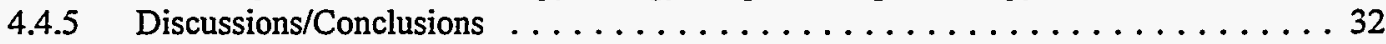

4.5 Examination of a Cracked Reducer from the Trojan Nuclear Plant . . . . . . . . 32 


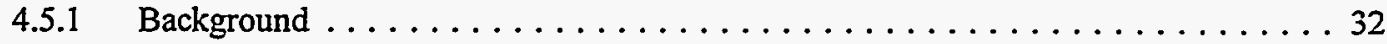

4.5.2 Material/Specimen Preparation ...................... 33

4.5.3 Scanning Electron Microscopy/Energy Dispersive Spectroscopy . . . . . . . 33

$4.5 .4 \quad \mathrm{Visual} /$ Photography . . . . . . . . . . . . . . . . . . . 33

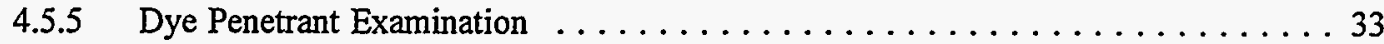

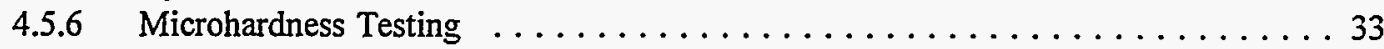

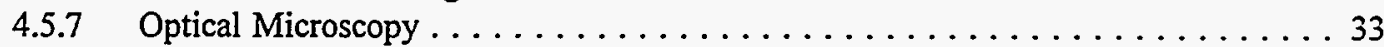

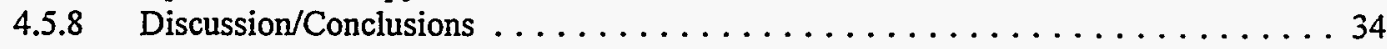

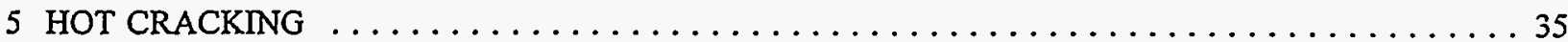

5.1 Evaluation of a Cracked RHR Pump Impeller from the Vermont Yankee Power Plant . . . 35

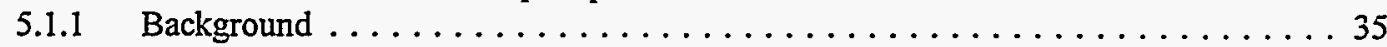

5.1.2 Visual Inspection/Photography/Optical Microscopy $\ldots \ldots \ldots \ldots \ldots \ldots \ldots 35$

5.1 .3 Hardness Testing . . . . . . . . . . . . . . . . . . . 36

5.1.4 Scanning Electron Microscopy/Energy Dispersive Spectroscopy $\ldots \ldots \ldots \ldots 36$

5.2 Evaluation of Cracks Found in Stellite Valve Guides at Vermont Yankee Nuclear Power

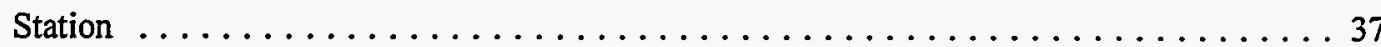

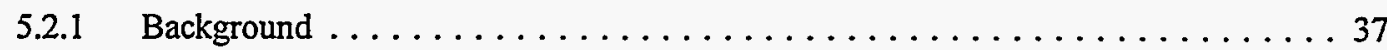

5.2.2 Visual/Photography/Dye Penetrant Inspection $\ldots \ldots \ldots \ldots \ldots \ldots \ldots \ldots \ldots$

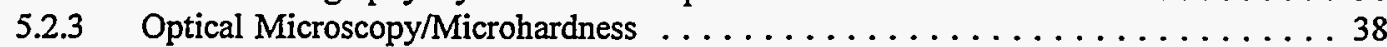

5.2.4 Scanning Electron Microscopy/Energy Dispersive Spectroscopy $\ldots \ldots \ldots \ldots . \ldots 38$

5.2 .5 Discussion/Conclusions . . . . . . . . . . . . . . . . . 39

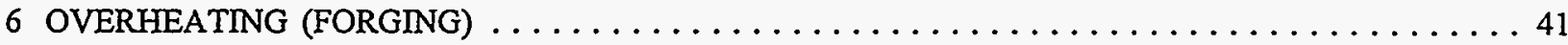

6.1 Evaluation of Intergranular Cracks on the Ring Header Cross at Grand Gulf Unit No.1 . . 41

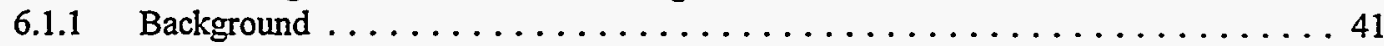

6.1.2 Visual Inspections/Photographs/Dye Penetrant Examination .......... 41

6.1.3 Chemical Analysis/Hardness Testing . . . . . . . . . . . . . . 42

6.1.4 Optical Microscopy/Metallography .................. 42

6.1.5 Scanning Electron Microscopy/Energy Dispersive Spectroscopy . . . . . . . 42

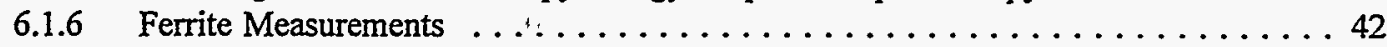

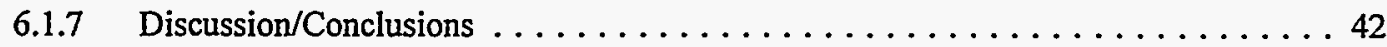

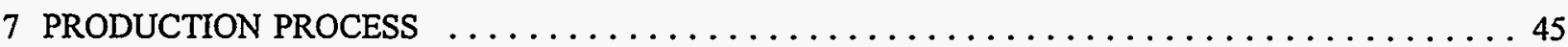

7.1 Failure Investigation of $3 \mathrm{M}$ Series 900 Static Eliminators $\ldots \ldots \ldots \ldots \ldots \ldots \ldots \ldots$

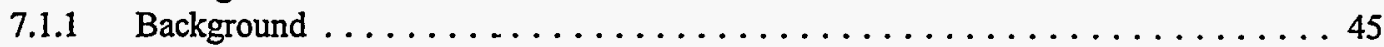

7.1.2 Receipt/Visual Inspection/Wipe Survey/Tap Test ............. 45

7.1.3 Evaluation of Epoxy and Non-Radioactive Microspheres ........... 46

7.1.4 Sectioning/Macrophotography/Scanning Electron Microscopy . . . . . . . . . 46

7.1.5 Discussion/Conclusions ........................ 46

7.2 Examination of Two $3 \mathrm{M}$ Type $902 \mathrm{~F}$ Static Eliminators $\ldots \ldots \ldots \ldots \ldots \ldots \ldots \ldots$

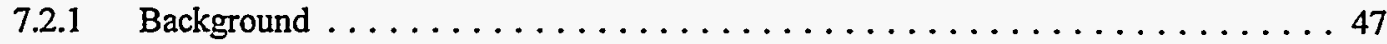

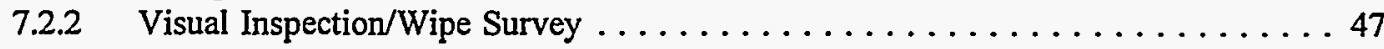

7.2.3 Macrophotography/Scanning Electron Microscopy . . . . . . . . . 47

7.2.4 Evaluation of Radioactive Microspheres . . . . . . . . . . . . . 48

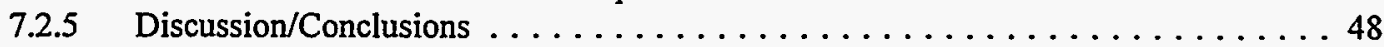

8 STRESS CORROSION CRACKING . . . . . . . . . . . . . . . . . . . . . . 49

8.1 Intergranular Stress Corrosion Cracking of Type 304 Stainless Steel in the Spent Fuel Pool

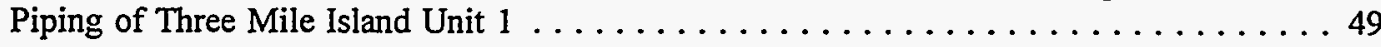

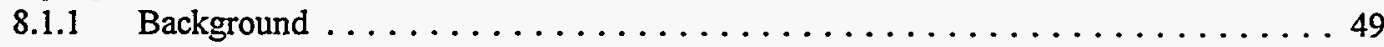


8.1.2 Visual Inspection/Photography $\ldots \ldots \ldots \ldots \ldots \ldots \ldots \ldots \ldots \ldots \ldots$

8.1 .3 Optical Microscopy . . . . . . . . . . . . . . . . . . 50

8.1.4 Scanning Electron Microscopy/Energy Dispersive Spectroscopy ........ 50

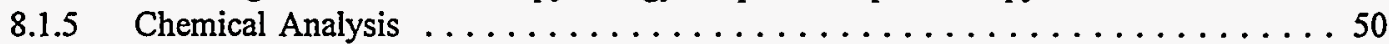

8.1.6 Constant Extension Rate Testing . . . . . . . . . . . . . . . . 51

8.1.7 Electrochemical Potentiokinetic Reactivation Analysis . . . . . . . . . . 51

8.1 .8 Discussion/Conclusions . . . . . . . . . . . . . . . . . 51

8.2 Examination of Failed Turbine Discs from Yankee-Rowe Nuclear Power Station . . . . . . 52

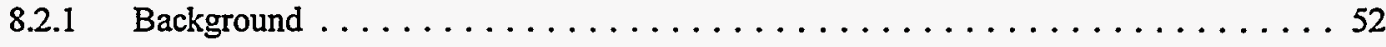

8.2.2 Visual Inspection/Optical Metallography/Photography $\ldots \ldots \ldots \ldots \ldots \ldots 52$

8.2.3 Scanning Electron Microscopy/Energy Dispersive Spectroscopy $\ldots \ldots \ldots \ldots .53$

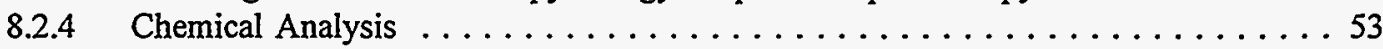

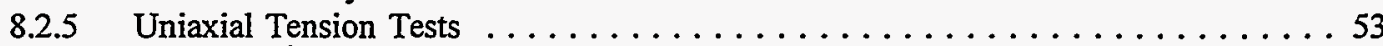

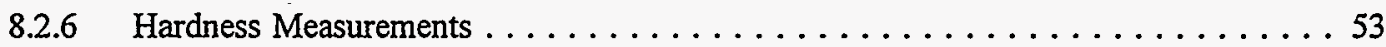

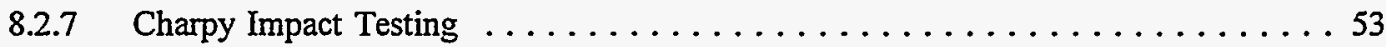

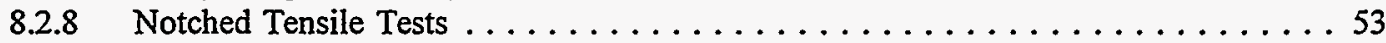

8.2 .9 Discussion/Conclusions . . . . . . . . . . . . . . . . . 53

8.3 Failure Analysis of a Bolt from "B" Reactor Coolant Pump at the H.B. Robinson Unit 2

Nuclear Power Station . . . . . . . . . . . . . . . . . . . . 54

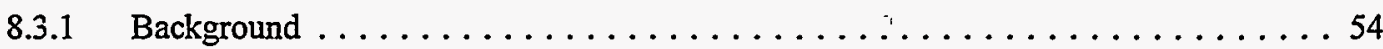

8.3.2 Visual/Photography/Dye Penetrant Examination $\ldots \ldots \ldots \ldots \ldots \ldots \ldots \ldots$

8.3.3 Scanning Electron Microscopy/Energy Dispersive Spectroscopy $\ldots \ldots \ldots \ldots \ldots 5$

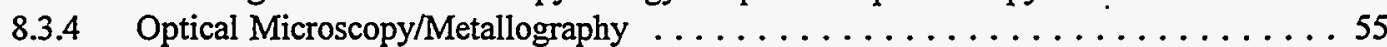

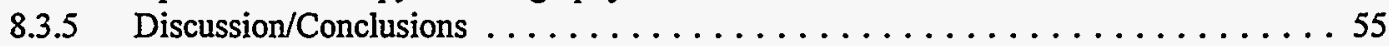

8.4 Evaluation of Failed Reactor Coolant Pumps Internal Bolts from the H.B. Robinson Nuclear

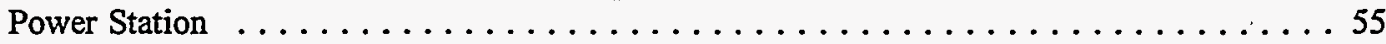

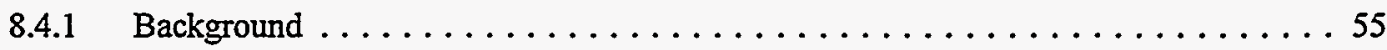

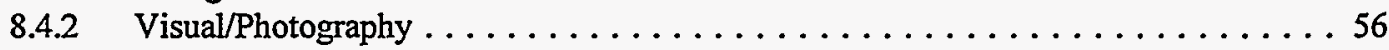

8.4.3 Scanning Electron Microscopy/Energy Dispersive Spectroscopy . . . . . . . 56

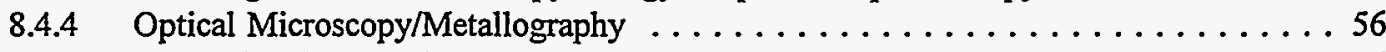

8.4 .5 Discussions/Conclusions . . . . . . . . . . . . . . . . . 56

8.5 Constant Extension Rate Testing of SA 302 Grade B Material in Neutral and Chloride

Solutions . . . . . . . . . . . . . . . . . . . . . . 56

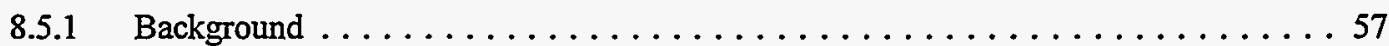

8.5.2 CERT Results/Optical Microscopy/Scanning Electron Microscopy . . . . . . . . 57

8.5.3 Discussion/Conclusions . . . . . . . . . . . . . . . . . . 58

8.6 Testing of Nuclear Grade Lubricants and Their Effect on A540 B24 and A193 B7 Bolting

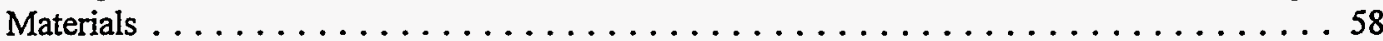

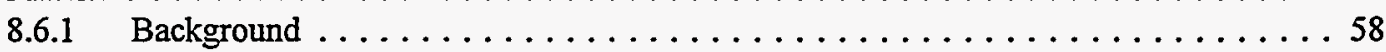

8.6 .2 Chemical Analysis . . . . . . . . . . . . . . . . . 59

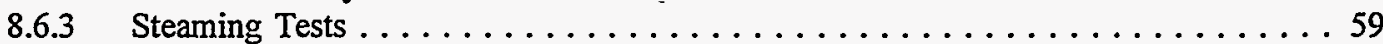

8.6 .4 Friction Tests . . . . . . . . . . . . . . . . . . . . 59

$8.6 .5 \quad$ Notched Tensile CERT Tests $\ldots \ldots \ldots \ldots \ldots \ldots \ldots \ldots \ldots \ldots \ldots \ldots$

8.6 .6 Weight Loss Testing . . . . . . . . . . . . . . . . . . . 59

8.6 .7 Discussion/Conclusions . . . . . . . . . . . . . . . . . . . 59

8.7 Investigation of Corrosion and Stress Corrosion Cracking in Bolting Materials on Light Water

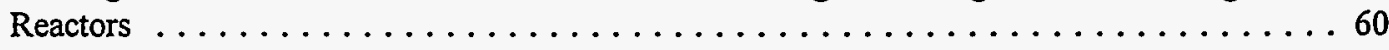

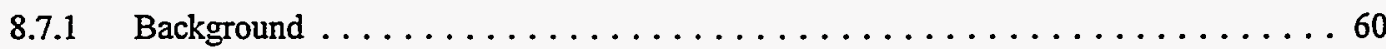

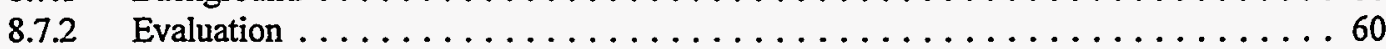

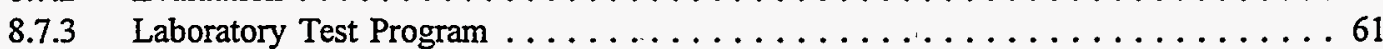

8.7 .4 Discussion $/$ Conclusions . . . . . . . . . . . . . . . . . . 61

$8.8 \quad$ Evaluation of the Pilgrim Inconel 182 Cracking $\ldots \ldots \ldots \ldots \ldots \ldots \ldots \ldots \ldots \ldots \ldots$

NUREG/CR-6489 viii 


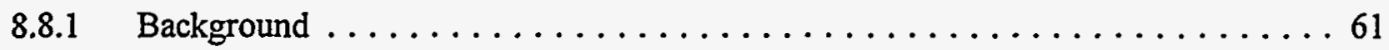

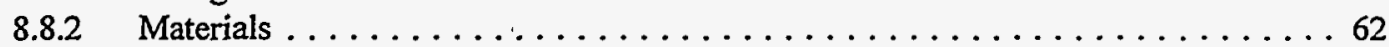

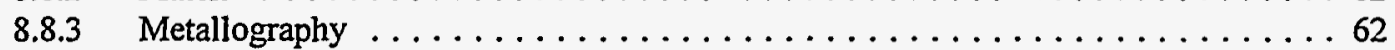

8.8.4 Scanning Electron Microscopy/Energy Dispersive Spectroscopy . . . . . . 63

8.8.5 Discussion/Conclusions . . . . . . . . . . . . . . . . . 63

8.9 Evaluation of Core Spray Line Cracks from Nine Mile Point Unit No. 1 and Isolation

Condenser Cracks at Oyster Creek Unit No. $1 \ldots \ldots \ldots \ldots \ldots \ldots \ldots \ldots . \ldots \ldots$

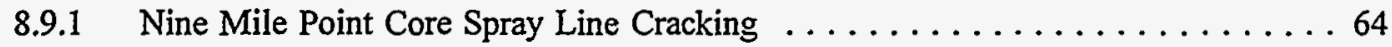

8.9.1.1 Background ....................... 64

8.9.1.2 Optical Metallography/Sensitization Testing . . . . . . . . . 64

8.9.1.3 Scanning Electron Microscopy/Energy Dispersive Spectroscopy . . . . 65

8.9.1.4 Discussion/Conclusions .....................65

8.9.2 Oyster Creek Isolation Condenser Line Cracking . . . . . . . . . . . . . 65

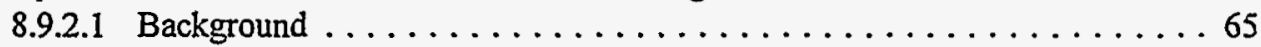

8.9.2.2 Visual Inspection/Photography $\ldots \ldots \ldots \ldots \ldots \ldots \ldots \ldots 65$

8.9.2.3 Optical Microscopy/Metallography/Sensitization Tests $\ldots \ldots \ldots \ldots 65$

8.9.2.4 Ferrite Measurements . . . . . . . . . . . . . . . . 66 66

8.9.2.5 Scanning Electron Microscopy/Energy Dispersive Spectroscopy $\ldots \ldots 66$

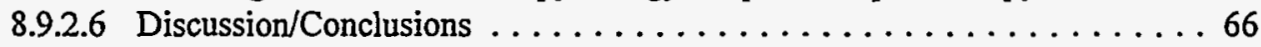

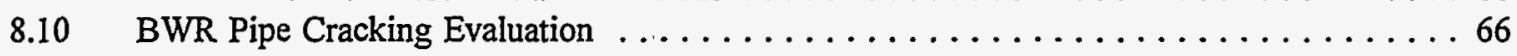

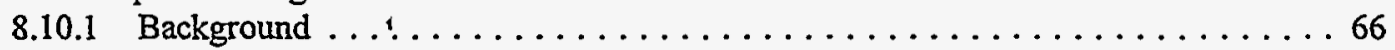

8.10 .2 Receipt/Storage and Cataloging the Samples . . . . . . . . . . . 67

8.10.3 Cutting/Decontamination of the Pipe Samples . . . . . . . . . . . 67

8.10 .4 Dye Penetrant Examination . . . . . . . . . . . . . . . . 67

8.10 .5 Comparison of Utility UT Data to Dye Penetrant Results . . . . . . . . . 68

8.10 .6 Discussion/Conclusions . . . . . . . . . . . . . . . . . 68

8.11 Evaluation of Cracked Pipe from Big Rock Point $\ldots \ldots \ldots \ldots \ldots \ldots \ldots \ldots \ldots \ldots$

8.11 .1 Background . . . . . . . . . . . . . . . . . . 69

8.11 .2 Visual Inspection/Photography . . . . . . . . . . . . . 69

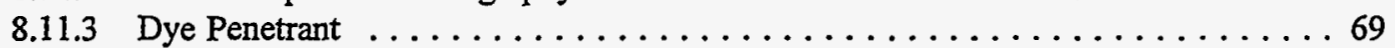

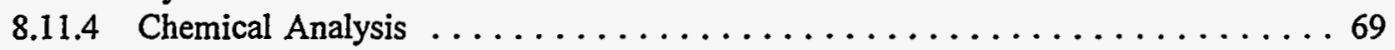

8.11 .5 Optical Microscopy . . . . . . . . . . . . . . . . . . . 70

8.11.6 Scanning Electron Microscopy/Energy Dispersive Spectroscopy $\ldots \ldots \ldots \ldots 70$

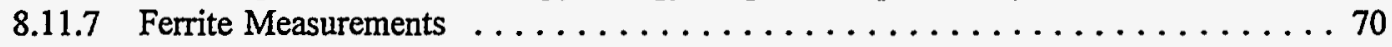

8.11 .8 Discussion/Conclusions . . . . . . . . . . . . . . . . 71

8.12 Evaluation of Cracked Cap Screws from the Control Rod Drive Mechanism of the Monticello

Nuclear Power Plant . . . . . . . . . . . . . . . . . . . . 71

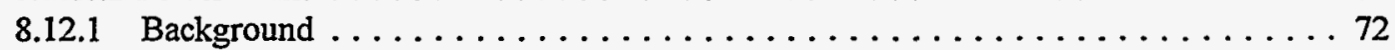

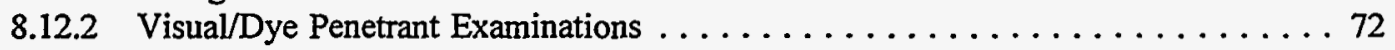

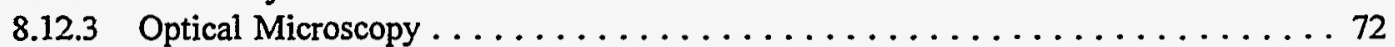

8.12 .4 Hardness Testing/Tensile Testing $\ldots \ldots \ldots \ldots \ldots \ldots \ldots \ldots \ldots \ldots \ldots \ldots$

8.12.5 Scanning Electron Microscopy/Slow Strain Rate Testing $\ldots \ldots \ldots \ldots \ldots \ldots 73$

8.12 .6 Discussion/Conclusions . . . . . . . . . . . . . . . . . 73

8.13 Metallurgical Evaluation of Weld Overlaid Pipe Sections from Brunswick Unit 2 Nuclear Power

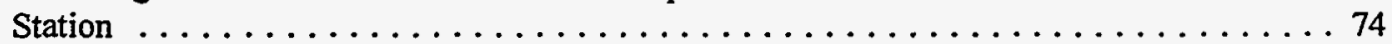

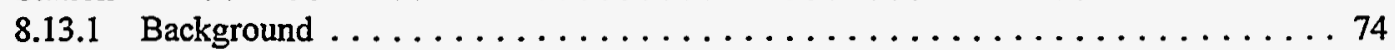

8.13.2 Visual Inspection/Dye Penetrant Examination/Radiography . . . . . . . . . 74

8.13.3 Residual Strain Measurements/Ferrite Measurements $\ldots \ldots \ldots \ldots \ldots \ldots 75$

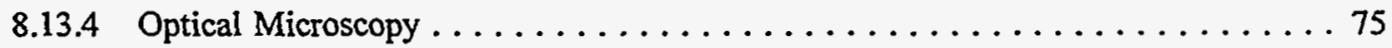

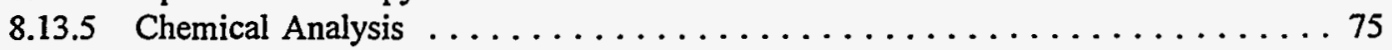

8.13.6 Microhardness Measurements . . . . . . . . . . . . . . . . 75

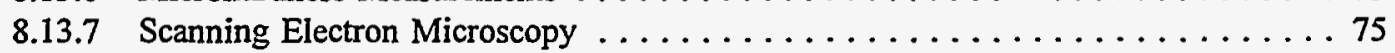


8.13.8 Discussion/Conclusions . . . . . . . . . . . . . . . . . 76

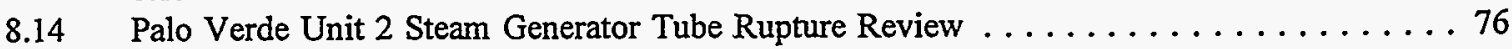

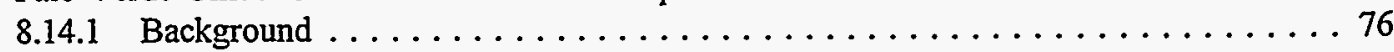

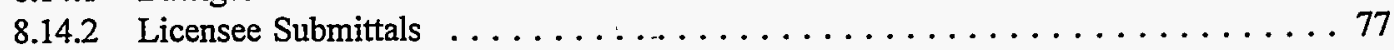

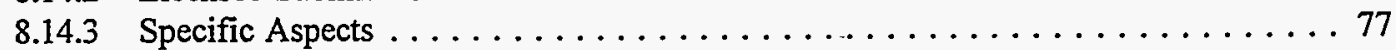

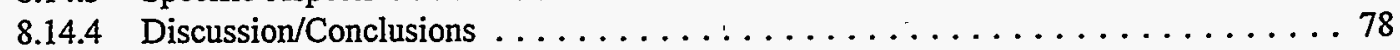

8.15 Palisades Nuclear Plant Safe-End to Pipe Cracking $\ldots \ldots \ldots \ldots \ldots \ldots \ldots \ldots \ldots$

8.15 .1 Background . . . . . . . . . . . . . . . . . . . . 79

8.15.2 Scanning Electron Microscopy/Energy Dispersive Spectroscopy . . . . . . . 79

8.15 .3 Microhardness ............................... 79

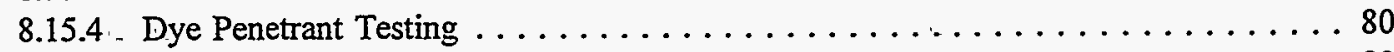

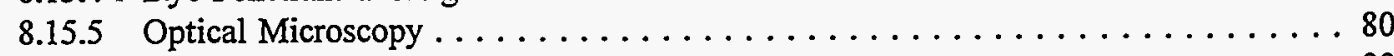

8.15 .6 Discussion/Conclusions . . . . . . . . . . . . . . . . 80

9 TEMPER BRITTLENESS $\ldots \ldots \ldots \ldots \ldots \ldots \ldots \ldots \ldots \ldots \ldots \ldots \ldots \ldots \ldots \ldots \ldots \ldots$

9.1 Investigation of Cracking on a Main Steam Isolation Valve Shaft from the Farley Unit \#1

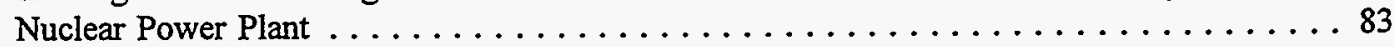

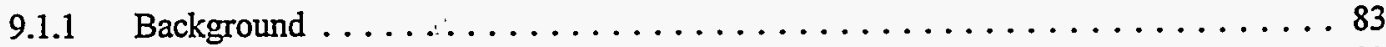

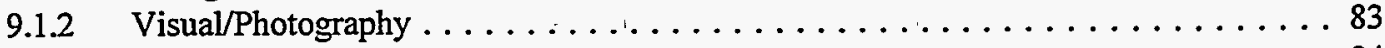

9.1.3 Chemical Analysis/Hardness Testing/Optical Microscopy ............ . 84

9.1.4 Scanning Electron Microscopy/Energy Dispersive Spectroscopy $\ldots \ldots \ldots \ldots .84$

9.1.5 Discussion/Conclusions . . . . . . . . . . . . . . . . . . . 84

9.2 Investigation of Failed Type 410 Stainless Steel Shafts from Main Steam Isolation Valves at

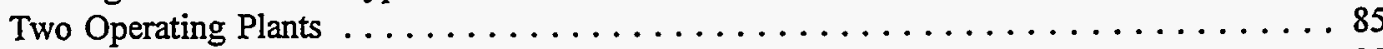

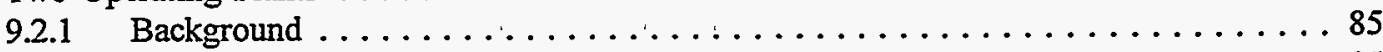

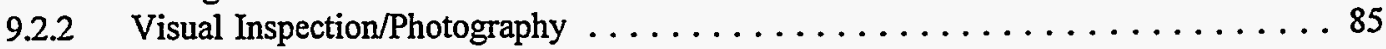

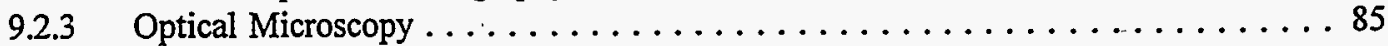

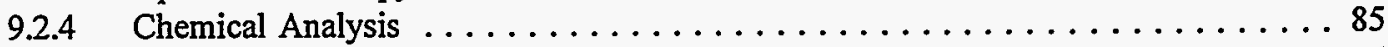

9.2.5 Hardness Testing . . . . . . . . . . . . . . . . . . . 86

9.2.6 Scanning Electron Microscopy/Energy Dispersive Spectroscopy . . . . . . . . 86

9.2.7 Discussion/Conclusions . . . . . . . . . . . . . . . . . 86

9.3 Evaluation of a Failed River Water Pump Shaft Coupling from the Beaver Valley Power

Plant . . . . . . . . . . . . . . . . . . . . . . . 86

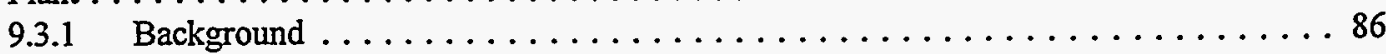

9.3.2 Visual Examination/Chemical Analysis $\ldots \ldots \ldots \ldots \ldots \ldots \ldots \ldots \ldots$

9.3.3 Optical Microscopy . . . . . . . . . . . . . . . . . . . 87

9.3.4 Scanning Electron Microscopy $\ldots \ldots \ldots \ldots \ldots \ldots \ldots \ldots \ldots \ldots \ldots$

9.3.5 Hardness/Tensile/Charpy Impact Testing . . . . . . . . . . . . . . 87

9.3.6 Discussion/Conclusions . . . . . . . . . . . . . . . . . . 87

9.4 Thermal Embrittlement Test Method Development for Type 410 Stainless Steel . . . . . 88

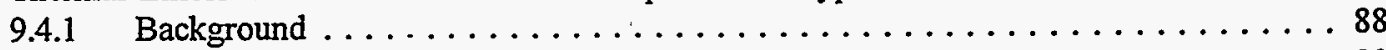

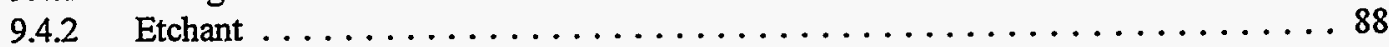

9.4.3 Materials/Heat Treatments/Hardness Testing $\ldots \ldots \ldots \ldots \ldots \ldots \ldots \ldots \ldots 8$

9.4 .4 Charpy Impact Testing $\ldots \ldots \ldots \ldots \ldots \ldots \ldots \ldots \ldots \ldots \ldots . \ldots \ldots$

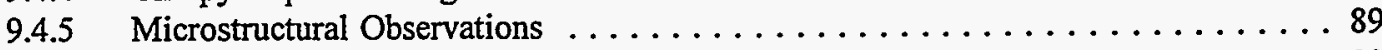

9.4 .6 Discussion/Conclusions . . . . . . . . . . . . . . . . . . 89

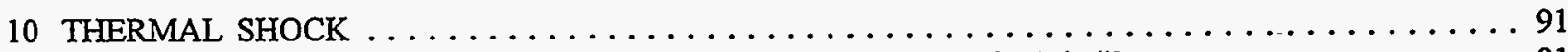

10.1 Evaluation of the Vent Header Crack at Edwin I. Hatch Unit $\# 2 \ldots \ldots \ldots \ldots \ldots \ldots$. $\ldots \ldots$

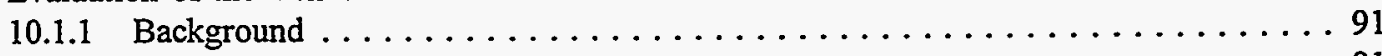

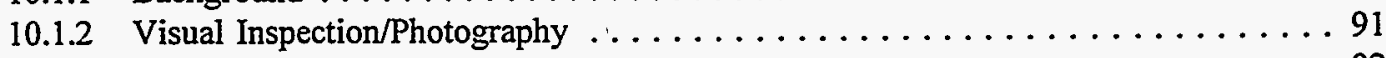

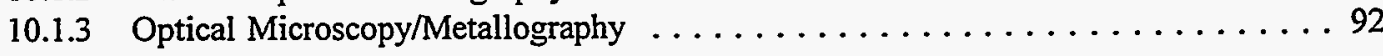


10.1.4 Chemical Analysis/Tensile Testing/Hardness Testing . . . . . . . . . . . 92

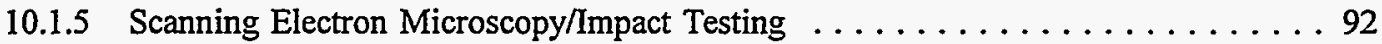

10.1.6 Discussion/Conclusions . . . . . . . . . . . . . . 92

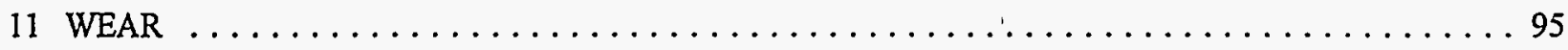

11.1 Investigation of Failed Tubes from "B" Steam Generator of the R.E. Ginna Nuclear Power

Plant . . . . . . . . . . . . . . . . 95

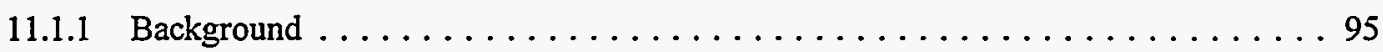

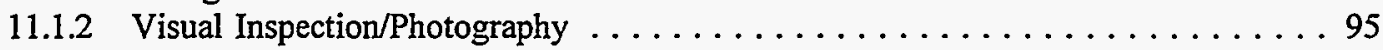

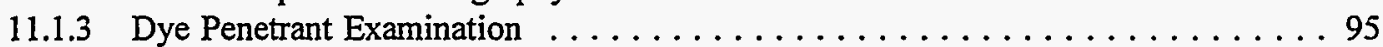

11.1.4 Optical Microscopy . . . . . . . . . . . . . . . . . . . 95

11.1.5 Scanning Electron Microscopy/Energy Dispersive Spectroscopy . . . . . . 96

11.1.6 Discussion/Conclusions . . . . . . . . . . . . . . . . . 96

11.2 Investigation of Reactor Coolant Pump Seal from Indian Point No. $2 \ldots \ldots \ldots \ldots \ldots 96$

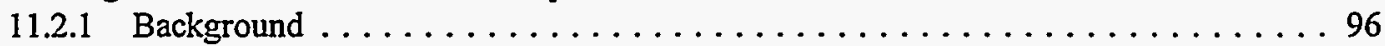

11.2.2 Visual Examination/Photography $\ldots \ldots \ldots \ldots \ldots \ldots \ldots \ldots \ldots \ldots . \ldots \ldots$

11.2.3 Scanning Electron Microscopy/Energy Dispersive Spectroscopy ........ 97

11.2.4 Discussion/Conclusions . . . . . . . . . . . . . . . . 97

12 OTHER FAILURE-RELATED REPORTS $\ldots \ldots \ldots \ldots \ldots \ldots \ldots \ldots \ldots \ldots \ldots \ldots \ldots$

12.1 Evaluation of Cracks Found in Indian Point Steam Generators Phase II . . . . . . . . 99

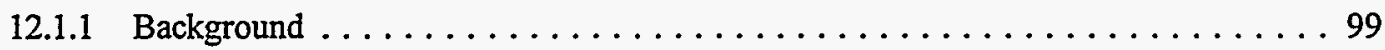

12.1.2 Materials . . . . . . . . . . . . . . . . . . . . 99

12.1.3 Hardness Measurements/Heat Treatment . . . . . . . . . . . . . 99

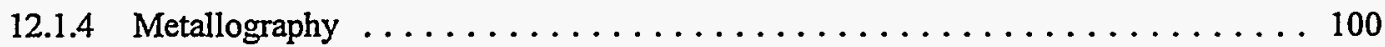

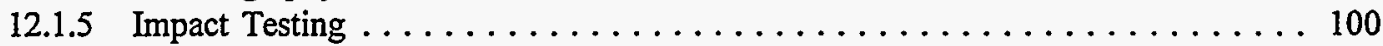

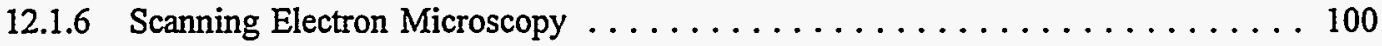

12.1 .7 Discussion/Conclusions . . . . . . . . . . . . . . . . . 100

12.2 Examination of Failed Controlled Closure Check Valve Bolts from the Seabrook Nuclear

Power Plant . . . . . . . . . . . . . . . . . . . 100

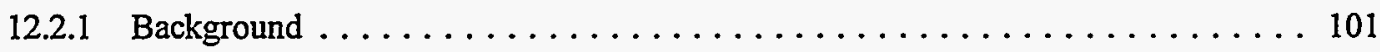

12.2 .2 Visual/Photography . . . . . . . . . . . . . . . . . . 101

12.2.3 Scanning Electron Microscopy . . . . . . . . . . . . . . 101

12.2.4 Hardness Measurements/Optical Microscopy . . . . . . . . . . . . . 101

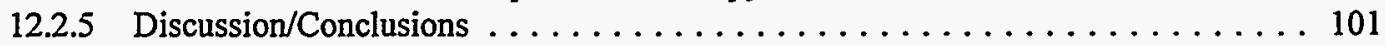

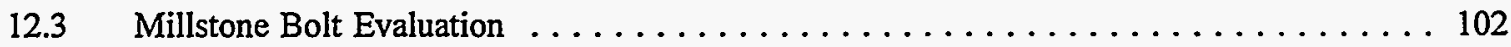

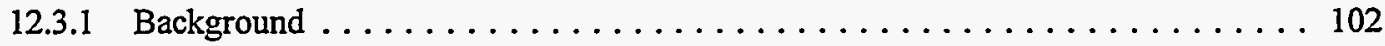

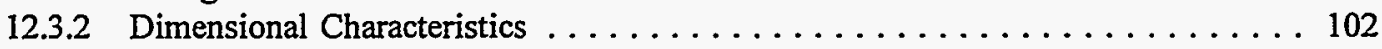

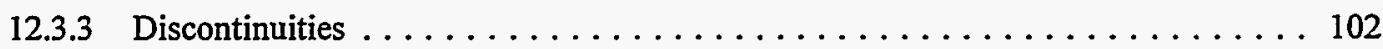

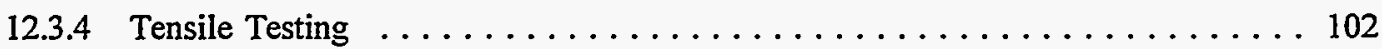

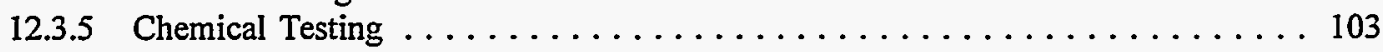

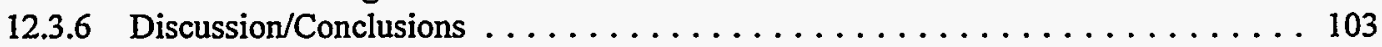

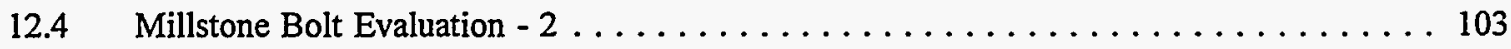

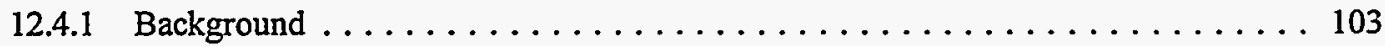

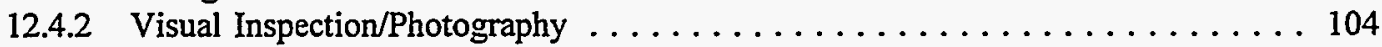

12.4.3 Dimensional Characteristics . . . . . . . . . . . . . . . . . 104

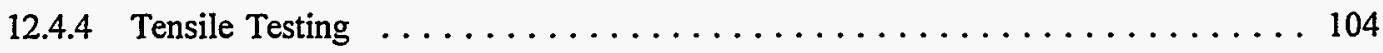

12.4.5 Hardness Testing . . . . . . . . . . . . . . . . . . . 104

12.4 .6 Chemical Analyses . . . . . . . . . . . . . . . . . . . . 104

12.4 .7 Discussion/Conclusions . . . . . . . . . . . . . . . . . . 104

12.5 Evaluation of Stainless Steel Tubes from TVA $\ldots \ldots \ldots \ldots \ldots \ldots \ldots \ldots \ldots \ldots$

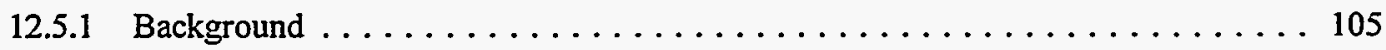




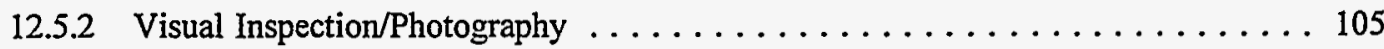

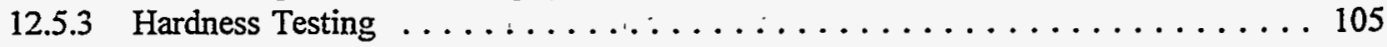

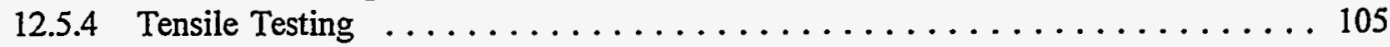

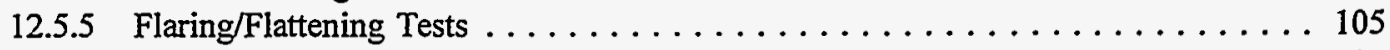

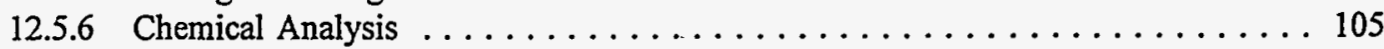

12.5 .7 Dimensional Characteristics . . . . . . . . . . . . . . . . 105

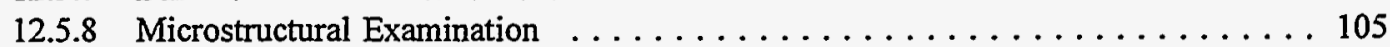

12.5.9 Discussion/Conclusions . . . . . . . . . . . . . . . . . . 105

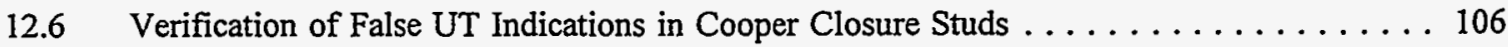

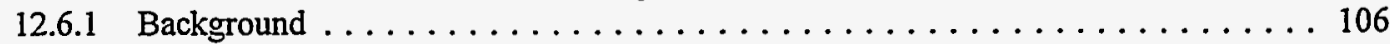

12.6.2 Document Review . . . . . . . . . . . . . . . . . . . 106

12.6.3 Magnetic Particle/Confirmatory UT Tests . . . . . . . . . . . . 106

12.6.4 Destructive Examination . . . . . . . . . . . . . . . . . . . 107

12.6.5 Discussion/Conclusions . . . . . . . . . . . . . . . . . . 107

APPENDIX: CHRONOLOGICAL LIST OF DOCUMENTS $\ldots \ldots \ldots \ldots \ldots \ldots \ldots \ldots \ldots$ 


\section{ABBREVIATIONS}

$\begin{array}{ll}\text { ANSI } & \text { American National Standards Institute } \\ \text { ASME } & \text { American Society of Mechanical Engineers } \\ \text { ASTM } & \text { American Society for Testing and Materials } \\ \text { BNL } & \text { Brookhaven National Laboratory } \\ \text { BWR } & \text { boiling water reactor } \\ \text { CERT } & \text { constant extension rate testing } \\ \text { CVN } & \text { Charpy V notch } \\ \text { DBA } & \text { design basis accident } \\ \text { ECT } & \text { eddy current testing } \\ \text { ECW } & \text { essential cooling water } \\ \text { EDM } & \text { electric discharge machining } \\ \text { EDS } & \text { energy dispersive spectroscopy } \\ \text { FN } & \text { ferrite number } \\ \text { GE } & \text { General Electric Company } \\ \text { GTAW } & \text { gas tungsten arc welding } \\ \text { HAZ } & \text { heat affected zone } \\ \text { IGA } & \text { intergranular attack } \\ \text { IGSCC } & \text { intergranular stress corrosion cracking } \\ \text { IHSI } & \text { induction heating stress improvement } \\ \text { LER } & \text { licensing event report } \\ \text { LOCA } & \text { loss-of-coolant accident } \\ \text { MSIV } & \text { main steam isolation valve } \\ \text { NA } & \text { not available } \\ \text { NDTT } & \text { nil ductility transition temperature } \\ \text { NRC } & \text { United States Nuclear Regulatory Commission } \\ \text { PWR } & \text { pressurized water reactor } \\ \text { PWSCC } & \text { primary water stress corrosion cracking } \\ \text { RCP } & \text { reactor coolant pump } \\ \text { RHR } & \text { residual heat removal } \\ \text { RWCU } & \text { reactor water cleanup } \\ \text { SCC } & \text { stress corrosion cracking } \\ \text { SEM } & \text { scanning electron microscopy } \\ \text { TMI } & \text { Three Mile Island } \\ \text { UT } & \text { ultrasonic test } \\ & \end{array}$




\section{INTRODUCTION}

Over the years, dating back to around 1980, the United States Nuclear Regulatory Commission (NRC) has placed, through the Office of Nuclear Reactor Regulation, a number of task orders with the Brookhaven National Laboratory (BNL) to conduct examinations related to the failures of nuclear components. These examinations included the confirmation of root cause analyses, the determination of the causes of failure, identification of the species that accelerate corrosion, and comparison of the results of non-destructive examinations with those obtained by destructive examination. The results of those examinations appeared in various publications (formal and informal reports, journal articles, etc.) but are not always easily accessible. Consequently, it was thought desirable that an omnibus report should be prepared that summarized the information contained in the prior publications. The present report was prepared to fill that need.

The report is divided into sections according to the general subject matter (for example, corrosion, fatigue, etc.). Each section contains one or more subsections, each of which presents a summary of the information contained in a specific publication. The subsections include the essential information (title, authors, report number or journal reference, date, the FIN number (if available) under which the task was performed) should the reader wish to consult the original document for more detailed information. A chronological listing of all the documents in reference format can be found in the Appendix to this report. 



\section{CORROSION}

\subsection{Corrosion of Structural and Poison Material in Spent Fuel Storage Pools}

Reference: Paper Number 163, Corrosion/81, The International Corrosion Forum Sponsored by the National Association of Corrosion Engineers, Toronto, Canada

Author(s): $\quad$ C. Czajkowski, J. R. Weeks, S. R. Protter

Date: $\quad$ April 6-10, 1981

Task: $\quad$ Not available (NA)

Key words: aluminum; boral; High Flux Beam Reactor; intergranular stress corrosion cracking; pitting corrosion; spent fuel storage; stainless steels; swelling; Three Mile Island Unit 1; Type 17-4PH stainless steel

\subsubsection{Background}

The cessation of fuel reprocessing in the U.S.A. and the lack of development of long-term storage for spent fuel had made it necessary for utilities to plan to store fuel on-site for much longer than one year. This situation required extensive modification and expansion of on-site fuel storage pools, including the installation in many cases of high-density storage racks containing nuclear poisons to prevent accidental criticality. This paper considered the situation concerning spent fuel storage in terms of:

* the behavior of the pool structural material

* the behavior of poison materials in pools.

\subsubsection{Structural Materials in Pools}

The structural materials used in spent fuel storage pools include austenitic stainless steel (liners, storage racks, piping), precipitation-hardened stainless steel (seismic restraint bolts, control rod drive pinions), and aluminum (storage racks).

Stainless steel liners have performed well over the years. Some leakage was detected on initial fill in a few cases but these were attributable to weld-related defects. Only one very minor leak had been experienced during service but no attempt was made to determine the root cause of the failure. Similarly, stainless steel storage racks have performed satisfactorily. However, several instances had been noted of intergranular stress corrosion cracking (IGSCC) in stainless steel piping systems.

Type 17-4PH stainless steel is generally used in the H1100 or H1025 heat treatment condition. Material in either of these conditions has operated satisfactorily in many applications in both boiling water reactors (BWRs) and pressurized water reactors (PWRs) spent fuel storage pools. The two potential problems were recognized to be stress corrosion cracking (generally found only with material in the H900 condition) and pitting due to the presence of residual scale on material in the H1100 condition. The latter can be countered by removal of the scale before insertion of the component in the storage pool water.

Aluminum components have stood up well in spent fuel storage pools but the potential exists for galvanic attack if it comes into contact with stainless steel. This attack is manifested in pitting of the aluminum in the 
immediate vicinity of the contact areas. However, the pitting has generally been observed to be of a minor nature and had no significant effect on the structural integrity of the components concerned.

\subsubsection{Poison Materials in Pools}

Boral poisons consist of an aluminum/boron carbide cermet clad in aluminum (either 1100 or 6061). Concern existed that $\mathrm{B}_{4} \mathrm{C}$ could leak from the cermet if exposed to spent fuel pool water but experience has shown this not to be the case. A more valid concern has been the production of hydrogen during the corrosion of the aluminum, leading to a pressure build-up and swelling of stainless steel that seals the boral in place. This can be averted by venting the boral racks. Another concern was the possibility of pitting corrosion when aluminum came into contact with stainless steel in spent fuel coolant, particularly if the coolant contained boric acid and had a pH of around 5. However, studies of this phenomenon indicated that significant corrosion loss was unlikely.

\subsubsection{Discussion/Conclusions}

In general, it was concluded that the performance of the structural and poison materials in the spent fuel storage pools had been excellent up to that time. IGSCC was possible in heavily sensitized and stressed material, particularly if accidental contamination of the pool water occurred. Type 17-4PH stainless steel components should be fabricated from material in the $\mathrm{H} 1100$ condition and the oxide scale formed during the heat treatment removed before placing the component in service. Pitting of aluminum racks was possible if contact existed with stainless steel but to date no significant degradation had been observed. Pitting of aluminum cladding on the boral poison rods was also possible but should not affect the poison capability of the boral.

\subsection{Boric Acid Corrosion of Ferritic Reactor Components}

$\begin{array}{ll}\text { Reference: } & \text { Report NUREG/CR-2827 (BNL-NUREG-51561) } \\ \text { Author(s): } & \text { C. J. Czajkowski } \\ \text { Date: } & \text { July } 1982 \\ \text { Task: } & \text { FIN A-3380 }\end{array}$

Key words: $\quad$ bolting degradation; boric acid; Calvert Cliffs Units 1 and 2; corrosion; Fort Calhoun; Kewaunee; low-alloy steel; Oconee Units 2 and 3; pH dependence; temperature dependence; Zion Unit 1

\subsubsection{Background}

Licensing Event Reports (LERs) from operating nuclear power plants had indicated that corrosion of ferritic steel reactor components by a boric acid corrosion phenomenon could potentially affect the integrity of the reactor coolant pressure boundary. In order to ascertain the extent and severity of these occurrences, BNL was requested by the NRC to evaluate the problem through a study of incidents at five nuclear plants - Fort Calhoun, Calvert Cliffs 1 and 2, Kewaunee and Oconee 3. This evaluation was to encompass three tasks: (1) review the LERs for a given plant and any other reports on ferritic steel corrosion history for this plant or similar plants; (2) determine the rate of boric acid corrosion under routine operating conditions for the plant by reviewing the data from field experience and laboratory experiments to validate and confirm assumptions used to extrapolate corrosion rates (these rates are used for the specification of allowable inspection intervals); (3) provide a summary report to serve as a basis for changing or not changing technical specifications for the plant. 
This particular report was written in order to satisfy the third of these tasks and contains information relative to $Z$ ion 1 and Oconee 2 in addition to the five principal units.

\subsubsection{Fort Calhoun}

A visual inspection prior to plant startup in May, 1980, revealed dripping insulation on reactor coolant pump (RCP). After the insulation was removed, reactor coolant leakage was observed at the pump case/ cover interface. Further investigation revealed that two of the remaining three pumps had similar coolant leakage. Subsequent removal of the pump insulation revealed that the closure studs had incurred conspicuous corrosion damage. Each pump is secured with sixteen such studs (3.5 inches in diameter), made of ASTM A-193 Grade B7 material and chrome-plated in the thread area. Inspection of the studs revealed that 6 of 16 studs on one pump and 3 of 16 studs on a second pump had sustained significant corrosion damage; in the worst case, the diameter of a stud had been reduced to approximately 1.1 inches. The calcium silicate block-type insulation surrounding the pumps had not been maintained prior to this occurrence, thus no information is available to aid in determining when the leakage began.

At a later date (January, 1982) it was disclosed that, during the current shutdown, inspections made on the previously affected four reactor coolant pumps had revealed evidence of corrosion on three of the four pumps ( $3 \mathrm{~A}$, $3 B, 3 C$ ). Four studs were affected on pump $C$, while five studs were affected on each of the $A$ and $B$ pumps. The worst case of corrosion noted was on a stud which suffered a metal loss of approximately $1 / 4$ inch. This corrosion had occurred in the interval between outages, approximately 14 months.

The utility also informed BNL that a failure analysis had been performed and that the cause of the degradation was a wastage type boric acid corrosion.

\subsubsection{Calvert Cliffs Units $1 \& 2$}

Inspections of the four reactor coolant pumps at Unit 1 prompted by IE Information Notice $80-27,6 / 11 / 80$, revealed that 27 of 64 RCP studs had indications of corrosion or other non-acceptable indications and had to be replaced. All of the affected studs were located in two of the RCPs. In addition, because of corrosion, eleven of forty studs had to be replaced in the Number 11 steam generator manway. Bolts from both the manway and RCP were sent to Combustion Engineering for analysis, the results of which indicated that the corrosion mode was a boric acid wastage-type corrosion.

Inspection of Calvert Cliffs Unit \#2 disclosed corrosion in three areas of the reactor. Twelve of sixty four studs in the RCPs and two of twenty studs in the pressurized manway exhibited boric acid wastage to the extent that they required replacement. In addition, after disassembly of safety injection check valve 2-SI-217, it was determined that corrosion had occurred on the carbon steel studs to the extent that all 16 had to be replaced.

The preliminary results of failure analyses on the bolts determined that corrosion was due to boric acid seepage via leaking gaskets.

Corrosion was also observed on the carbon steel suction piping to the reactor coolant pumps on January 28, 1981. This damage (approximately a 0.125 inch penetration through a 3.5 inch nominal wall thickness) occurred circumferentially at a dissimilar weld (a stainless steel-clad carbon steel elbow welded with Inconel to a stainless steel safe end). The corrosion was assumed to be caused by leaks in pump seal pressure lines/bleed off lines traveling down the pump casings through the pipe insulation to the floor of the containment.

\subsubsection{Kewaunee}

Wisconsin Public Service Corporation reported an incident in 1981 during steady state plant operation when an instrument isolation valve was noted to be leaking boric acid. After disassembly, the valve was found to have a 
leaking diaphragm and a corroded bonnet. A new bonnet assembly was installed in a timely manner and there was no need to shutdown the plant.

\subsubsection{Oconee Units 2 and 3}

In February, 1981, Duke Power reported that corrosion had been found on closure studs of RCP 2AI (Unit 3) during a cold shutdown inspection. Varying amounts of corrosion were discovered on the other three RCPs. As a consequence, the number 9 stud of RCP 3AI was replaced. The occurrence was diagnosed as boric acid corrosion wastage resulting from pump gasket leakage.

A cold shutdown inspection of Oconee 2 Unit in March, 1981 disclosed four closure studs of RCP 2A2 suffering from boric acid wastage corrosion. Only one stud had to be replaced. Again, the cause of the corrosion was determined to be gasket leakage in the area of the closure studs.

\subsubsection{Zion Unit 1}

A 1979 failure analysis performed on bolts from a Chemical and Volume Control System valve of the Zion Unit $I$ concluded that the bolts had failed through a boric acid $\mathrm{E} / \mathrm{C}$ mechanism.

\subsubsection{Discussion/Conclusions}

PWR primary coolant contains boric acid plus some lithium hydroxide in solution. This coolant has a pH. which varies over a relatively wide range, but is most acidic prior to plant startup. The studies of aqueous corrosion of carbon steel by boric acid solutions have revealed that some environmental and physical variables (e.g., compositional differences, water temperature in the range $260-315^{\circ} \mathrm{C}$, size, shape and surface finish of a component) have little or no effect on the corrosion rate. However, the $\mathrm{pH}$ of the solution appears to be relevant: solutions of $\mathrm{pH} 9.5$ corrode steel up to 6 times faster at PWR operating temperatures than solutions of $\mathrm{pH} 10.5-11.5$. Other factors that may influence the rate of corrosion include the force of steam impingement, the wicking effect of nonmetallic insulation, and the amount of flow through the leaking gaskets. Additionally, the washing effect of continuous leakage probably removes any benefit of an iron passive film forming and enhances the reaction.

Boric acid molten salt corrosion cannot be discounted as an additional possible factor. Although no corrosion rate data on a molten salt corrosion effect could be located in the literature, information was found on AISI 4135 steel in $\mathrm{H}_{3} \mathrm{BO}_{3}$ and $\mathrm{H}_{3} \mathrm{BO}_{3}-\mathrm{KOH}$ solutions at $70^{\circ} \mathrm{F}$ and $140^{\circ} \mathrm{F}$. In addition, some BNL work exists on ASTM A-193 Grade B7 and AISI 4130 material in $\mathrm{H}_{3} \mathrm{BO}_{3}$ and $\mathrm{H}_{3} \mathrm{BO}_{3}-\mathrm{LiOH}$ solutions at $70^{\circ} \mathrm{F}$ and $140^{\circ} \mathrm{F}$ at higher temperatures $\left(212^{\circ} \mathrm{F}\right.$ to $600^{\circ} \mathrm{F}$ ). The temperature dependence of the corrosion rate of these materials in the boric acid solutions is quite distinctive. As the temperature increases to the boiling point of water, the corrosion rate increases at a much faster rate. This increase continues until the boiling point is reached and then starts to diminish, probably due to the loss of water in solution. The decrease in corrosion rate continues through at least a temperature of $352^{\circ} \mathrm{F} \mathrm{in} \mathrm{H}_{3} \mathrm{BO}_{3}-\mathrm{LiOH}$ and $600^{\circ} \mathrm{F}$ in $\mathrm{H}_{3} \mathrm{BO}_{3}$. As the higher temperatures are attained, water of hydration would also start to evaporate, which would probably deposit a lithium salt of meta-boric acid $\mathrm{LiBO}_{2}\left(\mathrm{LiBO}_{2}\right.$ has a melting point as high as $845^{\circ} \mathrm{C}$ in nonhydrated form). Other corrosion products may have a similar stifling effect in the case of $\mathrm{H}_{3} \mathrm{BO}_{3}$ by itself, accounting for the drop in rate after water is lost, although they have not been examined in any detail. It should be noted that, although the rate was found to drop with temperature, appreciable metal loss still occurs.

The data from these tests also indicate that certain variables could be considered nonessential to this corrosion phenomenon. These are: the composition of the steels; the concentration of boric acid in solution up to the boiling point of water, and, $\mathrm{KOH}$ or $\mathrm{LiOH}$ additions to boric acid solutions up to $212^{\circ} \mathrm{F}$. The small additions of either $\mathrm{KOH}$ or LiOH appear to cause the corrosion to proceed at a faster rate than plain boric acid solution at higher temperatures. At lower temperatures, however, the $\mathrm{LiOH} / \mathrm{KOH}$ appear to be inhibitors to the corrosion process. This is probably due to the increased amount of ionic species present which aid in the reaction kinetics at elevated temperatures. 
The corrosion rate experienced at $212^{\circ} \mathrm{F}$ in $\mathrm{H}_{3} \mathrm{BO} \mathrm{O}_{3}-\mathrm{LiOH}$ ranged between 112 and 130 mils/year, while at $352^{\circ} \mathrm{F}$ the corrosion rate was in the range $46-54$ mils/year.

In conclusion, it can be stated that ferritic material is susceptible to corrosion attack by $\mathrm{H}_{3} \mathrm{BO}_{3}-\mathrm{LiOH}$ solutions up to at least $352^{\circ} \mathrm{F}$. The rate of corrosion rapidly increases up to $212^{\circ} \mathrm{F}$, then starts to decline as water is boiled off, but metal loss is still high. A corrosion rate of at least 112 mils/year can be attained at $212^{\circ} \mathrm{F}$. Faster rates may be attainable if the ferritic material is kept wet as higher temperatures are reached.

From the above, it is recommended that, since this type of corrosion is associated with leaking gaskets, every effort should be made to maintain leak tight seals at gasket interfaces. Further, inspection intervals should be established that are consistent with the higher corrosion rate observed - 130 mils/year.

\subsection{Investigation of a Reactor Head Bolt from Turkey Point No. 3}

$\begin{array}{ll}\text { Reference: } & \text { Report MT-3305-2 } \\ \text { Author(s): } & \text { C. Czajkowski and M.H. Schuster } \\ \text { Date: } & \text { March } 1988 \\ \text { Task: } & \text { FIN A-3305 }\end{array}$

Key words: bolting; boric acid corrosion; carbon steel; ultrasonic inspection; Turkey Point Unit 3

\subsubsection{Background}

In 1986 a boric acid leak was discovered in a Conoseal joint on the reactor head in an instrument port column assembly at the Turkey Point Plant. During reinspection in 1987, considerable corrosion from boric acid was found around the carbon steel reactor head bolts in the area of the leak. Additionally, one bolt showed an ultrasonic examination indication (in the tensioned condition) which disappeared after the bolt was detensioned. This bolt was later removed and sent to BNL for examination consisting of:

* visual examination, dye penetrant examination

* hardness measurements

* optical microscopy.

\subsubsection{Visual Examination/Dye Penetrant Examination}

The visual examination disclosed no evidence of cracking or apparent defects other than the severe corrosion. Subsequent dye penetrant testing similarly revealed no indications of cracks or defects other than corrosion damage. Sectioning allowed assessment of the inside surface of the bolt both visually and with dye penetrant. Again, no evidence of cracking or defects was found.

\subsubsection{Hardness}

Rockwell $D$ measurements on the end of the bolt produced values in the range 44.5 to $50 \mathrm{HRD}$. The lowest of these is equivalent to a tensile strength of approximately $125 \mathrm{ksi}$, indicating that the material met the minimum tensile requirement of its specification (ASTM A-320). 


\subsubsection{Optical Microscopy}

Metallography revealed that the material had a microstructure of a quenched and tempered material, consistent with that expected for this type and grade of material.

\subsubsection{Discussion/Conclusions}

A previous report on the problem of boric acid corrosion at a number of nuclear plants determined that ferritic material is susceptible to corrosion attack by $\mathrm{H}_{3} \mathrm{BO}_{3}+\mathrm{LiOH}$ solutions up to at least $352^{\circ} \mathrm{F}$. The rate of corrosion rapidly increases up to $212^{\circ} \mathrm{F}$, then starts to decline as water is boiled off, but metal loss is still high.

The same type of corrosion appeared to be the cause of the degradation of the Turkey Point bolt examined. Thus it was concluded that the degradation of the bolt from the Turkey Point Plant was caused by a general boric acid attack of the steel. It was noted that the hardness of the bolting material and its microstructure were consistent with that expected of a ferritic material.

\subsection{Evaluation of Dealloying in Aluminum Bronze Components at the South Texas Project}

Reference: Report MT-3851-4

Author(s): $\quad$ C. J. Czajkowski

Date: $\quad$ November 1988

Task: $\quad$ FIN A-3851

Key words: aluminum bronze casting; crevices; dealuminization; South Texas Project; valve assembly leak testing

\subsubsection{Background}

On April 1, 1988, various aluminum bronze valves and fittings in the essential cooling water (ECW) system at the South Texas Project were found to be leaking. The ECW system provides cooling water to various safetyrelated systems during normal plant operation and shutdown, and during and after postulated design basis accidents (DBAs). The design pressure of the system is $120 \mathrm{psig}$ with normal operating pressures of about 40 psig. Further inspection disclosed that the leakage was limited to small-bore socket welded components and involved a total of 90 out of 782 components.

Three samples were subsequently removed from the system and a preliminary analysis indicated the presence of dealloying in the crevices of the socket welds of the castings. Forty additional samples were removed from the ECW system and four sent to BNL for evaluation, together with a sample of welding flux. This evaluation consisted of:

\footnotetext{
* visual inspection

* leak testing

* microhardness testing

* chemical analysis of the flux

* optical microscopy/metallography
} 
energy dispersive spectroscopy (EDS).

\subsubsection{Visual Inspection/Photography}

Of the four samples received at BNL, three were castings made by AMPCO Metals. One of the three was a one-inch diameter elbow (ASME SB-148 CA 952, AMPCO heat number H9528-3) taken from a small-bore fitting. The other two casting samples were cut from valve bodies (ASME SB-148 CA 954) and were identified as EW269 (61-382, heat number H5174-44) and EW315 (466-185 heat number H5174-36). Both the fitting and valve EW269 leaked during service but valve EW315 did not. Both leaks were determined to be in the socket weld crevice area. of the fitting.

Visual examination of the elbow sample revealed no visible cracks on either the weld or the outside surface

The two valve body samples had been polished to a $6 \mu \mathrm{m}$ finish and etched with a $3 \% \mathrm{AgNO}_{3}$ solution (in water) acidified with 2 drops of $10 \% \mathrm{HNO}_{3}$. Both displayed grey/silver staining in the socket crevice area, indicative of dealloying.

The fourth sample received was an entire valve assembly with an elbow, two pieces of welded pipe and a threaded fitting. This valve was identified as EW0018. An area of staining (probable leakage) was noted on the elbow.

\subsubsection{Leak Testing}

In order to determine if any cracks were present in the valve assembly (near the area of probable leakage), the assembly was leak tested by closing the valve and then pressurizing the assembly through the open end. In the initial test, the assembly was pressurized to $400 \mathrm{psig}$ (design pressure of ECW is $120 \mathrm{psig}$ ) using nitrogen gas and a gas regulator, then the outside surface brushed with a leak detection solution. No discernible leakage was observed. In a second test, the valve assembly was immersed in room temperature bubble water then pressurized to $400 \mathrm{psig}$. Again, there was no evidence of leakage.

\subsubsection{Microhardness Testing}

Microhardness measurements were performed using a Knoop indenter and a 200g load. For all three samples examined (the elbow and the valve body sections EW315 and EW269), the dealloyed region (average values 59-85 $\mathrm{HK}$ ) was significantly less hard than the unaffected casting material (average values 135-163 HK).

\subsubsection{Chemical Analysis of Flux}

The fittings and the valve bodies incorporated gas tungsten arc welded socket welds, the welding procedures for which the use of a welding flux. This flux was incorporated into the weld by applying a flux and isopropanol mixture onto the filler wire used for welding the joint. A sample of this flux was chemically analyzed for chlorides, fluorides and total halogens (possible contributors to dealloying). The analysis revealed the chloride content to be less than $10 \mathrm{ppm}$, and the fluoride and other halogens to be less than $1 \mathrm{ppm}$.

\subsubsection{Optical Microscopy/Metallography}

After leak testing the valve assembly was cut on both sides of the fitting (elbow). The elbow was then sectioned longitudinally in the area of the stained (potentially leaking) area and mounted in epoxy. The other three samples were also mounted in epoxy and all four metallographic samples ground and metallurgically polished. Prior to microscopic examination, the four were swabbed with a solution composed of $50 \mathrm{cc} \mathrm{NH}_{4} \mathrm{OH}+50 \mathrm{cc} \mathrm{H}_{2} \mathrm{O}+30$ cc $\mathrm{H}_{2} \mathrm{O}_{2}$ (3\% solution) for approximately 5 seconds and then water rinsed. 
The microstructure revealed in the pipe material was typical of wrought aluminum bronze material ( $\alpha$ phase). This microstructure was similarly found in all of the specimens examined. The socket weld material was dendritic in appearance and no evidence of cracking was found in any of the sections examined.

The microstructure of the cast material outside the dealloyed area was composed of $\alpha$ plus $\beta$ phase with small iron rosettes. The dealloyed areas had all of the previously mentioned phases with the addition of a $\gamma_{2}$ phase present. Such a structure is typical of alloys dealuminized in salt water. Varying degrees of dealloying (dealuminization) were found in each of the four specimens examined. In all cases no cracks were evident and the dealloying was confined to the crevice area of the socket weld joint.

\subsubsection{Energy Dispersive Spectroscopy}

The four samples used for the metallographic examination were also evaluated by EDS. Three scans were performed on each specimen: (1) on the pipe material, (2) in the area of dealloying, and (3) on the casting material. With the exception of the fitting from valve EW0018, each of the scans showed a significant reduction in the aluminum peak in the dealloyed area. It is thought that the probable cause of the anomaly in the scans on the EW0018 sample lies in the very selective nature of this type of attack and its non-uniformity about the specimen's periphery.

The area of the crevice in the EW0018 specimen was also scanned to determine if any contaminants were present that might contribute to dealloying. None were detected.

\subsubsection{Discussion/Conclusions}

Dealloying has been defined as "the selective corrosion of one or more components of a solid solution alloy." When the phenomenon is associated with aluminum-copper alloy systems, it is known as dealuminization. It has been observed that, although there may be color changes associated with dealloying, there may be no visible cracks, pits, dimensional changes, grooving or obvious metal loss characteristics. However, the affected material becomes brittle, porous, lighter and loses its original tensile strength. In the case of the selective attack of aluminum-bronze alloys by seawater, dealloying has been linked to the distribution and quantity of an aluminum-rich $\gamma_{2}$ phase. The formation of this phase appears to vary with composition and with applied heat treatments. Additionally, dealloying of aluminum bronzes has been associated with crevices.

In the present investigation, no cracks were evident on any of the samples examined. However, the appearance of $\gamma_{2}$ phase in the structures examined, coupled with the lower hardnesses in dealloyed areas and the absence of general metal loss characteristics lead to the conclusion that the leakage associated with these components was due to the selective leaching of aluminum from the alloy used (i.e., dealuminization). This dealuminization is associated with the crevice formed in the socket weld joints examined. Additionally, the flux used in the welding did not appear to contain a significant amount of detrimental contaminants $(\mathrm{Cl}, \mathrm{F}$, halogens) nor were any such contaminants detected in the crevice region.

\subsection{Survey of Boric Acid Corrosion of Carbon Steel Components in Nuclear Plants}

$\begin{array}{ll}\text { Reference: } & \text { Report NUREG/CR-5576 } \\ \text { Author(s): } & \text { C.J. Czajkowski } \\ \text { Date: } & \text { June } 1990\end{array}$


Task:

FIN A-3851

Key words: $\quad$ audits; boric acid corrosion; carbon steel; prevention program

\subsubsection{Background}

Various components used in PWRs are constructed of carbon and low alloy steel, many of which come in contact with pressure boundary systems containing borated water. Numerous occurrences have been recorded of severe degradation of these alloys by concentrated boric acid solutions, typically due to a concentration of primary coolant from component leakage. This report provides brief summations of the 17 major recorded events (from 14 different power plants) of boric acid wastage corrosion on threaded fasteners and other carbon steel components between 1977 and 1989. The report also reviews the two possible mechanisms for corrosion attack - galvanic corrosion and acid corrosion.

From 1980 through 1988 the NRC issued several Information Notices, Bulletins, NUREG Reports and a Generic Letter 88-05 addressing this issue. These are all summarized in the report, together with the actions taken by the industry to develop and implement a comprehensive approach to solving the problem, as required by Generic Letter 88-05. Of particular importance were the audit guidelines contained in the Generic Letter. These addressed four broad areas of concern:

* determination of the principle locations where leaks of primary coolant below the specification limits could cause degradation of the reactor pressure boundary components;

* $\quad$ procedures for locating small leaks;

* procedures for evaluating boric acid induced corrosion of carbon steel components in the reactor pressure boundary;

* corrective actions taken by the licensee to prevent recurrences of similar types of corrosion.

Ten plants (encompassing 17 units in total) were subsequently selected as candidates for joint NRC/BNL audit in order to verify implementation of the utilities' actions, specifically in response to Generic Letter 88-05.

\subsubsection{Audit Results}

Each of the plants audited had a boric acid corrosion prevention program in effect at the time of the plant visit. In many cases, the program consisted of modifications to existing leakage control procedures. Some of the utilities placed implementation of this program under their maintenance departments with some augmented procedures for boric acid specific concerns.

Training of inspectors was accomplished by all audited licensees. In general, the inspectors were certified to the VT-2 qualification and in some instances to the EPRI visual inspection certifications. Records of training and certifications were available at each of the audited plants.

In one instance, the only procedure covering boric acid corrosion prevention was written as an administrative procedure to respond to the Generic Letter. At all of the other plants audited, procedures were in effect covering all four requirements of the Generic Letter.

In general, all of the sites audited kept their plants relatively clean (with one exception). This was an observation made during the various plant tours. The majority of plants either cleaned their spills in short order and 
repaired the leaks or found methods of draining or containment of the liquids. There were (with the noted exception) no large areas of spills apparent at any of the audited plants.

\title{
2.5.3 Discussion/Conclusions
}

It was clear from the plant audits that there was a good deal of diversity in the quality and method of implementation of boric acid corrosion prevention programs from utility to utility. In some instances, a single individual had the primary responsibility while at other plants the program implementation was shared among several line organizations, occasionally with little definition of implementation responsibilities.

The degree of importance of a boric acid corrosion control program (as viewed by the licensees) also varied considerably between plants. In the plants where a reasonably high priority was given to the problem, the leaks were identified and corrective actions taken in a timely manner. At other plants, however, the leaks were identified but remained uncorrected for considerable lengths of time.

Based upon the site audits and the review of the licensee's responses to Generic Letter 88-05 it was concluded that the four major concerns expressed in Generic Letter 88-05 had been addressed by the 10 audited licensees. By implication it was probable that similar programs had been instituted at all PWR plants in the U.S. However, though it was to state that the requirements of the Generic Letter had been met, there existed a great degree of variance between licensees. Thus, since only 10 plants had been audited, it was thought prudent that NRC resident inspectors should verify (at their plants) that a documented and auditable program complying with Generic Letter 8805 was in effect at each PWR plant.

\subsection{Corrosion Testing of Thermal Shield Support System - San Onofre Nuclear Generating Station}

\author{
Reference: $\quad$ Report MT-L1529-5 \\ Author(s): $\quad$ C. J. Czajkowski \\ Date: $\quad$ December 1991 \\ Task: $\quad$ FIN L-1529
}

Key words: autoclave testing; fasteners; San Onofre; Type 316 stainless steel

\subsubsection{Background}

The thermal shield support system on the San Onofre Nuclear Generating Station, Unit 1, was redesigned following premature failure of the previous design (Docket No. 50-206). The potential for stress corrosion cracking of the AISI Type 316 stainless steel bolts in the crimped locking cups of the thermal shield support system fasteners was considered by the utility but rejected because stress corrosion cracking had not been observed in AISI Type 316 stainless steel bolts in similar applications. However, the NRC decided that corrosion testing of these locking cups was required in order to provide reasonable assurance that the material would perform as intended and requested that BNL conduct testing of the redesigned fastener system. The test plan involved exposing the fastener system to a simulated PWR environment in a static autoclave system for a total of 180 days. 


\title{
2.6.2 Volumetric Examination/Autoclave Testing
}

Three separate bolting fixtures were received at BNL. Two of these had 0.5 -inch diameter bolts as part of the assembly while the third had a 0.875 -inch diameter bolt as the test bolt.

The three fixtures were first radiographed and ultrasonically examined in order to establish a baseline prior to autoclave testing. Following the nondestructive volumetric examinations, the fixtures were loaded into a stainless steel autoclave and tested in a simulated PWR primary coolant environment for 30 days. Upon completion of the autoclave testing, they were again radiographed to determine if any cracks had initiated. There was no evidence of cracking noted at this time. The fixtures were then reintroduced into the PWR environment for a 60 day run. Following this run, the specimens were again radiographed but no cracks were detected. The fixtures were then exposed to a third run, this one lasting 90 days. Subsequent radiography and ultrasonic evaluation provided no indication of cracking in any of the three fixtures.

\subsubsection{Dye Penetrant Testing}

After the fixtures had been volumetrically examined, a dye penetrant examination was first performed on the bolt head exterior area, after which the two locking tabs were ground out with a high speed grinder. The bolt was then removed from the fixture. After removal, the exterior (thread/shank/head bottom) was also examined by dye penetrant. No relevant indications (cracks) were observed in any of the three bolts.

The removal of the bolts was performed with a torque wrench and the following torque values recorded:

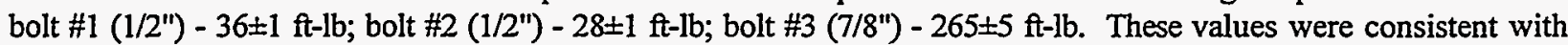
the original recommended torque values and indicate that loosening of the bolts had not occurred during testing.

\subsubsection{Discussion/Conclusions}

None of the three locking devices supplied showed any evidence of stress corrosion cracking after a total of six months testing in an autoclave in a simulated PWR environment. In addition, the locking devices retained their original torque values during the test program.

\subsection{Examination of a Bolt with Boric Acid Attack from Three Mile Island Nuclear Generating Station}

\author{
Reference: $\quad$ Report MCIT-E2089-01 \\ Author(s): $\quad$ Biays S. Bowerman, Carl J. Czajkowski, Thomas C. Roberts \\ Date: $\quad$ February 1995 \\ Task: $\quad$ FIN E-2089
}

Key words: $\quad$ bolting; boric acid corrosion; ductile fracture; low-alloy steel; Three Mile Island

\subsubsection{Background}

BNL was requested by the NRC to examine a failed bolt from Three Mile Island (TMI) nuclear power station and to confirm the results of the root cause analysis conducted by TMI personnel. Supplementary documentation supplied by NRC indicated that the bolt, stated to be 5/8 inch diameter and of ASTM A-193 Grade B7 material, had 
been removed from a valve in the pressurizer at TMI. Two pieces of the bolt (a threaded stud) were subsequently received by $\mathrm{BNL}$ and subjected to:

* visual examination and dimensional characterization

* hardness measurements

* $\quad$ scanning electron microscopy (SEM).

\subsubsection{Visual Examination/Dimensional Characteristics}

The two pieces, one with a nut in place and the other with no nut, were covered with rust-colored corrosion. The threads of both pieces appeared deformed, with signs of galling evident on the piece with the nut in place.

The two pieces of threaded stud were inspected according to System 21 and System 22 of ANSI/ASME B1.3M. Both failed the two tests.

\subsubsection{Hardness Measurements}

Sections of the two stud pieces were subjected to both Rockwell $\mathrm{C}$ and microhardness testing. The lowest average value recorded was $25.5 \mathrm{HRC}$, which would correspond to an approximate tensile strength of $124 \mathrm{ksi}$. As the minimum tensile strength for material to ASTM A-193 Class B7 is $125 \mathrm{ksi}$, it was concluded that the bolting material was within specification.

\subsubsection{Scanning Electron Microscopy}

The SEM examination confirmed that the two pieces had come from separate studs. Significant general corrosion was noted on both fracture faces examined. In one case, some wear before failure was observed on one of the fracture faces while the other face had possible fatigue indications. Generally, however, both faces indicated that failure had been via ductile rupture.

\subsubsection{Discussion/Conclusions}

Both stud pieces failed the ANSI/ASME gaging tests for dimensional characteristics, indicating that they did not meet ANSI specifications. However, because the gaging tests were conducted on failed stud pieces with obvious corrosion attack, no statement could be made about stud thread acceptability before the studs were put in service.

Tensile strength values estimated from Rockwell $C$ hardness measurements indicated that the stud pieces were within the tensile specification for ASTM A-193 Class B7 material.

Both visual examination and SEM confirmed that significant corrosion had taken place and that the corroded state of the stud pieces was consistent with that expected from boric acid attack. SEM examination of the stud fracture faces showed that they failed by ductile rupture. 


\section{EROSION-CORROSION}

\subsection{Metallurgical Evaluation of an 18-inch Feedwater Line Failure at the Surry Unit 2 Power Station}

Reference: Report NUREG/CR-4868 (also BNL-NUREG-52057)

Author(s): $\quad$ C. J. Czajkowski

Date: $\quad$ March 1987

Task: $\quad$ FIN A-3851

Key words: $\quad$ carbon steel; erosion/corrosion; Surry

\subsubsection{Background}

In December 1986, a suction line to the main feedwater pump A for the Surry Unit 2 power plant failed in a catastrophic manner, resulting in four fatalities among men working nearby. The pipe material was 18-inch diameter ASTM A-106 Grade B carbon steel with a nominal wall thickness of 0.5 inches. The material of the elbow, where the failure occurred, was of ASTM A-234 Grade WPB and also had a nominal diameter of 0.5 inches. Localized areas of the elbow were observed to be thinned to as low as 0.046 inches. The line temperature at this location was $370^{\circ} \mathrm{F}$ and the flow velocity 17 fps.

A total of five specimens from the failure area were sent to BNL for evaluation: three specimens with material from the pipe, weld, and elbow; and two pieces of the joint between the header and the fabricated "tee" joint. The failure investigation consisted of:

* visual examination and photography

* optical microscopy and metallography

* chemical analysis

* impact testing/bend testing/hardness testing/tensile testing

* scanning electron microscopy/energy dispersive spectroscopy.

\subsubsection{Visual Examination/Photography}

The specimens generally had a mottled and granular appearance on the inside surface. Two distinct types of oxide were present: a blackish, tight, adherent film (magnetite) and a rust colored powdery oxide. Wear patterns were evident on the two pieces of the joint between the header and the "Tee" joint. No indications of gross fatigue could be found on the fracture surfaces.

\subsubsection{Optical Microscopy/Metallography}

Metallography on the piece that had material from the pipe, elbow and weld revealed a microstructure consistent with that expected of a welded low carbon steel. The inside surface of the elbow was seen to have a scalloped appearance typical of that caused by an erosion type of mechanism. 


\subsubsection{Chemical Analysis}

Chemical analysis confirmed that the materials fell within the requirements of the stated specifications.

\subsubsection{Impact Testing/Bend Testing/Hardness Testing/Tensile Testing}

Three groups of six specimens, representing the piping, elbow and weld material, were tested at room temperature and at $375^{\circ} \mathrm{F}$ (the estimated temperature at which the failure occurred). The lowest absorbed energy values were recorded with the elbow material but even these values indicated that the material was in the "upper shelf" region of the NDTT curve. All the fracture surfaces showed a dimpled appearance typical of a ductile failure.

Bend tests failed to reveal any cracks or defects in the weld/HAZ/base metal samples after bending.

Knoop microhardness measurements produced values consistent with those expected of the materials being examined.

Tensile tests indicated that the materials had good tensile and ductility properties that generally met the specification requirements.

\subsubsection{Scanning Electron Microscopy/Energy Dispersive Spectroscopy}

All of the fracture surfaces examined had a dimpled rupture appearance, indicative of ductile failure. No evidence of any other failure mechanism could be found. None of the specimens sent to BNL had the probable fracture initiation area on them.

The inside surfaces of the elbow and the piping materials showed a scallop-like, almost peened, appearance and had areas of dense oxide. After removal of the oxide film (using Endox-214 solution), it was observed that many areas beneath the film were heavily corroded and pitted, indicating that an active corrosion process had been in place during the operational lifetime of the material. Examination of a cross-section of one of the scalloped areas revealed no signs of distortion in the microstructure such as would be suggestive that cold working had occurred.

The EDS scans of the inside surfaces of the elbow and piping failed to locate any potential contaminants.

\subsubsection{Discussion/Conclusions}

Reviewing the results of the evaluations conducted, it was concluded that the chemical and mechanical properties of the pipe, elbow and weld materials were consistent with those expected for the materials specified. In addition, the impact tests indicated that these materials had adequate toughness properties at the operational temperatures, thus eliminating consideration of brittleness as a contributory factor to the failure. This was borne out by the completely ductile appearance of the fracture surfaces studied. Examination of the elbow and piping revealed that severe thinning had taken place prior to failure. This, combined with the scalloped look of the inside surfaces of the elbow and piping, led to the conclusion that the material had degraded via an E/C mechanism until the sections concerned became susceptible to ductile overload.

\subsection{Erosion-Corrosion in Nuclear Power Plants}

Reference: Report MT-3305-1

Author(s): $\quad$ G. Cragnolino, C. J. Czajkowski 
Date: $\quad$ March 1988

Task:

FIN A-3305

Key words: $\quad$ carbon steel; environmental factors; erosion-corrosion; Haddam Neck; low-alloy steels; Surry Unit 2; Trojan; ultrasonic testing

\subsubsection{Background}

Following the catastrophic failure of a feedwater suction line pipe at the Surry Unit 2, the NRC initiated a contract with BNL to evaluate the Surry failure and identify the extent of the E/C problem in nuclear plants in general. As part of that program, BNL prepared this review document to provide information on the phenomenon of $\mathrm{E} / \mathrm{C}$, including descriptions of the relative importance of various factors involved, the models developed to describe it, and the incidents thus far uncovered.

\subsubsection{The Erosion-Corrosion Phenomenon}

The report defined $\mathrm{E} / \mathrm{C}$ as the acceleration or increase in the rate of corrosion caused by the relative movement between a corrosive fluid and the metal surface. It provided schematic illustrations to demonstrate the effect and pointed out how it is differentiated from other damage mechanisms that result in metal thinning. The susceptibility of the carbon steels to this kind of damage is described, as are the locations in plant systems where it generally occurs.

Discussion of the phenomenological aspects of $E / C$ is begun with a description of the basic concepts involved, such as the corrosion reactions and the physico-chemical understanding of the process. The report then addressed the role of the major influential factors:

* hydrodynamic (flow rate, flow path geometry)

* environmental (temperature, $\mathrm{pH}$, oxygen concentration)

* metallurgical (mainly chemical composition of the steels).

Following this, the report provided descriptions of some of the analytical models developed to describe the phenomenon.

\section{Hydrodynamic Factors}

The E/C rate is strongly dependent on fluid velocity but this is often an oversimplification of a more complex situation. In reality, consideration should also be given to flow geometry and temperature, and the mass transfer coefficient has been identified as the controlling parameter. In any given system, however, the mass transfer coefficient will have a range values depending on the various local geometries and thus a wide distribution of E/C rates can be experienced. An additional complicating factor is that small irregularities in the material surfaces (due, for example, to protrusions from welds) can significantly alter those coefficient values based on smooth surfaces.

\section{Environmental Factors}

Of the environmental factors, temperature is very important but its effect is not a simple one in which the $\mathrm{E} / \mathrm{C}$ rate continually increases as the temperature is raised. Rather, there are indications that the $\mathrm{E} / \mathrm{C}$ rate increases to a maximum at a certain temperature, above which it starts to decrease. The value of this maximum temperature is dependent on other variables such as flow rate. 
In general, the $\mathrm{E} / \mathrm{C}$ rate has been found to decrease as the $\mathrm{pH}$ value of the fluid increases, particularly at $\mathrm{pH}>9$. Similarly, as the dissolved oxygen content in the fluid is increased, lower E/C rates are experienced. The precise oxygen level required to inhibit $E / C$ is determined by the oxygen mass transfer coefficient and the density of the water.

\section{Metallurgical Factors}

The chemical composition of a steel has a predominant influence on its resistance to E/C. Whereas plain carbon steels are extremely susceptible to $E / C$, austenitic stainless steels are essentially immune. Generally, it is agreed that $\mathrm{Cr}$ is the most beneficial alloy element but additions of $\mathrm{Mo}$ and $\mathrm{Cu}$ also can improve the resistance to $\mathrm{E} / \mathrm{C}$.

\section{$\underline{\text { E/C Models }}$}

Various analytical models have been developed based on the qualitative descriptions of the relevant physicochemical processes associated with $\mathrm{E} / \mathrm{C}$. In all of them, the relevance of mass of $\mathrm{Fe}$ (II) species away from the oxide/solution interface has been considered one of the controlling factors in determining $\mathrm{E} / \mathrm{C}$ rates. However, there are differences between them arising from different assumptions. For example, the model developed by Berge et al. includes consideration of the dissolution of magnetite $\left(\mathrm{Fe}_{3} \mathrm{O}_{4}\right)$ whereas that of Sanchez Caldera is based on the reaction between $\mathrm{Fe}$ and water to produce $\mathrm{Fe}(\mathrm{OH})_{2}$ being the rate-controlling process. Other models have been proposed by Bignold et al., Kastner and Keller, but none appear to have universal applicability.

\subsubsection{Incidents}

\section{Surry Unit 2}

In December, 1986, an 18-inch suction line to one of the main feedwater pumps for the Surry Unit 2 nuclear power plant failed in a catastrophic manner (see section 3.1). The fluid in the pipe at the point of failure was considered to be single (liquid) phase. The pipe material was ASTM A-106 Grade B carbon steel of nominal thickness 0.5 inches. The elbow, made of ASTM A-234 Grade WPB carbon steel, had developed two ruptures close to pipe/elbow weld. The materials of the pipe, elbow and weld had properties consistent with the specifications. The fracture surfaces indicated that the failure was ductile and it was noted that localized areas had thinned to as low as 0.046 inches. Information was also provided in the form of the results of a later ultrasonic test (UT) program on two pieces of eroded piping.

\section{Trojan Power Station}

On March 9, 1985, a section of heater drain pump discharge piping (fabricated from ASME SA-106 Grade $B$ material) ruptured. The failure investigation conducted by the utility concluded that the cause of the failure was a single phase (water only) $\mathrm{E} / \mathrm{C}$ phenomenon.

\section{Haddam Neck}

On March 16, 1995, a steam leak was discovered and the reactor tripped. The cause of this event was traced to a pipe rupture immediately downstream of a feedwater heater normal level control valve. No formal failure analysis was performed by the utility but the event appeared to be a consequence of $\mathrm{E} / \mathrm{C}$ attack.

\section{Other Sites}

E/C problems have been reported by various utilities, including Toledo Edison. New York Power Authority, Baltimore Gas and Electric, and Duquesne Power, but little detail information was provided. However, all failures 
had occurred in two phase (water/steam) systems, in contrast to the Surry and Trojan incidents which involved single phase systems.

\title{
3.2.4 Discussion/Conclusions
}

It was concluded that a qualitative assessment of the major influential factors in $\mathrm{E} / \mathrm{C}$ of carbon steels in high temperature flowing water was complete. However, the opinion was expressed that the contribution of residual elements, particularly that of $\mathrm{Cr}$, was not fully appreciated. Possible counter measures against $\mathrm{E} / \mathrm{C}$ are discussed, including requiring minimum $\mathrm{Cr}$ contents in the steel where there exist a potential for $\mathrm{E} / \mathrm{C}$, and raising the $\mathrm{pH}$ or adding oxygen to the fluid system. Regarding modeling efforts, it was concluded that the predictive ability regarding $E / C$ rates on the basis of laboratory data was very limited and essentially restricted to the range of conditions over which the data were obtained.

\subsection{Evaluation of Pipe Samples from the Trojan Nuclear Power Station}

\author{
Reference: $\quad$ Report MT-3871-1 \\ Author(s): $\quad$ C. J. Czajkowski, M. H. Schuster, M. G. Cowgill \\ Date: $\quad$ January 1989 \\ Task: $\quad$ FIN A-3871
}

Key words: carbon steel; chromium content; copper deposits; erosion/corrosion; Trojan

\subsubsection{Background}

During the 1987 refueling outage at the Trojan Nuclear Plant, a total of nineteen elbows and two straight runs of the safety-related portion of the feedwater system were discovered to have been significantly degraded by the $\mathrm{E} / \mathrm{C}$ process. Areas of $\mathrm{E} / \mathrm{C}$ were also detected in non-safety-related piping. Subsequently, the NRC requested that BNL perform an independent failure analysis on piping samples from Trojan.

A total of seven sections of pipe were sent to BNL, four of which were large sections and included a Schedule 100 60-degree elbow, a Schedule 60 90-degree elbow, a Schedule 60 straight length and a Schedule 60 reducer. The 60-degree elbow was taken from just above the feedpump discharge, the 90-degree elbow from just before the steam generator, the straight length from inside containment and the reducer (identified as " $\mathrm{D}$ " reducer) going into the steam generator. The subsequent failure investigation consisted of:

* visual examination and photography

* chemical analysis

* optical microscopy and metallography

* scanning electron microscopy/energy dispersive spectroscopy.

\subsubsection{Visual Examination/Photography}

Each of the large sections of pipe was cut along the long axis and visually examined. Various specimens were also removed for both optical and electron microscopy examinations.

Visual examination of the inside surface of the 60-degree elbow revealed some slight $\mathrm{E} / \mathrm{C}$ wear in one area and a significant amount of metal removal in another area. The 90 degree elbow had areas of metal thinning similar 
to those observed on the 60-degree elbow. No obvious evidence of $E / C$ damage was noted on the inside surface of the straight section of pipe and only a slight amount could be seen in the reducer. The latter, though, had a crack in the area of the counterbore adjacent to the weld of the wider end of the reducer. No attempt was made to evaluate this crack.

All of the interiors of the four large pipe sections were covered with a thick, dark oxide-like coating. This oxide had areas of metallic copper which were revealed when the coating was scratched.

The three additional specimens received at BNL were from thermal shielding inside the reducer and were marked S/G B left side, S/G B right side and S/G B bottom. The interior surface of the specimen (concave side) of the S/G B left side piece showed some evidence of metal thinning and wear but the outside surface had no obvious evidence of $E / C$ damage. The specimen identified as $S / G$ B right side showed areas of $E / C$ damage on its inside surface. In addition, the outside surface of this pipe section had a severely damaged area of metal removal typical of an $\mathrm{E} / \mathrm{C}$ mechanism. A more global type of thinning was seen on the specimen identified as $\mathrm{S} / \mathrm{G} \mathrm{B}$ bottom. Each of the three smaller specimens appeared to have a hard, tightly adherent oxide film typical of that found in high temperature piping.

\subsubsection{Chemical Analysis}

Chemical analyses had been previously performed on three samples of pipe from Trojan. The results of these showed that the three samples generally conformed to the compositional requirements of either ASTM A-106 Grade B pipe or ASTM A-234 Grade WPB elbow material, the only deviation being the slightly higher manganese content for the 90-degree elbow material (B).

During the present investigation, some questions arose concerning the accuracy of the chromium evaluations (reported as $0.15-0.18 \%$ ). In order to check the compositions, four specimens (one each from the 60-degree elbow, the 90 degree elbow, the straight length of pipe and the piece identified as $S / G$ B bottom) were sent to an independent laboratory for analysis. All the standards used were traceable to National Bureau of Standards (NBS). The chromium results $(0.024-0.072 \%)$ were more consistent with those expected for a pipe susceptible to $E / C$.

\subsubsection{Optical Microscopy/Metallography}

Various specimens were cut from the pipe sections and metallurgically mounted, ground, and polished. The specimens were then etched in a $5 \%$ Nital solution and examined under the optical microscope. This revealed that the base materials, the weld heat affected zone (HAZ) and the weld metals had microstructures consistent with those of a welded low-carbon steel.

\subsubsection{Scanning Electron Microscopy/Energy Dispersive Spectroscopy}

Various specimens were examined by SEM and EDS.

SEM revealed that the inside surface of the reducer had a scallop-like appearance. The typical EDS scans of this specimen showed $\mathrm{Fe}$ and trace Ni peaks.

The scallop-like appearance seen on the reducer was also noted on the inside surface of the 90-degree elbow. EDS scans revealed nickel and copper in addition to the iron peaks.

The inside surface of S/G B bottom specimen also had a scallop-like appearance, together with evidence of possible wear marks associated with the scalloped appearance when viewed under high magnification. EDS scans of this specimen showed traces of $\mathrm{Ni}$ and $\mathrm{Cu}$ in addition to $\mathrm{Fe}$. 
SEM of some of the dense oxide found on the inside surfaces of the straight length of pipe revealed no unusual features. EDS scans for these areas detected $\mathrm{Cu}$ peaks in addition to Fe peaks, both of these scans exhibited $\mathrm{Cu}$ peaks, substantiating the visual observation of metallic copper in the oxide film noted earlier.

\subsubsection{Discussion/Conclusions}

Erosion-corrosion is caused by the relative movement of a corrosive liquid on the surface of a metal and causes accelerated attack on the surface. The attack is characterized by gullies, waves, valleys, and grooves cut into the metal surfaces. An additional characteristic seen in this type of attack are the "horse shoe" shaped pits which give a scalloped appearance to the metal surface.

The most common areas for this type of mechanism to occur are at locations of significant fluid turbulence (e.g., elbows, tees, bends). Susceptibility to this form of attack increases with decreasing chromium levels in carbon steels and the addition of small amounts (up to $2 \%$ ) of chromium greatly reduces the susceptibility. At the same time, dissolved copper in solution can greatly increase steel corrosion rates, especially where active corrosion pits are present in the steel. This type of enhanced corrosion is most common in boilers.

The thinning of the various sections of the piping removed from Trojan coupled with the scalloped appearance of the inside surfaces of the various specimens indicate the presence of an $E / C$ mechanism. There was no evidence of $\mathrm{E} / \mathrm{C}$ damage on the straight length of pipe examined. The sample chemical analysis on three pipe sections from Trojan indicate that the material used was consistent with the material specifications for the components but re-analysis for chromium content disclosed very low levels in the Trojan piping materials. Additionally, the presence of copper deposits in the oxide film possibly contributed to the $E / C$ process, either electrochemically or as a particulate erosive medium. 



\section{FATIGUE}

\subsection{Metallurgical Examination of Steam Generator Feedwater Pipe Cracks}

$\begin{array}{ll}\text { Reference: } & \text { Report BNL-NUREG-28146 } \\ \text { Author(s): } & \text { Brijesh Vyas } \\ \text { Date: } & \text { July } 1980 \\ \text { Task: } & \text { FIN A-3106 }\end{array}$

Key Words: $\quad$ Beaver Valley Unit 1; carbon steel; D.C. Cook Unit 2; Ginna; H.B. Robinson Unit 2; Kewaunee; low cycle fatigue; pitting; Point Beach Unit 2; Salem Unit 1; San Onofre; Surry Unit 1

\subsubsection{Background}

In May, 1979, Michigan Power Services notified the NRC of cracking in two feedwater lines at D.C. Cook Unit 2 facilities. Leaking circumferential cracks were identified in the 16" feedwater elbow adjacent to the steam generator nozzle-elbow weld. Subsequent radiographic examinations revealed crack indications in all steam generator feedwater lines of both units I and II. The Office of Inspection and Enforcement requested licensees of PWR plants in current outages immediately to conduct examinations of certain feedwater piping welds and crack indications were subsequently reported in 15 of the 40 PWR units inspected.

The NRC then initiated a review of metallographic analyses of the cracked areas by the licensees and the contractors, and an independent investigation by BNL. This report describes the results of the latter, a metallurgical investigation of the cracking in elbow sections of steam generator feedwater lines at nine plants: H.B Robinson Unit 2, D.C. Cook Unit 2, Beaver Valley Unit 1, Salem Unit 1, Point Beach Unit 2, Ginna, Surry Unit 1, Kewaunee, and San Onofre. The investigation included the following tasks:

* visual examination (inside surface of the pipe and elbow)

* metallographic examination

* microstructural characterization

* fractography

* chemical analysis of the corrosion deposits on the inside surface of the pipe and within the crack

\subsubsection{General Examination Procedures}

On receipt of the sections of the pipe-nozzle connections which included the crack, weld, section of the pipe, and the nozzle, the inside surfaces were visually examined for surface oxidation, local pitting or general corrosion, magnitude and color of the corrosion product, and any machining marks or unusual weld preparation. After visual observation, the samples were radiographed to determine the physical location of the cracks along the circumference of the pipe. On locating the position of the crack, generally 3 or 4 samples were dry cut such that they included the crack, weld, counterbore, and a section of the pipe.

One sample was used for optical microscopy of the internal surface of the pipe both before and after electrolytic cleaning to remove all the corrosion products. The second sample, used to study the piping cross-section, was mounted in epoxy, polished, examined by optical microscopy, etched using a nital solution and again observed optically to determine if the cracks were intergranular or transgranular. The cross-section was also used to study the microstructure of the steel, the weld and the HAZ. The third sample was used to study the fractography of the crack 
by opening up the largest crack and examining the two fracture surfaces so exposed. One of these surfaces was observed using SEM and EDS, in order to determine the distribution and the chemical composition of the corrosion products in the crack. Generally, the corrosion products were iron oxide with small amounts of chloride, sulfur, manganese and potassium, all believed to have been deposited in the crack during liquid penetrant examination at the reactor sites. The other half of the fracture surface was electrolytically cleaned before examination by SEM, to observe more clearly the form of the fracture

\subsubsection{Results}

\section{H.B. Robinson Unit 2}

Visual observation of the internal surface showed it to be heavily oxidized with corrosion product being particularly thick in the counterbore area. Removal of the oxide film revealed a mild machining mark in this area. Optical microscopy of the cross-section disclosed that the crack occurred at the notch of the counterbore where there was a reduction in the thickness of the pipe and thus the location of maximum stress. The crack itself was observed to be straight and transgranular, with only very slight branching at various locations. Also visible were some small (approx. 0.003 inches) cracks along the counterbore area. SEM of the crack surface showed that the main crack started at a heavily corroded region, suggesting that the initiation point was a pit of some sort. Crack arrest marks were also visible and high magnification showed the crack to be partially intergranular. Dimpled ductile-type fracture was noted at locations where the crack tended to branch, indicating that the failure there was due to plain mechanical loading of any stress corrosion assisted cracking mode. Striations were observed in the region at the tip of the crack but it was difficult to determine whether they were due to the steel morphology or some kind of a cyclic nature of the stress.

\section{D.C. Cook Unit 2}

Heavy thick oxide growth was visually observed on the inside surface of the pipe, including a large amount of corrosion product especially under the sleeve ring above the weld. This corrosion product was black and powdery, suggesting that extensive crevice corrosion had taken place in the region between the weld and the sleeve ring. It was observed that the cracks were only in the pipe section and not in the sleeve junction. Heavy machining marks and large pits were observed in the counterbore area of the pipe. The crack occurred at the root of the notch of the counterbore. In cross-section, it could be seen that the crack initiated at a heavily corroded machining mark. Fractography confirmed that the crack initiated at various points on the inner surface of the pipe where heavy corrosion has taken place. Beach marks and crack arrest lines along the length of the crack suggested that propagation was due to a cyclic stress. In general, the fractographic appearance of the crack at D.C. Cook Unit 2 was very similar to that of the crack observed in H.B. Robinson Unit 2.

\section{Beaver Valley Unit 1}

Three large cracks are observed along the circumference, at 12 o'clock, at 3 o'clock and at 9 o'clock. Sections taken from all three cracks revealed that the longest crack, twice as long as the other cracks, was at the 12 0 'clock location. It was generally transgranular, propagating in the circumferential direction, and with heavy corrosion along the length of the crack right to the tip. Also visible were small cracks initiated at the heavily corroded machining marks on the inner surface of the counterbore.

Fractography indicated that the cracks were similar to those found at H.B. Robinson and D.C. Cook. Initiation occurred at many machining marks along the inner surface in the counterbore region and there were large numbers of beach marks and river markings along the crack length in each case, all the way to the tip, suggestive of a cyclic stress mode. 


\section{Salem Unit 1}

The complete fracture surface was covered by corrosion product that was particularly heavy at the mouth of the crack, suggesting that the cracking initiated from a corrosion pit. The corrosion product, both in the pit and on the fracture surface, was mainly iron oxide with traces of $\mathrm{Si}, \mathrm{S}, \mathrm{Cl}$, and $\mathrm{K}$. The crack had initiated at various locations on the surface and combined to form one circumferential crack. Features such as beach marks were very similar to those observed in the previously discussed reactors.

\section{Point Beach Unit 2}

Corrosion was observed on the inner surface and very heavy machining marks in the counterbore area. Crack initiation appeared to be at a large pit or heavy corrosion at a machining mark at the root of the notch. In addition, small cracks were observed originating from machining marks along the counterbore region, supporting the theory that accelerated corrosion along these marks plays a role in crack initiation. However, the stresses at these points are not as high as those at the root of the notch, so the small cracks do not propagate. Corrosion products were observed over the complete surface of the main crack up to its tip. The corrosion product in the crack was granular, with larger grains at the mouth of the crack than at close to the tip, suggesting a slow rate of growth of the crack. The corrosion product was mainly an iron oxide, although traces of $\mathrm{Si}, \mathrm{S}, \mathrm{K}$, and Ca were detected. These latter may have been deposited from the water or during the liquid penetration technique for detecting cracks. The main crack apparently originated at various locations due to localized corrosion on the notch and propagated in a discontinuous fashion. However, close examination of the fracture surface at the tip of the crack revealed no fatigue striations or other microfeatures, though these may have been erased by the heavy corrosion that took place in the crack.

\section{Ginna}

The pipe sections from Ginna had the heaviest machining marks on the surface of all those received. Cracks initiated from the grooves of these machining marks, probably facilitated by the accelerated corrosion observed there. The cracks were straight and transgranular. Fractography revealed a large number of crack arrests on the surface and heavy corrosion over the whole crack surface, the latter obscuring any major features that might have been present near the crack tip. The corrosion product was granular and very similar to that found in the piping specimens from other reactors. It consisted mainly of iron oxide with traces of $\mathrm{Si}, \mathrm{S}, \mathrm{Ca}$ and $\mathrm{Cr}$ in it.

\section{Surry Unit 1}

The main large transgranular crack was observed to have started at a local pit on the surface. Some small cracks were also visible, again initiating at various pits. Fractography revealed the presence of crack arrest and beach marks on the fracture surface, together with corrosion product (mainly iron oxide). The fracture surface was sufficiently heavily corroded in some places that no metallurgical features could be observed.

In addition to the piping elbow in which the cracking had been observed, a separate section, consisting of a feedwater nozzle and thermal sleeve, was sent to BNL. The thermal sleeve was separated from the nozzle to look for any cracking in the nozzle or the thermal sleeve. Visual inspection and dry magnetic particle inspection revealed no evidence of cracks on the two components.

\section{Kewaunee}

Two small sections around the pipe nozzle weld from two locations along the circumference (location unknown) were examined.

The surface of one section was covered with a thick, black, adherent film. When this film was removed the cracks could be seen to start at machining marks. Viewed in cross-section, it could be seen that the cracks were at the weld-pipe interface and along the tapered section of the pipe. The difference in the microstructure along the pipe 
due to the heat affected zone had no appreciable effect on the character of the cracks. All the cracks were straight and transgranular with very slight branching, and filled with heavy corrosion products.

The other section was covered with a loosely adherent film characterized by orange coloration near the cracks. This orange color was thought to be due to localized pitting, visible when the film had been removed. The crack morphology observed was similar to that of the first section and, in addition, very small cracks were observed starting from corrosion pits or accelerated corrosion at the machining marks. This observation was very similar to the small cracks observed in both the Point Beach and Ginna sections, and lent support to the theory that localized surface corrosion could be initiating points for the cracks. However, cracks initiated at these locations propagate only if the localized stress is large enough.

\section{San Onofre}

The inner surface was very heavily corroded and had a thick scale which was orange in color with isolated black spots. It is known that sea water (containing chlorides) had leaked into the system and this could explain the heavy corrosion on the inner surface. Electrolytic removal of the oxide revealed an irregular surface due to general corrosion and some deep pits. Large surface pits and cracks were observed in the cross-section of the weld region, the only instance among the nine reactors where cracks were observed in the weld itself. This could also be explained by the presence of chlorides in the water. The cracks were shallow, had a broad mouth (both in the weld and the pipe), and contained within them heavy corrosion. Thus, in this reactor, the mode of failure appeared to have been stress-assisted accelerated corrosion, not unexpected for mild steel exposed to sea water. Unfortunately, no meaningful fractographic observations could be made due to the very shallow cracks and the heavy corrosion on the fracture surface.

\subsubsection{Discussion/Conclusions}

The cracking in the nine reactors investigated could be divided into three types: (a) a long crack at the root of the notch (D.C. Cook, H.B. Robinson and Beaver Valley); (b) a large number of small cracks along the tapered section of the pipe with the longest crack at the root of the notch (Salem, Ginna, Surry, and Kewaunee); (c) many shallow cracks in the pipe and weld (San Onofre).

The fractography of the cracks revealed a large number of crack arrest and beach marks, suggesting that crack propagation was discontinuous in nature and caused by a cyclic stress mode. Corrosion probably did not play a significant role in crack propagation. Although there were clear indications of low cycle corrosion fatigue, no unambiguous evidence for high cycle fatigue could be found.

The cracks initiated due to localized corrosion (pitting) and/or accelerated corrosion in the grooves of the machining marks. Since machining marks apparently play a large role in the initiation of the cracks, it was proposed that this factor could be minimized through better control of the machining procedure and subsequent cleaning.

The metallurgical characteristics of the steel, such as grain size, pearlite structure and distribution, and the presence of stringers, appeared to have no effect on crack location or propagation.

Since the largest crack occurred at the root of the notch, a point of a sharp geometric discontinuity and thus a stress raiser, it was proposed that piping should be designed to avoid such geometric discontinuities.

\subsection{Metallurgical Examination of Cracked Feedwater Pipes from Nine Pressurized Water Reactors}

Reference: Nuclear Technology, Vol. 55, pp. 525-537 
Author(s): $\quad$ Brijesh Vyas, Carl J. Czajkowski, John R. Weeks

Date: $\quad$ November 1981

Task: $\quad$ FIN A3106

Key words: $\quad$ Beaver Valley Unit 1; carbon steel; D.C. Cook Unit 2; Ginna; H.B. Robinson Unit 2; Kewaunee; low cycle fatigue; machining marks; pitting; Point Beach Unit 2; Salem Unit 1; San Onofre; Surry Unit 1

\subsubsection{Background}

After cracks were discovered in the feedwater lines of two steam generators at D.C. Cook Unit 2 facilities in 1979, the NRC requested U.S. licensees of pressurized water reactor (PWR) plants to conduct examinations of feedwater piping welds. As a result of this inquiry, indications of cracks were found in feedwater lines of 15 of the 26 units inspected. Samples of the cracked lines removed from nine of the affected units were subsequently sent to BNL for independent examination. These samples came from: H.B. Robinson-2, D.C. Cook-2, Beaver Valley-1, Salem-1, Point Beach-2, R.E. Ginna, Surry-1, Kewaunee, and San Onofre-1. The metallurgical failure analysis consisted of:

* visual examination of the inside surface of the pipe and elbow .

* metallographic examination

* microstructural characterization

* fractographic examination

* chemical analysis of the corrosion deposits.

\subsubsection{Results}

Most of the results of the evaluation are described in the previous item (BNL-NUREG-28146).

Table 4.2.1 summarizes the findings from all of the specimens investigated. The distribution of cracks on the nine reactors investigated can be divided into three general types:

* one long crack at the root of the notch in the tapered section as seen in D.C. Cook, H.B. Robinson, and Beaver Valley;

* a large number of small cracks along the tapered section of the pipe with the longest crack at the root of the notch as seen in the reactors at Salem, Ginna, Point Beach, Surry, and Kewaunee;

* many shallow cracks in the weld and the pipe, which have been very heavily corroded as seen in San Onofre.

\subsubsection{Discussion/Conclusions}

The fractography of the cracks revealed a large number of crack arrest and beach marks suggesting that the crack propagation was discontinuous in nature and had been caused by a stress mode that is cyclic in nature. Corrosion had not seemed to play a dominant role in the propagation of the cracks, except at San Onofre. Although there was a clear indication of low cycle corrosion fatigue, no unambiguous evidence for high cycle fatigue could be found. 
Table 4.2.1 Summary of Feedwater Pipe Cracking - Metallographic Observations

\begin{tabular}{|c|c|c|c|c|c|c|c|c|}
\hline \multirow[t]{3}{*}{$\begin{array}{l}\text { Reactor } \\
\text { Name }\end{array}$} & \multirow{3}{*}{$\begin{array}{c}\text { Inside } \\
\text { Surface } \\
\text { Observations } \\
\text { (Machining } \\
\text { Markings) }\end{array}$} & \multicolumn{2}{|c|}{$\begin{array}{l}\text { Single Largest } \\
\text { Cracks }^{a}\end{array}$} & \multicolumn{3}{|c|}{ Scanning Electron Microscopy } & \multicolumn{2}{|c|}{ Small Cracks ${ }^{b}$} \\
\hline & & \multirow[t]{2}{*}{ Length (mil) } & \multirow[t]{2}{*}{ Branching } & \multicolumn{2}{|c|}{ Types } & \multirow{2}{*}{$\begin{array}{c}\text { Crack } \\
\text { Arrest } \\
\text { and } \\
\text { Beach } \\
\text { Marking }\end{array}$} & \multirow{2}{*}{$\begin{array}{l}\text { Length } \\
\text { (mil) }\end{array}$} & \multirow[t]{2}{*}{ Number } \\
\hline & & & & Transgranular & Intergranular & & & \\
\hline $\begin{array}{l}\text { H.B. Robinson-2 } \\
\text { D.C. Cook-2 } \\
\text { Beaver Valley-1 }\end{array}$ & $\begin{array}{l}\text { Mild } \\
\text { Heavy }\end{array}$ & $\begin{array}{l}278 \\
290\end{array}$ & $\begin{array}{l}\text { Slight } \\
\text { Slight }\end{array}$ & Yes & $\begin{array}{l}5 \% \\
5 \%\end{array}$ & Yes & $\sim 3$ & 3 \\
\hline Beaver Valley-1 & Heavy & 125 & Slight & Yes & 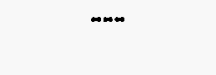 & Yes & 60 & 7 \\
\hline Salem-1 & Mild & 235 & Slight & Yes & $-\cdots$ & Yes & $\sim 5$ & 6 \\
\hline Point Beach-2 & Very heavy & 75 & Slight & Yes & --- & Yes & $\sim 5$ & $>10$ \\
\hline Ginna & Very heavy & 130 & Slight & Yes & -- & Yes & $\sim 10$ & $>10$ \\
\hline Surry-1 & Mild & 80 & Slight & Yes & -- & Yes & -- & $\cdots$ \\
\hline Kewaunee & Heavy & $30^{c}$ & Slight & Yes & $\cdots$ & $\ldots$ & $\sim 4$ & $>10$ \\
\hline San Onofre-2 & Heavy & $50^{\mathrm{d}}$ & Slight & Yes & --- & $-\cdots$ & $\sim 3$ & $>10$ \\
\hline
\end{tabular}

a Located at the root of the notch in the pipe section

${ }^{b}$ Generally starting from machining marks

${ }^{c}$ Large number of such large cracks observed

${ }^{d}$ Large cracks in weld metal 
The microstructural characteristics of the steel, such as grain size, pearlite structure and distribution, and presence of stringers in the steel, had no apparent effect on crack location or propagation. On the other hand, machining marks apparently played a large role in the initiation of the cracks, since they formed sites for localized corrosion, such as pitting, as well as being stress intensifiers. Better controls on the machining and cleaning procedures were recommended to minimize this effect. However, the primary remedial action should involve reducing the sources of the alternating fatigue stresses that propagate the cracks.

\subsection{Evaluation of the Transgranular Cracking Phenomenon on the Indian Point No. 3 Steam Generator Vessels}

Reference: Report NUREG/CR-3281

Author(s): $\quad$ C.J. Czajkowski

Date: $\quad$ June 1983

Task: $\quad$ FIN A3400

Key words: $\quad$ Indian Point Unit 3; low alloy steel; pitting; stress relief; transgranular stress corrosion cracking; weldments

\subsubsection{Background}

During a refueling outage in 1982 at the Indian Point No. 3 unit, a small leak was detected on the shell side of one of the steam generators. Further examination disclosed that the leak originated in the circumferential weld joining the transition cone to the upper shell of the steam generator. Upon closer examination a hole on the outer surface of the generator was found. Subsequent inspections discovered that the closure welds on each of the other steam generators had in excess of 100 cracks and that, associated with them was a significant amount of pitting (on the inside surfaces).

The steam generator shell is constructed of ASME SA-302 Grade B material approximately 4 inches thick. The original closure weld had a nominal $45^{\circ}$ included angle weld preparation and was welded from the outside surface of the vessel by the submerged arc process with backing. The spacer strip was back-gouged and the weld completed by welding from the inside surface with the shielded metal arc process using E8018-C3 electrode. The fabrication procedure called for continuously stress relieving of the weld at a minimum temperature of $1000^{\circ} \mathrm{F}$ for 3 hours/inch of thickness (12 hours total soak time).

BNL undertook to perform a metallurgical investigation of four specimens (a six-inch plug weld and three boat samples containing cracks) taken from the shells of two steam generators. The investigation included:

* visual examination

* hardness measurements/heat treatments

* optical microscopy

* scanning electron microscopy/energy dispersive spectroscopy. 


\subsubsection{Visual Examination}

The actual path of the through-wall leaking crack appeared to follow the weld HAZ. Other, smaller, cracks were noted, together with an area of lack of fusion and an area of porosity. All three boat samples showed evidence of pitting on the inside surface of the steam generator.

\subsubsection{Hardness Measurements/Heat Treatments}

Knoop hardness measurements made on the three principal microstructural zones in the plug sample yielded approximate average values of $260 \mathrm{HK}$ (base material), $310 \mathrm{HK}$ (HAZ), and $285 \mathrm{HK}$ (weld). Similar measurements were made on the three boat samples and produced slightly lower values for the base material and weld, but somewhat higher values for the HAZ.

The plug section was then subjected to two differing heat treatments, at $1000^{\circ} \mathrm{F}$ and $1125^{\circ} \mathrm{F}$, and additional hardness readings taken after each heat treatment. Both the base material and the HAZ showed only slight reductions in the average hardness after the $1000^{\circ} \mathrm{F}$ treatment but much more significant hardness losses following the $1125^{\circ} \mathrm{F}$ treatment. The weld material experienced the most significant loss following the $1000^{\circ} \mathrm{F}$ treatment and an additional but smaller reduction in hardness after the $1125^{\circ} \mathrm{F}$ treatment. These observations were taken to indicate that this particular section of the plug weld had received a prior heat treatment of less than $1000^{\circ} \mathrm{F}$.

\subsubsection{Optical Microscopy}

Optical microscopy revealed that some of shallow pits seen in the plug section had cracks associated with them. These cracks were tight and transgranular in nature, emanating at the bottom of the shallow pits. They were generally continuous with virtually no branching evident. Other pits had shallow, opened-mouthed cracks associated with them. These latter cracks had the appearance of having more active corrosion process associated with them than the predominantly transgranular ones.

Similar observations of transgranular cracks initiating at pits were made with sections taken from the boat samples.

The microstructures observed in the plug section and the boat samples were basically similar. The base material had a tempered martensite structure consistent with that expected with ASME SA-302 Grade B material. Likewise, the weld microstructures were typically dendritic, again consistent with the welding processes involved. However, the weld HAZ had a more acicular structure normally associated with untempered martensite.

\subsubsection{Scanning Electron Microscopy/Energy Dispersive Spectroscopy}

SEM revealed that all the fracture faces examined displayed the characteristics of fatigue fracture. Each of the surfaces exhibited transgranular features with wood-like characteristics and all of the fractures apparently initiated at pits.

EDS scans of the area of initiation on the fractures indicated $\mathrm{Fe}, \mathrm{Cr}, \mathrm{Ni}, \mathrm{Si}, \mathrm{S}, \mathrm{Cu}$ and $\mathrm{Zn}$ as typical constituents. Only one pit had additional elements ( $\mathrm{Al}, \mathrm{Si}, \mathrm{Cl}$, and $\mathrm{K}$ ) present.

\subsubsection{Discussion/Conclusions}

A review of the operating history of the Indian Point site was made, together with past observations on steam generators and the corrosion characteristics of carbon and low-alloy steels. In light of the observations made in the present case, it was concluded that low cycle corrosion fatigue was the primary cause of degradation, although the relative importance of corrosion in the crack initiation and propagation process could not be fully determined. The 
possibility of stress corrosion cracking being a contributing cause to the failure could not be entirely discounted due to the lack of information regarding this alloy's response in copper-containing oxygenated water.

\title{
4.4 Evaluation of Boat Samples from the Steam Generators at Indian Point No. 2
}

\author{
Reference: $\quad$ Report MT A-3851-1 \\ Author(s): $\quad$ C. Czajkowski \\ Date: $\quad$ December 1987
}

Task: $\quad$ FIN A-3851

Key words: $\quad$ carbon steel; copper; corrosion fatigue; Indian Point Unit 2; pitting; residual stresses; transgranular cracking; weldments

\subsubsection{Background}

In 1987, following a joint request from Consolidated Edison of New York and the NRC, BNL conducted a metallurgical evaluation of specimens removed from the cracked closure weld of the steam generators at the Indian Point No. 2 power station. The evaluation comprised:

* visual examination/hardness measurements/heat treatment

* optical microscopy

* scanning electron microscopy/energy dispersive spectroscopy.

\subsubsection{Visual Examination/Hardness Measurements/Heat Treatment}

The examination involved three elliptically shaped boat samples, all of which showed evidence of pitting on the inside surface of the steam generator. Discussions with utility personnel disclosed that the steam generators were constructed from ASTM A-302 Grade B material and that the closure weld was stress relieved after welding at $1000^{\circ} \mathrm{F}$ minimum for three hours per inch of thickness.

Knoop microhardness readings were taken on sections of the base material, the weld and the heat-affected zone and proved to be consistent with what would be expected from this material (base material $207 \mathrm{HK}$, weld 270 HK, heat-affected zone $271 \mathrm{HK}$ ). There also existed a more hardened band ( $386 \mathrm{HK}$ ) immediately adjacent to the weld fusion line. Concern had been expressed that perhaps the closure weld had not received a complete stress relief so the microhardness specimens were subjected to an additional stress relief heat treatment. Follow-up microhardness measurements showed only a very slight change in the hardness values recorded in the four areas, indicating that the original stress relieving operation had essentially achieved its goal.

\subsubsection{Optical Microscopy}

Optical microscopy revealed that the cracking was transgranular with no evidence of branching. A number of crack propagation arrests were noted, indicating that a corrosion mechanism may have been the dominant mode at times. 


\subsubsection{Scanning Electron Microscopy/Energy Dispersive Spectroscopy}

SEM of the fracture faces indicated that the crack initiated on the inside surface of the steam generator and progressed transgranularly via a fatigue-like mechanism. EDS scans revealed traces of $\mathrm{Cu}, \mathrm{S}, \mathrm{Sn}$ and $\mathrm{Si}$ in addition to the expected metallic constituents.

\subsubsection{Discussions/Conclusions}

The cracking observed on the Indian Point \#2 specimens were predominantly transgranular in appearance and were associated with pits on the inside surface of the steam generators. The cause of the pitting/cracking is considered to be related to copper species in the coolant solution. The appearance of crack arrests and beach marks on the fracture surfaces suggested that the propagation was discontinuous in nature and caused by a cyclic stress mode. This formed the basis for the conclusion that the failure mode low cycle corrosion fatigue. The observance of possible fatigue interaction indicated that the probable cause of the failure is a low-cycle corrosion fatigue phenomenon. A similar conclusion was reached in a previous investigation at the Indian Point \#3 unit.

At the same time, the possibility of stress comosion cracking being a contributor to the failure could not be totally discounted. The comparatively high hardness level found on a band at the weld fusion line indicated the presence of some high residual stresses at the weld. However, the very slight lowering of the hardness values after a $1000^{\circ} \mathrm{F}$ heat treatment indicated that the weld had probably received most, if not all, of the intended benefits from the original stress relieving operation.

\subsection{Examination of a Cracked Reducer from the Trojan Nuclear Plant}

Reference: $\quad$ Report MT-3851-5

Author(s): $\quad$ C. J. Czajkowski

Date: $\quad$ October 1988

Task: $\quad$ FIN A-3851

Key words: $\quad$ carbon steel; low cycle fatigue; pitting; transgranular cracking; Trojan

\subsubsection{Background}

During a refueling outage at the Trojan Nuclear Power Plant in 1987, the feedwater reducers to all four steam generators were replaced because three of the four piping reducers had shown indications of flaws when examined by ultrasonic testing.

Since the cracking morphology on the reducers examined appeared to be similar to those previously evaluated at other nuclear units (e.g., Salem, Oconee, etc.), BNL was contracted to perform a failure analysis of one of the reducers from the Trojan Unit. The subsequent investigation included the following examinations:

* scanning electron microscopy/energy dispersive spectroscopy

* visual/photography

* dye penetrant examination

* microhardness testing

* optical microscopy. 


\subsubsection{Material/Specimen Preparation}

The feedwater reducer (identified as "D" reducer) received at BNL was a $16 \times 14$ size and had been welded to a steam generator 16 inch feedwater nozzle on one end and a 14 inch schedule 60 pipe on the smaller end. Discussions with the utility disclosed that the reducer was fabricated from ASME SA-106 Grade B material and data on the chemical and mechanical properties received from the utility indicated that the material was within the specification requirements.

The reducer was cut in half with a power saw but without the use of lubricants (in order to prevent contamination of any cracks by cutting oils). Only one crack (approximately 5 inches long) was noted, this in the weld end preparation area of the 16 inch end of the reducer.

Two sections were cut and opened up for SEM/EDS and visual examination. This was accomplished by cutting a V-notch below the crack, cooling the cut section to liquid nitrogen temperature then pulling it apart in such a way that no damage occurred to the fracture surface. The cracks (after opening) were typically half moon shaped and covered with a tight, black adherent oxide film.

Following SEM/EDS examination, the fracture surfaces were cleaned using an electrolytic procedure.

\subsubsection{Scanning Electron Microscopy/Energy Dispersive Spectroscopy}

SEM fractographs taken of the two specimens prior to electrolytic cleaning exhibited multiple initiation sites, were transgranular, and had "beach marks" on the fracture surfaces. There was also evidence of pitting on the inside surface of the reducer on the fracture surface.

Various areas were examined by EDS. In addition to $\mathrm{Fe}$, trace amounts of $\mathrm{Cu}, \mathrm{S}, \mathrm{Si}, \mathrm{Ca}$, and $\mathrm{Ni}$ were seen as well as trace amounts of $\mathrm{Cl}$ on two of the scans. However, in general, no specific corrodent species was identified.

\subsubsection{Visual/Photography}

After cleaning the specimens were visually examined. Both specimens exhibited thumbnail-like cracks with "beach marks" visible on all fractures examined. The deepest crack observed was measured to be 0.235 inches in depth with the second specimen having a 0.150 inch crack depth.

\subsubsection{Dye Penetrant Examination}

Discussions with utility personnel suggested that there may also have been cracking on the small (14 inch) side of the reducer. Since visual examination disclosed no cracks on this side, a dye penetrant examination was performed on the 14 inch weld area. No cracks were seen on the 14 inch weld area of the reducer.

\subsubsection{Microhardness Testing}

Microhardness (Knoop, 500g load) measurements were taken on the base metal, the weld and the heat affected zone of the reducer (16 inch side). Average values ranged from $184 \mathrm{HK}$ (base material) to $211 \mathrm{HK}$ (weld) and were typical for SA-106 Grade B material.

\subsubsection{Optical Microscopy}

Metallurgical cross sections of the reducer were cut, mounted and polished. The specimens were etched in a $10 \%$ Nital solution and then examined. 
The base metal, weld metal, and heat affected zone microstructures were consistent with those of a $0.28 \%$ welded carbon steel. The cracks were observed to be transgranular in nature with no apparent branching. In one instance small areas of pitting were noted along the crack length, indicative of a corrosion process at work in tandem with the crack propagation driving force.

\subsubsection{Discussion/Conclusions}

Both of the fractures displayed "beach marks" under visual examination and in the scanning electron microscope. These marks, the consequence of a large number of crack arrests, are indicative of discontinuous crack propagation and are typically found on service fractures where the part is loaded randomly, intermittently, or with periodic variations in mean stress or alternating stress. Similar cracking has been previously observed on feedwater pipes at various nuclear power plants. The location (counterbore) of the single crack is similar to that observed on D. C. Cook, H. B. Robinson, and Beaver Valley. The Trojan crack as well as those previously mentioned had crack arrests and a tight oxide film associated with them. The nature of the nozzle/reducer area of the steam generator is such that the mean stress in the pipe is occasionally superimposed by a thermal stress which could easily result in a low cycle phenomenon.

In addition, the corrosion process appeared to play a minor role in the crack propagation as evidenced by both pits on the fracture surface and corrosion pits observed in the cracks by optical microscopy. Thus the reducer cracks seemed to be the result of a low cycle corrosion fatigue phenomenon similar to that which has been previously observed at nuclear units. 


\title{
5 HOT CRACKING
}

\subsection{Evaluation of a Cracked RHR Pump Impeller from the Vermont Yankee Power Plant}

\author{
Reference: Report MT-3851-2 \\ Author(s): C. Czajkowski \\ Date: $\quad$ February 1988 \\ Task: $\quad$ FIN A-3851
}

Key words: $\quad$ cast stainless steel; hot cracking; interdendritic cracks; intergranular stress corrosion cracking; Vermont Yankee; weld repair

\subsubsection{Background}

On May 20, 1986 the NRC issued an IE Information Notice No. 86-39 entitled "Failures of RHR pump motors and pump internals." This notice provided information to utilities regarding significant damage to a BinghamWillamette pump at a nuclear plant. The damage was determined to have been caused by IGSCC of the pump impeller's wear rings.

Prompted by this information notice, personnel at the Vermont Yankee Power Plant in April 1987 performed inspections of their residual heat removal (RHR) pump impellers for wear ring damage. These pumps were of a type very similar to that referred to in the information notice. Although the inspection disclosed no IGSCC of the wear rings, indications of cracking were noted on the impeller castings of two pumps. These crack indications were of sufficient interest that the NRC contracted with the BNL to perform a failure analysis on one of the pump impellers.

In July 1987, a BNL representative visited the Vermont Yankee Plant in order to select an impeller for examination. The impeller selected, identified as "B," had a linear indication approximately five inches long roughly three-eighths of an inch from the wear ring. The base material was reported to be ASTM A-296, Grade CA-15 but no details were available on any non-destructive testing that may have been performed at time of manufacture. The impeller was subsequently shipped to BNL, decontaminated, then subjected to an evaluation consisting of:

* visual inspection/photography/optical microscopy

* hardness measurements

* scanning electron microscopy/energy dispersive spectroscopy.

\subsubsection{Visual Inspection/Photography/Optical Microscopy}

The machined surface of the hub exterior showed a number of areas that had the appearance of having been ground. Dye penetrant examination on the hub exterior and the wear rings revealed a crack-like indication approximately five inches long near the upper wear ring and approximating the outer contour of the wear ring in directionality. There were no crack indications on the wear rings. Three hardness specimens and a section containing the crack were then machined from the impeller.

The section containing the crack was further cut perpendicular to the long axis of the crack, mounted in epoxy, metallurgically ground and polished, and then etched in Vilella's Reagent. This revealed that the crack 
appeared to have initiated in weld metal and propagated into the base material. The crack was relatively straight with little evidence of branching. There was some indication of general corrosion attack near the surface of the crack which had the appearance of pits along its length. A second section, cut near the main crack indication, was mounted, polished and etched, and confirmed that the crack occurred entirely in weld metal. The size of the dendrites and the directionality in the area of the crack indicate that there was probably non-uniform cooling of the deposit. The crack itself appeared to be more interdendritic in appearance and there was little branching evident. It also appeared to be oxide filled in many areas.

While examining one of the hardness samples visually, a number of crack-like indications initiating on the interior surface of the casting were noticed. The existence of cracks was confirmed, one of which appeared to be solely in weld metal. Again, a strong directionality of dendrite growth in the weld metal was observed. A number of additional smaller cracks seen on this specimen appeared to originate on the machined side of the casting. All had an interdendritic appearance and were filled with oxide.

The base material of the casting appeared to be tempered martensite.

\subsubsection{Hardness Testing}

Three hardness specimens were cut approximately 120 degrees from each other on the impeller's outer periphery and six hardness measurements performed on each specimen. The average hardnesses estimated for each specimen were: $80.33 \mathrm{HRB}$ ( $\equiv 148 \mathrm{BHN}$ ), $85.25 \mathrm{HRB}$ ( $\equiv 164 \mathrm{BHN}$ ), and $81.83 \mathrm{HRB}$ ( $\equiv 152 \mathrm{BHN}$ ). The original casting specification, ASTM A-296, Grade CA-15, specifies a maximum hardness of Brinell 241.

\subsubsection{Scanning Electron Microscopy/Energy Dispersive Spectroscopy}

The first fracture examined, from the original $5^{\prime \prime}$ long crack, was predominantly interdendritic in appearance and with at least two initiation sites on the fracture face. The corresponding EDS scan of a deposit of apparent oxide adjacent to the fracture indicated that it was composed of iron and chromium. The other fracture face examined was from a crack found on one of the hardness specimens. Its appearance was very similar to that of the first fracture examined.

A polished metallographic mount of the impeller was subjected to EDS. This showed that the casting was welded with a weld material of similar composition to that of the casting material. This matching of weld metal to casting composition is in accordance with the specification.

\subsubsection{Discussion/Conclusions}

Failures in castings and weldments can often be subscribed to hot cracks or hot tears. The former are caused by internal stresses that develop after solidification and during cooling from an elevated temperature. Hot tears form prior to completion of solidification because of hindered contraction. A hot crack is less visible (less open) than a hot tear and usually exhibits less evidence of oxidation and decarburization. In addition, it has been noted that, since hot cracking is related to grain boundary liquation, hot cracks would generally be intergranular or interdendritic in appearance. Such a description would apply equally well to the appearances of the fracture faces in the present investigation.

Based on the above discussion and the observations recorded during the investigation, the following conclusions were drawn:

1) The chemical analyses of the casting and weld repair areas generally conformed to the specifications contained in ASTM A-296, Grade CA-15 
2) The cracking was predominantly interdendritic in appearance and associated almost entirely with areas of weld repair

3) The observation of cracks between surfaces of a weld repair led to the conclusion that the cracking was directly related to the original weld repairs of the casting. The probable cause was hot cracking resulting from large weld repairs of defects in the original casting.

\title{
5.2 Evaluation of Cracks Found in Stellite Valve Guides at Vermont Yankee Nuclear Power Station
}

\author{
Reference: $\quad$ Report MT-L1529-3 \\ Author(s): $\quad$ C. J. Czajkowski \\ Date: $\quad$ September 1991 \\ Task: $\quad$ FIN L-1529
}

Key words: hot cracking; inadequate welding; interdendritic cracks; Stellite valve guides; Vermont Yankee

\subsubsection{Background}

During the 1989 outage at the Vermont Yankee Nuclear Power Station cracking was identified on four feedwater check valves. The valves were 16 inch "Cast Steel Pressure Seal Lift Check Valves," Model \#5386, manufactured by Walworth Company in 1969. Utility personnel "sized" cracks on four valves during this outage. The cracks were located in the Stellite guides of the valves. Two of the four valves (identified as V2-28A and V228B) were removed from service during the 1990 outage. The other two valves were left in service after resizing their cracks (V2-27B and V2-96B).

The failure mode (cracks) of the feedwater valves was suspected to be IGSCC which could potentially compromise the piston action of the check valve. Owing to the possible safety significance of these cracks, the NRC requested BNL to perform a metallurgical failure analysis on one of the cracked valves (V2-28B). This assessment was to include:

$\begin{array}{ll}* & \text { visual/photography/dye penetrant inspection } \\ * & \text { optical microscopy/microhardness } \\ * & \text { scanning electron microscopy/energy dispersive spectroscopy. }\end{array}$

After uncrating of the 3000-lb, 16-inch check valve was completed, the utility sent one of its nondestructive testing personnel to resize the cracks prior to destructive sample removal. These examinations were performed prior to disassembly of the valve.

The valve was disassembled and internally examined visually. This disclosed disparities between the actual cracks in evidence and the nondestructive inspection reports. A reinspection was performed by Yankee Atomic nondestructive test personnel after which it was confirmed that BNL had been sent the wrong check valve by the utility: valve V2-28A had been received in lieu of V2-28B. Following more discussions, it was decided that BNL would also receive check valve V2-28B and an expanded evaluation of both check valves would be performed. 


\subsubsection{Visual/Photography/Dye Penetrant Inspection}

After receipt of check valve V2-28A, the valve was disassembled and the piston removed. Some wear areas were noted on the piston.

The check valves were placed in one of the BNL hot cells where three-inch diameter plugs were cut to facilitate removal of the cracks. Two plugs were removed from V2-28A and four from V2-28B. All of the cracking appeared to be confined to the areas of the Stellite weld metal. The six plugs were photographed following their removal then various cuts were made through the observed cracks in order to facilitate specimen removal for optical microscopy or SEM examination. Many of these sections defined the cracks as being essentially in the Stellite weld metal and a number showed defects (lack of fusion and inclusions) in the weld metal areas. The majority of sections cut were approximately two inches thick with the Stellite approximately one-quarter inch in depth.

Cracks were also seen on the splitter bar on the valves. Due to the thickness of the material in these areas and the lack of flat cutting base on the valve exterior, these specimens were not removed.

The dye penetrant examinations clearly revealed the cracks in the Stellite hardfacing.

\subsubsection{Optical Microscopy/Microhardness}

The various samples cut from the plugs were ground and metallurgically polished for examination. Optical microscopy clearly revealed that the cracks were associated with weld defects (inclusions, lack of fusion, etc.) in both valves. Most of the defects initiating the cracks appeared to be at the weld fusion line (Stellite/base metal). Additionally, the microscopy definitely showed the crack progressing outward from the weld fusion line into the Stellite and towards the valve's inside surface. Corrosion cracking sometimes appeared to be associated with the crack propagating into the base metal. This appeared to be related to the crevice formed after the crack had propagated through the Stellite and a corrosion path had been formed to the feedwater in the valve.

The specimens were also etched to reveal their microstructure. This was revealed the weld metal (Stellite) to have a dendritic structure typical of the kind expected from gas tungsten arc welding (GTAW) of this material.

Vickers microhardness measurements performed on the Stellite hardfacing material and the base metal revealed an average hardness of the former of 496 and of the latter 148. The average value of 496 for the Stellite is equivalent to a Rockwell "C" value of approximately HRC 49 and is significantly higher than the average value of approximately HRC 40 typically reported by the manufacturers for GTAW ( 2 passes). This also indicates the probability that a stress relieving operation was not performed after welding.

\subsubsection{Scanning Electron Microscopy/Energy Dispersive Spectroscopy}

Various fracture surfaces were examined by SEM. Interdendritic cracking was typical on all of the fracture areas examined on both V2-28A and V2-28B. Two apparent inclusions were also seen associated with the two fractures from V2-28B. These latter were large and had lack of fusion areas associated with them. Lack of fusion was also apparent in one of the fracture faces from V2-28A.

EDS scans of typical fracture areas indicated the constituents were typical of those expected for Stellite 6 . The EDS scan of an inclusion area was entirely different, being dominated by a high titanium peak and having no trace of cobalt (the major constituent in Stellite 6). 


\subsubsection{Discussion/Conclusions}

The failure investigation revealed that the cracking that occurred in the Stellite valve guides is predominantly interdendritic in nature and typical of hot cracking. All of the cracks examined appeared to be associated with some sort of welding defect (e.g., inclusions, lack of fusion, etc.). Some of the cracks were "through wall" cracks (through the Stellite), leading to the belief that they initiated at the weld fusion line (Stellite to base metal). The cracking was probably the result of the original welding process being inadequate for the production of a "defect free" weld deposit. The weld deposit was found to be of higher hardness than would have been expected, from which it might be inferred that stress relief was not performed after welding. Lack of stress relief would probably have contributed to the cracking process.

The apparent crack propagation into the base metal observed with some of the cracks suggested the possibility of corrosion cracking after a leak path to the valve inside surface had been established. 



\section{OVERHEATING (FORGING)}

\subsection{Evaluation of Intergranular Cracks on the Ring Header Cross at Grand Gulf Unit No.1}

Reference: Intl. Journal of Pressure Vessels \& Piping, Vol. 27, pp. 353-365

Author(s): $\quad$ Carl J. Czajkowski

Date: $\quad 1987$

Task: $\quad$ FIN A-3500

Key words: $\quad$ burning; forgings; Grand Gulf; intergranular cracking; overheating; Type 304 stainless steel

\subsubsection{Background}

During a thermocouple removal procedure on the ' $\mathrm{A}$ ' loop ring header cross at the Grand Gulf Unit No. 1 Nuclear Power Station, various linear indications were discovered by dye penetrant examination. The thermocouple removal and dye penetrant procedure were performed after the ' $\mathrm{A}$ ' loop ring header cross had been subjected to induction heating stress improvement (IHSI) techniques for mitigation of potential IGSCC of the cross. The indications were located in a band running circumferentially below the cross-to-cap weld with a similar band above the cross-to-discharger pipe weld. Similar linear indications were uncovered on a spare cross from Grand Gulf Unit No. 2 that had been used for development of the IHSI procedures and had not been installed. The IHSI method of stress mitigation had been used extensively by the nuclear industry and any indication of a possible 'generic' cracking problem as a result of the process was thus of much concern.

As a result, BNL was contracted by the NRC to perform a failure investigation and a sample was sent to BNL. This had been cut from the cross which had not seen actual service but which had been used to qualify the IHSI technique for the Grand Gulf units. The base material was ASME SA-182 material manufactured to ASME SA-403 Type WP 304 stainless steel.

The failure investigation consisted of the following:

* visual inspection/photographs/dye penetrant examination

* chemical analysis/hardness testing

* optical microscopy/metallography

* $\quad$ scanning electron microscopy/energy dispersive spectroscopy

* ferrite measurements.

\subsubsection{Visual Inspections/Photographis/Dye Penetrant Examination}

Initial visual examination indicated that the outside surface had been coarse ground and had some crack-like indications. Dye penetrant examination revealed many linear indications with a definite intergranular appearance.

It was also noted that another pipe from the same heat of material (prior to IHSI) had been examined and linear indications had been observed on the pipe. The observed indications were, however, neither as severe nor as dense as those on the specimen sent to BNL. 


\subsubsection{Chemical Analysis/Hardness Testing}

Chemical analysis confirmed that the material met all the requirements of ASME SA-182, F304 stainless steel. Measurements performed on a cross-section of the specimen gave an average hardness of about 23 HRC, equivalent to a tensile strength of approximately $117 \mathrm{ksi}$ and thus well in excess of the minimum specification requirement of $75 \mathrm{ksi}$.

\subsubsection{Optical Microscopy/Metallography}

Cross-sectional metallography revealed the cracks to be practically all intergranular and filled with oxide. The material also exhibited a tremendously large grain size, greater than ASTM grain size 00 (as defined by ASTM E-112). Sensitization testing according to ASTM A-262, Practice A, proved negative; that is, the material was not in a sensitized condition. Additional metallography failed to detect the presence of any second phases such as sigma.

\subsubsection{Scanning Electron Microscopy/Energy Dispersive Spectroscopy}

SEM of the fracture surface confirmed the intergranular nature and also the very large grain size noted in the optical microscopy examination. The fracture face was covered with a rust-colored oxide film, consistent with the optical microscopy observation of oxide-filled cracks.

EDS scans of the fracture faces produced peaks of the major constituents of this material $(\mathrm{Fe}, \mathrm{Cr}, \mathrm{Ni})$ and occasionally traces of other elements such as $\mathrm{Si}, \mathrm{S}$, and $\mathrm{Cl}$. The latter two were thought to be remnants of the prior dye penetrant examination.

\subsubsection{Ferrite Measurements}

Delta ferrite readings were mostly in the range 0.3 to $0.9 \%$, much lower than is normally required to prevent hot cracking of cast materials.

\subsubsection{Discussion/Conclusions}

The chemical analysis of the header cross was consistent with that of ASME SA-182 Type 304 stainless steel while the hardness measurements indicated a tensile strength well above the minimum specified for this material. The material was not in the sensitized condition and there was no evidence of second phase formation. However, the material had an extremely large (ASTM 00) grain size and a very low ferrite content.

The cracking was observed to be intergranular and had initiated on the forging's exterior surface. The cracks themselves were filled with oxide. EDS examination revealed no significant evidence of the presence of corrodents on the fracture surface.

Possible failure modes which were considered during the analysis included IGSCC, second phase formation, and overheating/burning of the forging. It was concluded that IGSCC was very unlikely in the present case as the material was not in the sensitized condition nor were any definitive contaminants found on the fracture face. Second phase formation was also considered an unlikely contributor to the failure. Not only was there no visible second phase present but the material was found to contain a very small amount of delta ferrite, a phase which can contribute to the rapid formation of sigma phase.

The most probable cause of the failure appeared to be either overheating or burning of the forging. Of the two, overheating was considered the most likely, as evidenced by a large grain size, an intergranular fracture surface and fine oxide particles dispersed throughout the grains. The IHSI process may have opened the pre-existing cracks 
so that they were discovered by dye penetrant. However, the IHSI process did not appear to have contributed to the cause of cracking. 


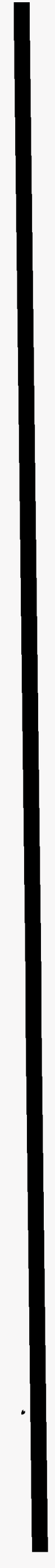




\title{
7 PRODUCTION PROCESS
}

\subsection{Failure Investigation of 3M Series 900 Static Eliminators}

\author{
Reference: Report NUREG/CR-5145 \\ Author(s): $\quad$ C. J. Czajkowski \\ Date: July 1988 \\ Task: $\quad$ FIN A3901
}

Key words: cracked microspheres; environmental damage; epoxy binder; polonium-210; static eliminators

\subsubsection{Background}

On January 25, 1988, the NRC issued an order to the Minnesota Mining and Manufacturing Company suspending the distribution of certain static eliminating devices containing polonium-210. This was prompted in part by the reporting of radioactive polonium-210 contamination at the Ashland Chemical Company's facilities in Easton, PA, and Dallas, TX, stemming from leakage of these devices. Static eliminators of the type in question contain radioactive polonium-210 fused into small (30-35 $\mu \mathrm{m}$ diameter) spheres (microspheres) composed of a zirconium pyrophosphate $\left(\mathrm{ZrP}_{2} \mathrm{O}_{7}\right)$ ceramic. Fabrication involves adsorption of purified polonium-210 on the outer layers of the microspheres which are then fired at $700^{\circ} \mathrm{C}$ to form a ceramic bead containing polonium-210. After firing, the microspheres are plated with $1 \mu \mathrm{m}$-thick coating of nickel then incorporated into an epoxy binder. The epoxy is subsequently installed into the metal tube used as the static eliminator.

In order to independently ascertain potential failure modes of the 900 series static eliminators, BNL was requested to perform a failure investigation on a sample of the eliminators used at the Easton, PA, facility. This investigation included:

* receipt/visual inspection of new and failed devices

* wipe surveys of new and failed devices to check radioactivity levels

* selection of two new and at least one failed device from each use environment ( 6 total).

Each of these six devices was then examined using:

* visual examination/photography

* disassembly/sectioning

* optical microscopy

* scanning electron microscopy.

In addition, a scanning electron microscopy evaluation was made of two types of epoxy and a sample of nonradioactive microspheres

\subsubsection{Receipt/Visual Inspection/Wipe Survey/Tap Test}

A total of thirty-four type 908 series static eliminators were received. Twelve of these were new, unused devices, two of which were chosen at random for sectioning. The remainder of the devices (other than 12 new ones) had seen service at the Easton, PA, facility. Four of these were chosen to be reasonably representative of those exposed to the service environment. 
Five of the six specimens chosen for further examination appeared to be jacketed in stainless steel while the sixth appeared to be made from a copper alloy (probably brass). Three of the devices appeared to have scratches on them from service, one of them having gouges on the outside surface similar to those which pliers might produce.

All 34 devices were dry wiped (smeared) on the exterior surface and the wipes counted in an alpha scintillator. The results of this survey indicated that 11 of the 34 devices were contaminated including 6 of the 12 new devices.

Because it was apparent that normal handling could possibly loosen the polonium microspheres, two of the devices were subjected to a "TAP TEST," the intent of which was to ascertain if rough handling could loosen the microspheres from the epoxy matrix. The test consisted of taping over both openings of the static eliminator (male and female threaded ends), then giving a single sharp tap on each end of the device against a hard surface. The resultant four pieces of tape were then counted in the alpha scintillator. One of the four tapes was found to show activity, an indication that rough handling could have contributed to the contamination problem.

\subsubsection{Evaluation of Epoxy and Non-Radioactive Microspheres}

Samples of two types of epoxy (black and amber) and a vial of non-radioactive microspheres (fused and nickel coated but no polonium-210) were examined by SEM. Both of the epoxy blanks appeared to be continuous in nature with no cracks visible. Discussions with NRC personnel disclosed that the addition of $2 \%$ carbon black was the only difference between the compositions of the two epoxies. However, a significant number of the microspheres were in a cracked, split or otherwise damaged condition. An EDS scan performed on the microspheres confirmed that they had been coated with nickel.

\subsubsection{Sectioning/Macrophotography/Scanning Electron Microscopy}

The six sample static eliminators were sectioned by hand cutting lengthwise with a mini-hacksaw until the jacketing material was penetrated. A single edged straight razor blade was then used to cut the epoxy tape in order to open the various devices' internals for inspection.

Because depth-of-field limitations precluded meaningful optical microscopy, it was decided to perform macrophotography of the devices' internals and rely on scanning electron microscopy of the specimens' features. For the latter evaluation, one half of each cut device was sputter coated to a thickness of $300 \AA$.

Both of the new devices examined were characterized by intact epoxy with no signs of degradation. However, the epoxy in the four used devices had evidence of varying degrees of degradation, as evidenced by discoloration and by cracking. Distribution of microspheres in the epoxy was uneven in all devices, there being areas in which no microspheres could be detected. Additionally, all devices had discrete areas in which the microspheres appeared to have separated from the epoxy matrix ("decohesion"). Actual damage (cracking and breaking) of the microspheres was observed in all the devices, including the two unused ones. The degree of damage appeared to be greater in the four used devices. It was also noted that there was no evidence of swelling or blistering of the epoxy, suggesting that the contribution of radiation damage was not a major factor in microsphere dislodgement or damage.

\subsubsection{Discussion/Conclusions}

The observations of cracked and damaged microspheres on non-radioactive samples and on new, unused devices encouraged the hypothesis that quality control of microsphere manufacturing methods deserved closer scrutiny. In addition, the deposition of activity on a tape sample after a "TAP TEST" suggested that rough handling of these devices could initiate a contamination incident. The results from dry wipe tests performed on various new (still in the original plastic envelopes) devices gave a clear indication that some of these devices may have been a source of 
contamination in the "as received" condition. Thus it was concluded that the manufacture of the microspheres did not consistently produce uniform and perfect spheres.

With respect to the epoxy binder, significant environmental and material damage appeared to have been suffered even under ambient conditions. The effect of solvents, heat, moisture or vibration may accelerate this damage. The breakdown of the epoxy binder appeared to be an important factor in the contamination by loose microspheres or microsphere fragments during service. Consequently, an evaluation of the "suitability for service" of this epoxy binder seemed warranted.

\subsection{Examination of Two 3M Type 902F Static Eliminators}

$\begin{array}{ll}\text { Reference: } & \text { Report NUREG/CR-5266 } \\ \text { Author(s): } & \text { C. J. Czajkowski } \\ \text { Date: } & \text { January } 1989 \\ \text { Task: } & \text { FIN A3901 }\end{array}$

Key words: $\quad$ cracked microspheres; environmental damage; epoxy binder; polonium-210; static eliminators

\subsubsection{Background}

An earlier investigation into the failures associated with the 3M Company's Type 908 static eliminators (see previous summary item) determined that breakdown of the epoxy binder (used to hold together the microspheres containing polonium-210) might be a significant contributor to the contamination caused by loose microspheres and microsphere fragments. It was subsequently discovered that the epoxy binder material had been altered in 1983 with the addition of carbon lamp black to the amber epoxy material. This led to speculation that the older epoxy compound might have been more resistant to environmental variances than the current mixture. In addition, an evaluation of radioactive polonium-210 microspheres (as manufactured) was considered a priority item to determine if the qualities of the non-radioactive and radioactive microspheres were consistent. Consequently the NRC sent two older model static eliminators (1983 vintage) to BNL for evaluation together with a sample of radioactive microspheres. The evaluation included:

* visual inspection/wipe survey

* macrophotography/scanning electron microscopy.

\subsubsection{Visual Inspection/Wipe Survey}

Two Type 902F series static eliminators were sent to BNL. Both devices were dry wiped (smeared) on the exterior surface. Subsequent counting in an alpha scintillator indicated no discernible exterior contamination of the devices.

\subsubsection{Macrophotography/Scanning Electron Microscopy}

The two static eliminators were sectioned by hand cutting the devices lengthwise then the epoxy tape cut to facilitate internal examination. The amber epoxy appeared to be intact on both specimens with no apparent degradation of either the binder or polonium-210 microspheres. Optical microscopy of both specimens showed no obvious areas of microsphere dislodgement, although cracking of the epoxy was detected. 
After visual inspection and macrophotography, one-half of each cut device was sputter coated to a thickness of $300 \AA$ with gold-palladium and then examined using SEM. Both devices were found to contain cracked epoxy, and both imperfect microspheres and cracked and broken pieces of microspheres.

\subsubsection{Evaluation of Radioactive Microspheres}

The sample of radioactive microspheres was received sandwiched between two layers of clear tape. The method used to open the tape was to stick one side of the clear tape to a piece of masking tape and then separate with tweezers the clear tape sections. The masking tape (with microspheres adhering) was sputter coated prior to SEM evaluation.

The conditions of the microspheres ranged from good through cracked and broken, and included some hollow-appearing microspheres. A "drumstick"-shaped microsphere was also seen during the examination.

\subsubsection{Discussion/Conclusions}

Observations in the present investigation revealed a significant amount of cracking in the original amber epoxy binder material, indicating that the addition of lamp black to the epoxy neither enhanced nor mitigated its proclivity to environmental degradation.

In addition, the appearance of cracked, broken, and odd-shaped radioactive microspheres in the two older devices was consistent with observations reported earlier on more recently made devices. Thus the conclusion reached in the earlier report, that the manufacturing process was producing imperfect microspheres, remained valid. 


\title{
8 STRESS CORROSION CRACKING
}

\subsection{Intergranular Stress Corrosion Cracking of Type 304 Stainless Steel in the Spent Fuel Pool Piping of Three Mile Island Unit 1}

\author{
Reference: Report BNL-NUREG-28879 \\ Author(s): $\quad$ C. J. Czajkowski \\ Date: $\quad$ October 1980 \\ Task: $\quad$ FIN A-3011
}

Key words: $\quad$ intergranular stress corrosion cracking; sensitization; Three Mile Island Unit 1; Type 304 stainless steel

\subsubsection{Background}

Inspection of the piping in the Three Mile Island Unit \#1 spent fuel system in April, 1979 revealed five through-wall cracks near welded joints. Reports indicated that the cracks were circumferential in nature and located in the weld HAZ adjacent to girth welds. Several months later, two more through-wall cracks were detected in the system and were reported as having the same cracking characteristics as the first five. Subsequently, a section of radioactively-contaminated 8 " diameter pipe was sent to BNL for analysis in more detail. The section measured approximately 30 " in length and contained two circumferential welds, one a through-wall cracked field weld and the other an uncracked shop weld, and three uncracked longitudinal seam shop welds.

The program to examine the pipe included:

* visual inspection/photography

* optical microscopy

* scanning electron microscopy/energy dispersive spectroscopy

* chemical analysis

* constant extension rate testing (CERT)

* electrochemical potentiokinetic reactivation analyses.

\subsubsection{Visual Inspection/Photography}

Preliminary visual examination of the pipe disclosed that the crack was adjacent to what appeared (later confirmed) to be a weld repair area. The weld was a single "V" type with a shallow edge preparation, the process GTAW with an ER308 electrode and an E308 consumable insert filler metal. The repair area was in the R-2 stage (two repairs completed). The pipe had also been counterbored prior to installation for ease in pipe fit up prior to welding. The crack on the outside surface of the pipe was approx. 5 inches long, parallel to the girth weld and was thought to be in the HAZ. The pipe was subsequently sectioned longitudinally and the inside surface visually inspected. This revealed a crack approx. 5.5" long, parallel to the girth weld for half its length with its direction varying into the counterbore at its terminals. The inside surface was covered with an oxide film and showed evidence of significant heat during welding. Eight sections were then cut bracketing the crack to facilitate further examinations. 


\subsubsection{Optical Microscopy}

Metallographic examination on a cross-section of the pipe's circumference, using electrolytic etching with a 10\% oxalic acid etch, revealed the macrostructure of the pipe, the crack, the counterbore area, and a smaller nonthrough-wall crack on the weld side of the main crack. After repolishing and re-etching, it was established that the cracking was intergranular in nature with secondary cracks branching out from the body of the main crack. A grain size variance outside the weld HAZ was noted (finer in the center than at the pipe surfaces), possibly the result of cold working operations prior to the solution annealing heat treatment in the pipe's manufacture. Considerable sensitization was in evidence in the area surrounding the crack and in the $\mathrm{HAZ}$, indicating that the failure was due to IGSCC in the sensitized region of the weld repair HAZ. No evidence of sensitization was noted in the base material outside the HAZ.

There were also a few indications of incipient cracking on the inside surface of the weldment in the counterbore area and some stringer-like inclusions (MnS).

\subsubsection{Scanning Electron Microscopy/Energy Dispersive Spectroscopy}

Examination of the major fracture face by SEM confirmed the grain size variance noted during optical microscopy. The fracture face also had a typically IGSCC topography.

EDX scans across the fracture face indicated the presence of $\mathrm{Fe}, \mathrm{Cr}$ and $\mathrm{Ni}$ (the major elements in Type 304 stainless steel), together with trace amounts of $\mathrm{A}, \mathrm{Si}, \mathrm{S}$, and $\mathrm{Ca}$ in many cases. In addition, $\mathrm{Cl}$ was detected in trace amounts on the fracture surface near the inner surface of the piping. Various particulates in the fracture face were also examined by EDS and determined to contain, in addition to $\mathrm{Fe}, \mathrm{Cr}$ and $\mathrm{Ni}$, traces of $\mathrm{Si}$ and $\mathrm{S}$, and, occasionally, traces of $\mathrm{Cl}, \mathrm{Ca}$ and $\mathrm{K}$.

The non-through wall crack was also examined. Initial EDS scans, done prior to opening up the crack, revealed traces of both $\mathrm{Si}$ and $\mathrm{Cl}$ in addition to the normal Type 304 stainless steel constituents. Examination of the fracture face after opening up the crack indicated that it was composed of a partially ductile fracture (consistent with a non-through wall crack) and an IGSCC topography. Again, the grain size variance was noted. EDS scans of both the ductile and intergranular fracture areas showed traces of $\mathrm{Si}, \mathrm{Al}$ (stress corrosion cracking (SCC) surface only), $\mathrm{S}$ and $\mathrm{Ca}$ (ductile surface only) in addition to $\mathrm{Cr}, \mathrm{Fe}$, and $\mathrm{Ni}$. Various particles found on the fracture face were examined and found to contain $\mathrm{Si}$ and $\mathrm{Cl}$, and occasionally traces of $\mathrm{S}, \mathrm{P}, \mathrm{K}, \mathrm{Ca}$, and $\mathrm{Al}$.

An examination was also made of the inner surface of the pipe where there appeared to be etched grain boundaries. The base metal adjacent to the grain boundary etching showed $\mathrm{Al}, \mathrm{Si}, \mathrm{S}, \mathrm{Ca}$ and a trace of $\mathrm{Cl}$. Further examination into an etched boundary disclosed what appeared to be initiation sites for grain boundary cracking. EDS scans of these areas also showed $\mathrm{Cl}$ and $\mathrm{S}$ peaks, together with $\mathrm{Al}, \mathrm{Si}$ and $\mathrm{Ca}$. Machining marks were apparent on the pipe inner surface.

EDS scans of the stringer-like inclusions observed by optical microscopy showed high $\mathrm{S}$ and $\mathrm{Mn}$ peaks (probably MnS) and at least one scan exhibited a Ti peak.

\subsubsection{Chemical Analysis}

The chemical analysis on the base material and weld metal generally confirmed that the materials met the specification for Type 304 stainless steel and corresponding weld metal. 


\subsubsection{Constant Extension Rate Testing}

The CERT method is basically the application of slow dynamic straining to a stress corrosion (tensile type) specimen while it is exposed to the environment. This particular mode of testing has the advantage of always resulting in a fracture at its completion and normally does so in a relatively short time (a few days).

Twelve CERT tests were performed, three in air and nine in a solution containing $2000 \mathrm{ppm} \mathrm{B}\left(\right.$ as $\left.\mathrm{H}_{2} \mathrm{BO}_{3}\right)$ and with additions of $\mathrm{Cl}^{-}(1-15 \mathrm{ppm})$ and $\mathrm{MnS}$. The solution was maintained at $86^{\circ} \mathrm{F}$; strain rates were in the range 1.3 to $1.7 \times 10^{-6} \mathrm{in} . / \mathrm{s}$. After the completion of the CERT tests all specimens were sectioned in order to look at the fracture face by SEM and for viewing by optical microscopy (after oxalic acid etching).

Six of the twelve failures were identified as either fully or partially intergranular in nature. Five of these occurred in the field weld, while only one partially intergranular-type failure occurred in the shop weld. All others, including the CERT test with the MnS addition, resulted in a ductile-type failure, typified by a dimpled rupture appearance and with no areas of intergranular fracture.

The microstructures exhibited in the field weld were primarily of the ditched type, indicative of a highly sensitized material according to ASTM A-262. The shop weld displayed a predominantly dual type structure, signifying a lesser degree of sensitization. These observations correlated reasonably well with the results of the CERT testing.

Overall, the most significant observation made was the partially intergranular-type fractures of two air-tested field weld specimens. This failure occurred with no corrodent species present and is indicative of the importance of the presence of a highly sensitized structure (confirmed by optical microscopy).

\subsubsection{Electrochemical Potentiokinetic Reactivation Analysis}

This is a nondestructive test developed for determining the degree of sensitization of a stainless steel. In it, the susceptibility to IGSCC is evaluated electrochemically by performing a controlled potential sweep from the passive to the active region in a $0.5 \mathrm{M} \mathrm{H}_{2} \mathrm{SO}_{4}+0.01 \mathrm{M} \mathrm{KSCN}$ solution at $86^{\circ} \mathrm{F}$ and recording the resultant potentiokinetic curves. In this instance, it was applied to the area surrounding the repaired portion of the field weld. The results indicated that a significant degree of sensitization approximately $8 \mathrm{~mm}$ away from the weld centerline, the smallest distance from the weld tested. At larger distances from the weld, less sensitization was indicated, until, at the largest distances examined $(62 \mathrm{~mm})$ the material was virtually free from sensitization. These observations were consistent with the microstructural observations made on samples etched with oxalic acid, and confirm this particular heat of material is susceptible to sensitization on welding.

\subsubsection{Discussion/Conclusions}

Intergranular corrosion is defined as local attack on the grain boundaries of a metal by a corrosive media. In stainless steels, susceptibility to intergranular corrosion is greatly enhanced by sensitization, a process in which chromium carbide precipitates at the grain boundaries, resulting in depletion of chromium in the material immediately adjacent to the boundaries. The degree of material sensitization is a cumulation of the material's prior thermal and mechanical treatments, weld cycle history, (\# passes, heat input, etc.) material chemistry, thickness and thermal conductivity, and time at temperatures in the sensitization range. If, in addition to the material being sensitized, it is in a state of stress (either externally imposed or residual from previous fabrication processing), then stress corrosion cracking may occur and the phenomenon is known as IGSCC.

In the case of the failed spent fuel pool piping, observations and analyses indicated that many of the factors described above were present. The primary cause of the cracking appears to be intergranular stress corrosion cracking in the weld sensitized heat affected zone of a weld repair. Although no definite corrosive species were identified as 
the cause of the cracking, the detection by EDX scans of traces of $\mathrm{Cl}^{-}$on both the pipe inside surface and in the areas of the crack fracture faces and the inside surface etched grain boundaries is evidence of etching and possible contamination of the system by chloride ions perhaps during a cleaning or pickling operation. The significance of the MnS stringer-like inclusions as pit nucleation sites is indeterminate, as also is the importance of the widely dispersed sulfur traces throughout the fracture face. The results of the analysis demonstrated that at least one area of the pipe's cross-section had been sensitized significantly by the welding process which is a reasonable indication of the pipe's condition after installation. The results from the CERT, corroborated by the oxalic acid etched microstructures, showed that this particular heat of Type 304 stainless steel, with its high carbon content and complex thermal history ( 2 repairs), was severely sensitized at various locations about its girth. The degree of sensitization was sufficient to cause intergranular-type fractures during CERT testing in air and, coupled with the residual stresses from welding and the possible contamination by $\mathrm{Cl}^{-}$ions, was apparently sufficient to induce IGSCC in the piping.

\subsection{Examination of Failed Turbine Discs from Yankee-Rowe Nuclear Power Station}

Reference: Report BNL-NUREG-29964

Author(s): C. Czajkowski

Date: $\quad$ March 1981

Task: $\quad$ FIN A-3363

Key words: $\quad$ fast fracture; intergranular attack; low-alloy steels; molybdenum disulfide; notched tensile strength; Yankee-Rowe

\subsubsection{Background}

The low pressure turbine at the Yankee-Rowe Nuclear Power Station failed catastrophically in 1980 . The failure occurred during start up, after the turbine had reached operating speed but before the generator was placed on line. Conditions at the time were $1800 \mathrm{rpm}$ and $2 \%$ steam. The inlet steam temperature to the LP turbine was approximately $300^{\circ} \mathrm{F}$ and the turbine had operated more than 100,000 hours on line. Subsequently BNL was requested to examine the failed fragments (from the governor and generator end discs) and to perform a failure analysis. The investigation was to determine the cause of the intergranular attack noted on the bore surface of the generator end disc, and also if the generator end disc differed in any way from its uncracked (no intergranular attack) sister disc on the governor end. The associated examinations included:

* visual inspection/optical metallography/photography

* $\quad$ scanning electron microscopy/energy dispersive spectroscopy

* chemical analysis

* uniaxial tension tests

* ' hardness measurements

* Charpy "V" notch impact tests

* notched tensile tests.

\subsubsection{Visual Inspection/Optical Metallography/Photography}

The fracture faces of the generator end disc appeared to be mostly intergranular and had a tightly adherent black oxide on them. There was also evidence of secondary cracking not associated with the intergranular cracks. 
Two cracks from the disc were examined in cross-section and determined to be generally intergranular with very little branching. the failure.

The governor end disc had a large rubbed area, probably the result of its location during the rundown after

Both discs had microstructures of tempered martensite with areas of proeutectoid ferrite, consistent with that expected in a quenched and tempered high strength low alloy steel.

\subsubsection{Scanning Electron Microscopy/Energy Dispersive Spectroscopy}

Various fracture faces were examined and found to be intergranular in nature. EDS scans of the faces detected, in addition to the expected $\mathrm{Fe}, \mathrm{Ni}, \mathrm{Cr}, \mathrm{Mn}$ and $\mathrm{Si}$ from the steel, traces of $\mathrm{Cl}$ and $\mathrm{S}$. A grayish substance found on the bore of both discs was found to be $\mathrm{MoS}_{2}$, a normal bore lubricant.

\subsubsection{Chemical Analysis}

The chemical analyses confirmed that the end discs were low alloy steels containing approximately $2.1 \%$ $\mathrm{Ni}, 0.6 \% \mathrm{Cr}, 0.4-0.5 \% \mathrm{Mo}$, and $0.07 \% \mathrm{~V}$, values similar to those found for ASTM A-294 Class C and ASTM A-471 Class 5 material. However, the carbon content of approximately $0.53 \%$ was significantly higher then the $0.35 \%$ maximum contained in those specification. Variations in measured values for $\mathrm{Mo}, \mathrm{V}$ and $\mathrm{Cr}$ indicated that there was some segregation of these elements.

\subsubsection{Uniaxial Tension Tests}

The tension tests revealed that the governor end disc material had slightly higher yield and ultimate tensile strength than had the material from the generator end disc.

\subsubsection{Hardness Measurements}

The governor end disc material was found to have slightly higher hardness than that of the generator end disc, consistent with the strength measurements from the tension tests.

\subsubsection{Charpy Impact Testing}

The generator end disc material was found to be slightly more resistant to brittle fracture than that of the governor end disc.

\subsubsection{Notched Tensile Tests}

The governor end disc material was found to have a significantly lower notch tensile strength in air than that of the generator end disc. However, it was also determined to be significantly less sensitive to sulfide attack.

\subsubsection{Discussion/Conclusions}

Examination of the fracture surfaces indicated that the turbine generator end disc failed as the result of a fast fracture, probably from the growth of an intergranular crack to a critical size. These intergranular cracks were found on the bore surface of the generator disc and had a thumbnail-like shape. No corrodent species were found to be present in the usual sense but the results of the notch tensile specimen testing combined with a review of the relevant literature indicated that failure of the generator discs could be related to the presence of $\mathrm{MoS}_{2}$ (detected on the bore 
surface). Acting either alone or as part of a hydrolysis reaction forming $\mathrm{H}_{2} \mathrm{~S}$, the bore lubricant caused the cracking of the turbine disc to initiate by a hydrogen assisted cracking mechanism. Subsequent propagation occurred in a clean steam environment.

On the other hand, the governor end disc, the fracture faces of which showed no indication of intergranular attack, failed as a result of fast fracture, probably following impact by one or more of the fragments produced by failure of the generator disc. The reason for the generator end disc to crack while the governor end disc remained unaffected by the same environment could be related to the fact that the governor end disc was more resistant than the generator end disc to crack initiation in the $\mathrm{MoS}_{2} / \mathrm{H}_{2} \mathrm{O}$ environment. This was demonstrated by the higher resistance of the governor end disc material to sulfide attack in notch tensile tests. Although the two discs were nominally made of the same material, the greater resistance could have resulted from a slight difference in heat treatments arising from the relative position of the original ingot in the heat treating furnace or possibly from microsegregation of alloy constituents in that ingot. Another contributory factor could have been that the amount of $\mathrm{MoS}_{2}$ applied to the generator end disc was greater than that applied on the governor end disc.

\subsection{Failure Analysis of a Bolt from "B" Reactor Coolant Pump at the H.B. Robinson Unit 2 Nuclear Power Station}

$\begin{array}{ll}\text { Reference: } & \text { Report BNL-NUREG-31530 } \\ \text { Author(s): } & \text { C. Czajkowski } \\ \text { Date: } & \text { July } 1982 \\ \text { Task: } & \text { NA }\end{array}$

Key words: $\quad$ austenitic stainless steel; bolting; cold-work; H.B. Robinson Unit 2; pitting; transgranular cracking; stress corrosion cracking

\subsubsection{Background}

In 1982 Carolina Power and Light informed the NRC that four of the sixteen RCP diffuser adapter-to-casing adapter bolts had failed at the H.B. Robinson Unit 2 plant. The failures, discovered during disassembly of the RCP during a scheduled ten-year inservice inspection, were initially thought to be due to a stress corrosion mechanism. Subsequent disassembly of a second RCP by the utility disclosed that five of the sixteen bolts had missing hex heads and that eight other bolts broke during removal.

The original notification prompted the NRC to initiate an independent failure analysis, performed by BNL, of one of the cracked bolts from the H.B. Robinson Unit 2. This analysis, intended to evaluate the failure mechanism and confirm the chemistry of the bolting materials (300 series austenitic stainless steel), comprised:

* $\quad$ visual/photography/dye penetrant examination

* $\quad$ scanning electron microscopy/energy dispersive spectroscopy

* optical microscopy/metallography.

\subsubsection{Visual/Photography/Dye Penetrant Examination}

The bolt received at BNL was $5 / 8$ inch in diameter and 4 inches long, and was determined to be nonmagnetic, indicating it to be an austenitic material. No cracks were apparent during the visual examination. However, dye penetrant testing revealed indications on three threads. 


\subsubsection{Scanning Electron Microscopy/Energy Dispersive Spectroscopy}

SEM of the fracture surface indicated a transgranular mode was in effect with no evidence of fatigue striations. Some pitting was noted on the machined portions of the threads.

EDS examination confirmed that the chemical composition of the bolt was approximately that of Type 304 stainless steel. In addition, molybdenum was detected on the surface of the bolt, near the tip, and was thought to be related to the use of a molybdenum-containing lubricant on the bolt threads. Studies of the Cr:Fe ratio produced values in the range 0.63 to 0.78 , a possible indicator of the existence of a chloride stress corrosion cracking phenomenon.

\subsubsection{Optical Microscopy/Metallography}

Cross-sectional metallography revealed that the cracking was predominantly transgranular. There was no evidence of sensitization but the structure in the area of the threads was seen to be heavily cold worked. In addition, a small transgranular crack appeared to have initiated at a thread root.

\subsubsection{Discussion/Conclusions}

The failure analysis revealed that the bolt material was an austenitic type stainless steel, probably Type 304, was not sensitized and had been subjected to considerable cold working. The crack observed was transgranular and with no definitive evidence of fatigue failure on the fracture face of the bolt. Pitting was noted in the thread area of the bolt and the results of the EDS analyses indicated the possibility of chloride-assisted stress corrosion cracking. Both chlorides and hydroxides will cause transgranular cracking in austenitic stainless steels. However, only chlorides will cause pitting as well as transgranular cracking in an austenitic stainless. The presence of a molybdenum-based lubricant might also have been a contributory factor.

\subsection{Evaluation of Failed Reactor Coolant Pumps Internal Bolts from the H.B. Robinson Nuclear Power Station}

Reference: Report BNL-NUREG-31743

Author(s): $\quad$ Carl J. Czajkowski

Date: $\quad$ October 1982

Task: $\quad$ NA

Key words: $\quad$ austenitic stainless steel; H.B. Robinson; fatigue-assisted stress corrosion cracking; transgranular cracking

\subsubsection{Background}

In April 1982, during the 10 year inservice inspection of reactor coolant pumps at the H.B. Robinson plant, various adaptor bolts were found to have failed in service. One of the failed bolts, which had cracked in the thread area, was examined at BNL and it was concluded that the bolt probably failed by a stress corrosion cracking mechanism arising from high tensile stresses in the bolt and probable chloride contamination. Three additional specimens were subsequently sent to BNL and subjected to the following methods of examination: 
* visual/photography

* scanning electron microscopy/energy dispersive spectroscopy

* optical microscopy/metallography.

\subsubsection{Visual/Photography}

One of the specimens received, an archive specimen, had no visual cracks. The second specimen ("B") was the shank portion of a bolt with a fracture on one end and the appearance of mechanical severing on the opposite end. The third ("13/14") consisted of two parts, a portion of the threaded area of a bolt with the same appearance of mechanical severing on one end, and a bolt head with a thin metallic sheath surrounding it. This bolt head had fractured at the bolt head/shank juncture.

\subsubsection{Scanning Electron Microscopy/Energy Dispersive Spectroscopy}

The fracture face of "B" was essentially transgranular in appearance but contained an area of pitting and a ridge with some intergranularity present. There was also an indication of a fatigue contribution. The fracture face of the bolt head of "13/14" was similarly generally transgranular in appearance with indications of a fatigue wavefront but with no signs of pitting.

An EDS scan of the archive material provided Cr:Ni:Fe ratios generally consistent with those expected for Type 304 stainless steel. EDS scans of the fracture faces of the other two bolts generated $\mathrm{Cr}: \mathrm{Fe}$ ratios in the range 0.8 to 2.1 , thought to be reflective of prolonged contact with corrodent and also indicative of the possibility of chloride-induced stress corrosion cracking.

\subsubsection{Optical Microscopy/Metallography}

The microstructures observed in the cross-sections of the fractured bolts were typical of those expected in an austenitic stainless steel and had virtually no evidence of sensitization. The cross-section of specimen "13/14" also contained evidence of cold work and pitting.

\subsubsection{Discussions/Conclusions}

The results from the failure analysis confirmed that the bolting material was austenitic stainless steel, probably Type 304, and that it was in the non-sensitized condition. The transgranular characteristics of the cracking, together with the observations of pitting, indicated chloride contamination, an observation substantiated by the very high $\mathrm{Cr}$ :Fe ratios encountered on the fracture surface.

The fracture surfaces contained, in addition to the generally transgranular characteristics, some evidence of fatigue interactions. Thus it was concluded that the overall failure was attributable to a fatigue-assisted stress corrosion cracking mechanism caused by probable chloride contamination.

\subsection{Constant Extension Rate Testing of SA 302 Grade B Material in Neutral and Chloride Solutions}

$\begin{array}{ll}\text { Reference: } & \text { Report NUREG/CR-3614 } \\ \text { Author(s): } & \text { C. J. Czajkowski } \\ \text { Date: } & \text { February } 1984\end{array}$

NUREG/CR-6489 
Task:

FIN A3716

Key words: chlorides; constant extension rate testing; low alloy steel; transgranular stress corrosion cracking; weldment

\subsubsection{Background}

On March 27, 1982, during a refueling outage (with the reactor in a cold shutdown condition), a small leak was detected on the shell side of a steam generator at the Indian Point Unit 3 nuclear power plant. Further examination of the steam generator disclosed that the detected leak originated in the circumferential weld joining the transition cone to the upper shell (closure weld) of the steam generator. Additional details concerning the incident and the subsequent failure evaluation have been described in a previous item (see item 4.3). Among the findings from that investigation was that, although corrosion fatigue was considered the primary cause of degradation, the relative importance of corrosion in the crack propagation rate could not be determined at that time. The possibility of SCC being a contributing cause of the failure could not be entirely discounted due to the lack of literature concerning the response of the alloy concerned (ASME SA-302 Grade B) in copper-containing oxygenated water. Consequently a test program was devised in order to simulate the cracking phenomenon of the steam generator vessels in the laboratory. This program was primarily aimed at determining if SCC could be a contributing cause in the failure of the steam generator vessel.

The program was conducted on both base metal and welded specimens of ASME SA-302 Grade B material, , with the welds being in both the stress relieved $\left(1000^{\circ} \mathrm{F}\right)$ and non-stress relieved conditions. A total of 20 acceptable tests were run with the specimens subject to $\mathrm{CERT}$ in various environments (air, water, $\mathrm{NaCl}$ solution, $\mathrm{CuCl}_{2}$ solution) at room temperature and at $515^{\circ} \mathrm{F}$. All tests were performed in a static system with no attempt made to control the oxygen content. Following the tests the specimens were examined by optical microscopy and SEM.

\subsubsection{CERT Results/Optical Microscopy/Scanning Electron Microscopy}

The data (time to failure, total extension, tensile strength) obtained from the base metal specimens were reasonably consistent and independent of environment and temperature. In all except one case, typically ductile failure and necking was apparent by SEM and optical microscopy. The one exception, from the test in $\mathrm{CuCl}_{2}$ solution, showed a transgranular failure mode and an absence of necking.

The data obtained from the welded specimens showed some dependence on test temperature and environment. There was little significant difference between the stress-relieved and non-stress-relieved specimens when tested either in water at $515^{\circ} \mathrm{F}$ or in air at room temperature. All fractures were ductile in appearance and necking was observed in the specimens. The stress-relieved specimen tested in $515^{\circ} \mathrm{F}$ water containing $25 \mathrm{ppm} \mathrm{NaCl}$ provided data similar to the pure water-tested specimen but a non-stress-relieved specimen tested in $515^{\circ} \mathrm{F}$ water with $325 \mathrm{ppm} \mathrm{NaCl}$ showed a noticeable reduction in ductility. This latter specimen experienced virtually no necking, had a more brittle fracture appearance and displayed some secondary cracking, evidence of environmental interaction. The specimen also fractured in the base metal, not the weld metal.

The remaining ten tests on welded specimens were conducted at $515^{\circ} \mathrm{F}$ in solutions of varying chloride (as $\mathrm{CuCl}_{2}$ ) levels (from $325 \mathrm{ppm}$ down to $1 \mathrm{ppm}$ ). At all but the lowest chloride levels, reduced ductility (as measured by the failure extension and time) was observed compared with the pure water tests and the fractures appeared generally transgranular in nature. Most of the fractures took place in the weld metal but two occurred in the base metal. Secondary cracking was observed in all specimens and often initiated at corrosion pits. At the low chloride contents (5 ppm and $1 \mathrm{ppm})$, differences were increasingly noticed between the stress-relieved and non-stress-relieved specimens. The latter continued to exhibit predominantly brittle fracture modes but this became less apparent in the former which also had fewer secondary cracks. 


\subsubsection{Discussion/Conclusions}

Although the test results were not totally conclusive, it was concluded that this particular alloys (ASME SA302 Grade B) is susceptible to a transgranular SCC attack in CERT with as low as 1 ppm chloride at $515^{\circ} \mathrm{F}$. However, it was pointed out that no attempt had been made to either measure or control the oxygen levels during the testing.

It was further observed that welded SA-302 Grade B, even in the stress-relieved condition, continued to susceptible to a SCC failure at a level below yield (approximately $70 \%$ ) when tested in $515^{\circ} \mathrm{F}$ water with $325 \mathrm{ppm}$ chloride. At lower chloride concentrations (5 ppm and $1 \mathrm{ppm}$ ) there was a beneficial effect of stress relief on weldments in that this kind of attack was minimized. Although stress relief could be of some benefit, the cracking of even the base metal specimen in $\mathrm{CuCl}_{2}$ solutions indicated that the material itself was susceptible to SCC in this environment.

In order to mitigate the possibility of additional cracking occurring in the field, the environment should be maintained low in oxygen and chloride, and copper ions in solution should be minimized or eliminated. Implementation of these precautions, coupled with a thorough stress relief of the pressure vessel, should dramatically reduce the propensity for cracking.

\subsection{Testing of Nuclear Grade Lubricants and Their Effect on A540 B24 and A193 B7 Bolting Materials}

Reference: Report NUREG/CR-3766 (BNL-NUREG-51767) (also Paper 112 at Corrosion/85, Boston, MA, March 1985)

Author(s): $\quad$ Carl J. Czajkowski

Date: $\quad$ March 1984

Task: $\quad$ FN A-3011

Key words: bolting materials; friction coefficients; graphite; lubricants; molybdenum disulfide; steaming tests; transgranular stress corrosion cracking; weight loss

\subsubsection{Background}

In 1983 the NRC reported that, over a period of 18 years, 44 distinct instances of bolting degradation had been recorded at nuclear power plants. The largest single cause (19 of the 44 incidents) was SCC and at least two analyses had linked the failures to a lubricant/moisture interaction that had resulted in a corrosive environment. BNL was requested to conduct a test program designed to determine the effects of lubricants on fastener degradation and which consisted of:

$\begin{array}{ll}* & \text { chemical analysis of the lubricants } \\ * & \text { steaming teșts } \\ * & \text { friction tests } \\ * & \text { notched tensile CERT } \\ * & \text { weight loss tests. }\end{array}$

The test program looked at 11 different lubricants, including some based on $\mathrm{MoS}_{2}$ and others containing graphite. In addition to determining basic chemical and physical properties of the lubricants, the program investigated 
interactions with bolting materials using bolts made from ASTM A-193 Grade B7 and ASTM A-540 Grade B24 Class 2 materials.

\subsubsection{Chemical Analysis}

EDS scans of carbon blocks covered in lubricant indicated that there were significant variations in the chemical constituents of even nominally similar lubricants. In one instance a supposedly molybdenum-containing lubricant was found to contain no molybdenum. In other cases, possibly detrimental elements such as antimony and free sulfur were detected.

\subsubsection{Steaming Tests}

These tests were designed to determine if a gaseous sulfide could be produced by steaming $\mathrm{MoS}_{2}$. The results of the tests verified that this happens and that the amount of gas produced increases with increased exposure times.

\subsubsection{Friction Tests}

Friction tests were conducted on the lubricants using a "sled-and-bed" technique and with the lubricants being tested both wet and dry when possible. The results showed wide variability in the coefficients of friction, even for similar types of lubricants.

\subsubsection{Notched Tensile CERT Tests}

CERT tests were performed using a total of 62 specimens from both types of bolting materials. The results of the tests indicated that both materials were susceptible to SCC in steam at $536^{\circ} \mathrm{F}$ and that the use of a $\mathrm{MoS}_{2}$-based lubricant or a copper/graphite lubricant appeared to enhance this susceptibility.

\subsubsection{Weight Loss Testing}

The weight loss tests were designed to determine if specimens coated with bonded solid film lubricant corroded a similar rate to that of bare steel. Exposures were conducted at $212^{\circ} \mathrm{F}, 352^{\circ} \mathrm{F}$ and $600^{\circ} \mathrm{F}$. At the two lower temperatures the corrosion rates noted for the solid bonded film lubricant were almost an order of magnitude less than those measured for bare metal. However, at the highest temperature, there was no significant difference in corrosion rates for all materials.

\subsubsection{Discussion/Conclusions}

The EDS scans of the various lubricants clearly showed a marked difference in composition between supposedly similar lubricants. In line with this a wide variation was noted in the measured coefficients of friction for similar lubricants, demonstrating that generalization of this value for sample type should not be made. The EDS scans also detected the presence in the lubricants of potentially detrimental elements.

The series of notched tensile tests showed that both bolting materials were susceptible to SCC failure in steam at $536^{\circ} \mathrm{F}$ and that the use of $\mathrm{MoS}_{2}$ or a (copper+graphite) lubricant appeared to enhance this susceptibility. Additionally, the steaming tests of the chemically pure $\mathrm{MoS}_{2}$ showed that, in the presence of $212^{\circ} \mathrm{F}$ steam $\mathrm{MoS}_{2}$ will hydrolyze to form detrimental gaseous sulfides $\left(\mathrm{H}_{2} \mathrm{~S}\right)$. These observations combined to verify the observation made in previous studies that $\mathrm{MoS}_{2}$ can have a significant material effect on low alloy steels in the presence of moisture. 
The solid bonded film lubricant weight loss specimens show a marked decrease in metal loss at $212^{\circ} \mathrm{F}$ and $352^{\circ} \mathrm{F}$ when compared to previously reported bare metal data. This lubricant protection disappears at $600^{\circ} \mathrm{F}$, where the results on previously coated specimens differed little from results on bare metal specimens.

\subsection{Investigation of Corrosion and Stress Corrosion Cracking in Bolting Materials on Light Water Reactors}

Reference: $\quad$ Intl. Journal of Pressure Vessels \& Piping, Vol. 26, pp. 87-96

Author(s): $\quad$ C.J. Czajkowski

Date: $\quad 1986$

Task: $\quad$ FIN A-3011

Key words: bolting materials; boric acid attack; friction coefficients; stress corrosion cracking; lubricants; molybdenum disulfide

\subsubsection{Background}

In a number of PWR gaskets around pumps have leaked small amounts of primary coolant. As the water flashed to steam, it left behind a sludge consisting of dissolved boric acid and lithium hydroxide. Subsequent inspection of the pumps revealed corrosion damage on some of the studs. The most notable incident of this type of degradation occurred at Fort Calhoun plant in 1980.

Related to this, when steam leaks through a gasket in a PWR, it can also react with any lubricants used to assemble the bolted joint. An occurrence of this type occurred in March 1982 at maintenance outage of the Maine Yankee Power Plant, where five of 20 primary manway studs failed during removal of the (cold leg) primary manway cover from steam generator No. 2.

These two different instances of bolting degradation at nuclear power plants were evaluated at BNL in conjunction with a laboratory test program that studied the effects of various lubricants on common bolting materials. The latter comprised several methods of examination:

* scanning electron microscopy/energy dispersive spectroscopy

* $\quad$ steaming tests

* friction testing

* notched-tensile CERT

* weight loss testing of a bonded solid film lubricant.

\subsubsection{Evaluation}

Fort Calhoun Incident

Inspection of two reactor coolant pumps revealed that six of the sixteen studs on one pump and three on the second pump had sustained significant corrosion damage. The subsequent investigation concluded that ferritic material was susceptible to boric acid attack and that corrosion rates determined from laboratory experiments were consistent with field experience. 
Examination of one of the five cracked studs revealed that the cracking was generally transgranular in nature and that the microstructure of the stud was typical of that of ASTM A-540 Class B24 steel. Molybdenum and sulfur were detected in the threaded area, indicating that a molybdenum disulfide type lubricant probably had been used. The analysis concluded that the cracking was environmentally assisted and typical of a SCC phenomenon induced by lubricant-coolant interaction.

\subsubsection{Laboratory Test Program}

The laboratory test program involved testing the effects of eleven lubricants on ASTM A-540 Class B24 and ASTM A-193 Class B7 bolting materials. A summary of the results obtained in this program are given in a previous item in this report ("Testing of Nuclear Grade Lubricants and Their Effect on A540 B24 and A183 B7 Bolting Materials").

\subsubsection{Discussion/Conclusions}

Observations of bolting degradation at nuclear power plants were determined to be due to corrosion and SCC phenomena, and there were indications that the presence of lubricant might be a contributory factor. Subsequently a laboratory test program was conducted to study the effects of various lubricants on two common bolting materials, ASTM A-540 Grade B24 Class 2 and ASTM A-193 Grade B7.

\subsection{Evaluation of the Pilgrim Inconel 182 Cracking}

$\begin{array}{ll}\text { Reference: } & \text { Report A-3763 5-8-85 } \\ \text { Author(s): } & \text { C. J. Czajkowski } \\ \text { Date: } & \text { May } 1985 \\ \text { Task: } & \text { FIN A-3763 }\end{array}$

Key words: Alloy 182 welding electrode; Alloy 82 filler metal; interdendritic cracking; intergranular stress corrosion cracking; low-alloy steel nozzle; Pilgrim; transition joint; Type 304 stainless steel safe-end

\subsubsection{Background}

In May 1984, a dye penetrant examination of a 12-inch diameter recirculation system inlet nozzle in Unit \#1 at the Pilgrim Nuclear Power Station revealed multiple crack indications on the pipe's inside surface. Subsequent dye penetrant examination of the inside surfaces of the other inlet nozzles disclosed that two of them had multiple cracks in the weld build-up area. Additional examinations (dye penetrant) were performed on the inside surfaces of the two 28-inch diameter recirculation outlet nozzles and revealed multiple cracks in the weld build-up area on one of them. The observed cracks were primarily in the axial direction and were located in the Alloy 182 weld "butter" on both the nozzle side and the safe-end side of the weld. There were some instances of crack propagation into the stainless steel (safe-end side) base material but no propagation was observed into the low alloy steel base material or into the Alloy 82 root pass material.

Safe-ends are used primarily in construction as a method of avoiding local post-weld heat treatment during field fabrication of dissimilar materials. The affected safe ends at Pilgrim provided a material and geometric transition 
from the reactor pressure vessel (low alloy steel) to the recirculation system piping (austenitic stainless steel). The Pilgrim safe-end welds had experienced a very complex thermal and fabrication history.

Characterization of the cracking phenomenon was obtained by cutting four boat samples from the 28-inch recirculation outlet nozzle N1-B. One of the samples was sent to BNL for evaluation under a NRC contract. This evaluation of the boat sample included:

* metallography

* scanning electron microscopy/energy dispersive spectroscopy.

\subsubsection{Materials}

The Pilgrim nozzles were fabricated from low alloy steel with the safe-end constructed of austenitic Type 304 stainless steel. Both the nozzle and the safe end had their weld preparation "buttered" (weld build-up) with Alloy 182 weld metal. The initial root pass and subsequent two passes of the connecting weld were accomplished using the GTAW process and Alloy 82 filler metal. The inside surface of the low alloy steel nozzle had been previously clad with Type 308 stainless steel weld metal. Dye penetrant examination had been performed after the third pass and on the inside and outside surfaces of the weld after completion. Additionally, radiography was performed on the completed weld.

The major differences between the Alloy 82 filler metal and the Alloy 182 welding electrode lie in the relative amounts of some of the alloying additions. Alloy 82 is richer in $\mathrm{Cr}$ than 182 (18-22\% vs. $13-17 \%)$ but lower in both $\mathrm{Mn}(2.5-3.5 \%$ vs. $5.0-9.5 \%)$ and $\mathrm{Fe}$ (3.0\% max. vs. $6.0-10 \%)$. Aside from these compositional differences, the two alloys are very similar and their mechanical properties comparable.

The boat sample sent to BNL appeared to be cut from only the Alloy 182 "butter" and was approximately 1.25 inches long by .250 inches wide. Visual examination disclosed two cracks running approximately perpendicular to the boat sample's long axis.

\subsubsection{Metallography}

Since the specimen received was so small, the cuts for the metallographic sections were made in order to optimize the data acquisition while not significantly reducing the sections needed for SEM. All cuts were made dry (no lubricant) using a jeweler's saw.

The first cut made was parallel to the long axis of the boat sample and appeared to cross only one of the visible cracks. A small section fell away from the larger section as the crack itself was cut. These two sections were subsequently mounted in bakelite, ground and polished. When examined at low magnification, a second crack was revealed running approximately parallel to the main fracture but 0.10 inches away from it. This section was then polished down to $0.25 \mu \mathrm{m}$ and lightly etched in a $5 \%$ bromine + methanol solution. Two more cracks were revealed. The specimen was then repolished back to $0.25 \mu \mathrm{m}$ and electrolytically etched in a $10 \%$ oxalic acid + demineralized water solution for 45 seconds. The resultant structure was that of deposited weld metal with distinct grain boundaries in evidence due to the recrystallization effect of subsequent weld passes on the original dendritic structure of the weld metal. The intercrystalline nature (intergranular/interdendritic) was evident at high magnification.

A second section, perpendicular to the long axis of the specimen, was then cut from the boat sample. This specimen was mounted and polished, then etched electrolytically in the oxalic acid solution. This section again showed the solidification structure of "as deposited" weld metal with recrystallization evident on the pipe's inside surface.

NUREG/CR-6489 


\subsubsection{Scanning Electron Microscopy/Energy Dispersive Spectroscopy}

Two fracture faces were examined by SEM and EDS.

The first one had a "wood-like" grained appearance. A total of four areas were scanned on this fracture face. The oxide film covering the face ranged from a light powdery type to a more granular type. The second fracture face examined had a similar appearance to the first although the oxide on the second face appeared less dense than on the first face examined. The elongated dendritic structure was also observed on this fracture.

The major alloying elements, $\mathrm{Ni}, \mathrm{Cr}, \mathrm{Mn}$ and $\mathrm{Fe}$, were present in all nine EDS scans from the two fracture faces but there was some variance in $\mathrm{Cr}: \mathrm{Ni}$ and $\mathrm{Mn}: \mathrm{Ni}$ ratios based on the EDS peak heights. These ranged from 0.24 to 1.15 for the Cr:Ni ratio and from 0.16 to 0.54 for the $\mathrm{Mn}$ :Ni ratio. Although not accurate, these variations may be indicative of segregation of these elements in the "as deposited" Alloy 182 weld metal.

Only two of the nine scans showed only the peaks from the four major elements; the other seven scans displayed additional element peaks in various combinations. Thus, of the six scans that displayed Si peaks, three also had $\mathrm{S}$ peaks. Of the two scans that included both $\mathrm{P}$ and $\mathrm{Cl}$ peaks, one also contained a $\mathrm{Mg}$ peak while the other had peaks attributable to $\mathrm{Ca}$ and $\mathrm{Ti}$.

Following the initial SEM/EDS examination, the two fracture surfaces were cleaned electrolytically.

SEM of the cleaned fracture surfaces confirmed their interdendritic (intercrystalline) nature. There was no evidence of fatigue interaction, (striations, beach marks., etc.) on either of the two fracture faces.

\subsubsection{Discussion/Conclusions}

The failure of nickel-based weld metal in transition welds is not a regular occurrence at fossil fueled plants but some instances have been recorded. A survey of utilities revealed that, of all those reporting boilers failures, $19 \%$ of the failures were in transition joints and, of this $19 \%$, only $12 \%$ had occurred in nickel-based weld metal.

Experience with Alloy 182 weld metal has been good with no boiler failures recorded to 1982 . However, metallographic examination of sectioned Alloy 182 welds had revealed a large incidence of welding defects, typically lack of fusion or root penetration. Such defects occur due to inherent problems in making dissimilar welds with this type of alloy. This type of defect is of concern since a crevice is formed at the weld root. Crevices can play a prime role in SCC of austenitic stainless steels and the nickel-based alloys, acting not only as stress intensifiers but also as local areas of potentially low $\mathrm{pH}$.

Several series of SCC experiments have been reported on both Alloys 82 and 182 in simulated reactor environments, and have demonstrated that, under specific conditions, one or both alloys are susceptible to this mode of failure. These specific conditions include:

* the presence of crevices when exposed to $550^{\circ} \mathrm{F}$ pure water containing 16 ppm oxygen (fractography of the specimens appeared quite similar in nature to the Pilgrim cracks);

* $600^{\circ} \mathrm{F}$ water at simulated resin bed intrusion conditions (in these tests, the $\mathrm{Cr}$ content of the filler metal and the welding process were both considered significant factors);

* $\quad 550^{\circ} \mathrm{F}$ high purity air saturated with water containing sulfuric acid (these tests indicated the strong influence of higher nickel-content on IGSCC susceptibility). 
conclusions:

Combining the above literature data with the observations from the present study led to the following

- The fractures observed on the boat sample from Pilgrim Unit \#1 were interdendritic (intercrystalline) in appearance.

- The optical microscopic cross section showed the weld metal to be typical of Alloy 182.

- $\quad$ EDS scans indicated that traces of potentially detrimental elements $(\mathrm{S}, \mathrm{P}, \mathrm{Cl})$ were present on the fracture faces but that these elements may have been deposited as a result of prior dye penetrant examinations.

- $\mathrm{Cr} / \mathrm{Ni}$ and $\mathrm{Mn} / \mathrm{Ni}$ ratios of the fracture faces indicated possible segregation of these elements.

- The cracking is considered to be intercrystalline SCC of susceptible Alloy 182 weld metal in a BWR environment.

\subsection{Evaluation of Core Spray Line Cracks from Nine Mile Point Unit No. 1 and Isolation Condenser Cracks at Oyster Creek Unit No. 1}

Reference: $\quad$ Intl. Journal of Pressure Vessels \& Piping, Vol. 27, pp. 1-15 (see also BNL report A-3763 1-11-85)

Author(s): $\quad$ C.J. Czajkowski

Date: $\quad 1987$

Task: $\quad$ FIN A-3763

Key words: $\quad$ crack depths; intergranular cracking; interdendritic cracking; Nine Mile Point Unit 1; Oyster Creek Unit 1; stress corrosion cracking; Type 304 stainless steel; weld heat-affected zone

This paper describes instances of cracking of stainless steel components at two nuclear power plants (Nine Mile Point Unit 1 and Oyster Creek Unit 1) and their subsequent evaluation at BNL.

\subsubsection{Nine Mile Point Core Spray Line Cracking}

\subsubsection{Background}

A periodic dye penetrant examination performed in May 1984 on the outside surface of a core spray line at Unit No. 1 disclosed several circumferentially oriented indications. In addition, ultrasonic inspections revealed the presence of several cracks penetrating the piping base material (Type 304 stainless steel), a finding later confirmed by grind-out operations. The subsequent evaluation at BNL consisted of:

* optical metallography and sensitization tests

* $\quad$ scanning electron microscopy/energy dispersive spectroscopy

\subsubsection{Optical Metallography/Sensitization Testing}

A polished section revealed the cracks to be transgranular, considerably branched, and with two initiation points. There was no evidence of surface pitting at or near the cracks. 
condition.

Sensitization testing using ASTM A-262, Practice A, showed the material to be in the non-sensitized

\subsubsection{Scanning Electron Microscopy/Energy Dispersive Spectroscopy}

Examination of a fracture face using SEM revealed the fracture to be essentially transgranular and with evidence of fatigue interactions. EDS scans indicated the presence of $\mathrm{Cl}$ on the fracture face and of a low $\mathrm{Cr}$ :Fe ratio (in the vicinity of 0.5 ). The latter is normally taken to be an indication of a hydroxide-induced cracking mechanism but appeared at odds with the detection of chloride on the fracture surface. This led to the proposition that the cracking occurred at low temperatures.

\subsubsection{Discussion/Conclusions}

Based on results of the evaluation and a literature review, it was concluded that the transgranular cracking observed resulted from a SCC mechanism. There was no evidence of material sensitization, elimination that condition as a contributory factor. The detection of chlorine on the fracture surface indicated that the fracture was chlorideinduced. In addition, the lack of pitting observed plus the low $\mathrm{Cr}$ :Fe ratios measured were taken as that the cracking was a low-temperature phenomenon.

\subsubsection{Oyster Creek Isolation Condenser Line Cracking}

\subsubsection{Background}

In March 1984, the Oyster Creek Unit No. 1 facility developed a leak in the condensate piping during hydrostatic testing of the system. Ultrasonic measurements were then performed on all the isolation condenser piping welds and approximately 50 indications were found, affecting 27 welds. The subsequent failure analysis of selected Type 316 stainless steel failed pipe sections consisted of:

* visual inspection/photography

* optical microscopy/metallography/sensitization tests

* ferrite measurements

* $\quad$ scanning electron microscopy/energy dispersive spectroscopy

\subsubsection{Visual Inspection/Photography}

Each of the three sections of piping to be examined contained welds and had heavy oxide scale evident on the inside surface. Preliminary visual examination revealed no evidence of cracking on one section but indications on the other two.

\subsubsection{Optical Microscopy/Metallography/Sensitization Tests}

Of the two crack indications examined on one section, one was found to be entirely within the weld and interdendritic. A second one initiated at the base metal/weld metal fusion line, followed the weld contour for a short distance then changed direction to enter the weld. This crack was completely intergranular while following the weld line and interdendritic after entering the weld.

Of the two indications noted on another section, one crack was found which initiated and propagated entirely within the HAZ. Another crack initiated and propagated in the HAZ for a short distance before entering and propagating in the weld.

Sensitization tests using ASTM A-262, Practice A, revealed that all three sections were sensitized. 


\subsubsection{Ferrite Measurements}

Ferrite readings showed a wide range of ferrite contents between the welds of the three sections. The lowest numbers, from 1.3 to 2.6 , were found with the section in which one crack was entirely within the weld. The ferrite readings from the other section containing cracks ranged from 5.1 to 11.0. The third section, in which no significant cracking had been found, had ferrite numbers from 3.4 to 5.9 .

\subsubsection{Scanning Electron Microscopy/Energy Dispersive Spectroscopy}

With the exception of the crack located entirely within the weld metal, all the fracture faces had intergranular characteristics. EDS scans of the fracture faces showed the expected constituents of these stainless steels $(\mathrm{Fe}, \mathrm{Cr}, \mathrm{Ni}$, and, where applicable, Mo). Additional elements often detected were Si and S.

\subsubsection{Discussion/Conclusions}

All three conditions that are mandatory for SCC to occur appeared to be present in the case of the Oyster Creek failures. The fact that the materials were found to be in a sensitized condition meant that they were already susceptible. This condition will lead to intergranular attack of the type observed in the present case. In addition, resistance to IGSCC increases with ferrite content in the material. In the present case, particularly low ferrite numbers would lead to increased susceptibility. The second condition, that of a corrosive environment, existed in the form of the reactor coolant. The presence of $S$ on the fracture faces indicated that this particularly deleterious species was available in some form in the coolant. The presence of stress, the third condition, is almost inevitable in welded structures unless extensive stress relief is applied following the welding. Thus it was concluded that the cracking observed with the Oyster Creek isolation condenser was probably due to IGSCC.

\subsection{BWR Pipe Cracking Evaluation}

Reference: Report MT-3739-1

Author(s): $\quad$ C. J. Czajkowski, M. H. Schuster and J. Clinton

Date: $\quad$ March 1988

Task: $\quad$ FIN A-3739

Key words: Brunswick Unit 1; crack growth rates; crack sizes; intergranular stress corrosion cracking; nondestructive evaluation; Peach Bottom Unit 2; Vermont Yankee

\subsubsection{Background}

The phenomenon of IGSCC has been the object of extensive research by the NRC and utility-sponsored organizations, such as the Electric Power Research Institute, and many methods of mitigation have been proposed. The NRC has an interest in evaluating the various methods of both detecting and sizing IGSCC cracks since industry has proposed various acceptance criteria for returning nuclear units to service with known, unrepaired flaws, based upon ultrasonic measurement of the defects. This information, coupled with crack growth rates and stress intensity factors for operating conditions, provide the bases for the utilities' requests for "return to service."

In 1983, the NRC requested BNL to review the situation regarding pipe cracking in BWRs. The emphasis was to be on the reliability of non-destructive evaluation techniques for determining crack sizes, the dynamics and rates of crack growth, and the effectiveness of proposed remedial actions. The results of that work were published 
in NUREG/CR-4545 and NUREG/CR-4221. A follow-on effort was subsequently placed with BNL in 1986, to consist of the following tasks:

* receipt and storage of piping samples from Peach Bottom 2, Brunswick 1 and Vermont Yankee power stations at BNL

* $\quad$ sorting and cataloging the sample piping

* decontaminating the specimens

* dye penetrant examination, to determine the presence or absence of inner surface defects in the sample piping

* based on the UT data received from the utility and the dye penetrant data obtained under Task 4 , selecting specimens from the sample piping for detailed examination to determine the depth and extent of IGSCC present

* $\quad$ proper disposal of the remaining contaminated piping

* issue final report.

\subsubsection{Receipt/Storage and Cataloging the Samples}

A total of 10 pieces of piping were received:

* from Peach Bottom Unit 2, two pieces of twenty-inch diameter piping, from the Residual Heat Removal system, each with an elbow-to-pipe weld located essentially in the center of each piece and with a structural overlay welded over the weld;

* from Brunswick Steam Plant Unit 1, two pieces of six-inch diameter piping, encompassing three welds from the reactor water cleanup suction line;

* from Vermont Yankee, six pieces from the Recirculation System piping, four of twenty-two-inch diameter pipe and two of twenty-four-inch diameter pipe, encompassing the twenty three welds in all.

\subsubsection{Cutting/Decontamination of the Pipe Samples}

It was determined that, because of the contaminated condition of the piping, the large sections should be cut using a plasma arc cutting process. Sleeves were used for the internal protection of the piping from slag and spatter from the cutting operation.

After the plasma arc cutting, those pipe sections containing welds to be examined by dye penetrant testing were decontaminated and the surface layers of dirt and crud were removed, either by shotblasting or by soaking in a nitric-acid-based industrial descaler solution. Except for. one piece that had a final radioactivity level of $300 \mathrm{mR} / \mathrm{h}$, the cleaning procedure reduced the level of radioactivity from a range of $500-1500 \mathrm{mR} / \mathrm{h}$ gamma-plus-beta radiation measured at 12 inches from the pipe surface to a range of 10 to $100 \mathrm{mR} / \mathrm{h}$ gamma-plus-beta radiation measured to 3 to 4 inches from the pipe surface. Radiation doses of personnel were kept as low as reasonably achievable by employing a number of personnel. The total dosages were estimated at 3.5 man-rem for the whole operation.

A total of eighteen specimens were cut encompassing twenty nine welds of various sizes: twenty eight inches, twenty two inches, twenty inches, twelve inches, and six inches.

\subsubsection{Dye Penetrant Examination}

Each of the welds capable of being inspected was dye penetrant inspected after decontamination/cutting (four were unable to be tested due to the inside surface condition of the pipe). The dye penetrant examination revealed: 
* no detectable indications were found in three of the six pipe sections from Vermont Yankee; indications were associated with one weld in each of two others and with two welds in the sixth section;

* each of the two pipe sections from Peach Bottom had linear indications, most being faint in nature and widely spaced;

all three welds contained in the two sections from Brunswick yielded linear indications.

\subsubsection{Comparison of Utility UT Data to Dye Penetrant Results}

The results of the various ultrasonic inspections made by the three utilities were compared with those from dye penetrant tests performed at BNL. The comparison revealed that:

* for the Vermont Yankee piping, for the twelve-inch welds that could be compared, it appeared that the utility had a conservative inspection plan which called out IGSCC when dye penetrant could not detect any. However, these welds were weld overlaid and the dye penetrant results could have been influenced by crack closure due to the compressive stresses induced by the overlay process. This also appeared to be the case with the twenty-two-inch welds able to be evaluated by both techniques. The twenty-four-inch welds showed a good correlation of results, no indications being observed by either technique. Of the three twenty-eight-inch welds which could be directly compared by the techniques, the results from two welds compared very favorably while those from the third had a complete undercall by the utility.

* comparisons of the dye penetrant examinations of the Brunswick piping with the UT previously performed at the utility showed a minimum correlation. Dye penetrant testing disclosed discontinuities in all three welds while the ultrasonic examination gave indications for only one of the welds.

* the two ultrasonic inspections done by the utility on the Peach Bottom piping indicated IGSCC, as did the dye penetrant examination in the same general areas (though not to the same extent).

\subsubsection{Discussion/Conclusions}

All the piping received at BNL from the Vermont Yankee Power Station, Peach Bottom Unit 2 and Brunswick Unit 1 had been cut, decontaminated and dye penetrant inspected. The decontamination process reduced the radiation levels of the piping to levels consistent with those necessary for relative ease in handling and inspection by most facilities. To that extent, the original "as shipped" (contaminated) condition of the piping determines ultimately what can be accomplished on any given program.

The comparison of the results of the UT inspections made by the three utilities with those from dye penetrant tests performed at BNL revealed that there was a lack of consistent correlation between the two methods. There was reasonable correlation in the case of the Peach Bottom piping and with some of the welds from the Vermont Yankee piping. Lack of correlation in the case of other Vermont Yankee piping welds could possibly be attributable to the existence of overlay on the welds, the presence of which might obscure the detection of IGSCC cracking by dye penetrant testing. In one case there was a complete undercall by the utility. Comparison of the dye penetrant results from the Brunswick piping with the UT results showed a minimum correlation, the dye penetrant giving indications in all three welds while the UT gave indications for only one weld. 


\title{
8.11 Evaluation of Cracked Pipe from Big Rock Point
}

\author{
Reference: Report MT-L1529-1 \\ Author(s): $\quad$ C. J. Czajkowski \\ Date: $\quad$ November 1990 \\ Task: $\quad$ FIN L-1529
}

Key words: $\quad$ Big Rock Point; ferrite content; intergranular stress corrosion cracking; transgranular cracking; sensitization; Type 304 stainless steel

\subsubsection{Background}

In July 1990, a leak was discovered in three-inch stainless steel piping at the Big Rock Point Nuclear Station. The leak occurred in the reactor water cleanup (RWCU) piping in the vicinity of a butt weld and was suspected of being due to IGSCC. In order to evaluate the leak indication, two sections of RWCU piping (the leaker and a nonleaking section) were sent to BNL at the request of the NRC. The subsequent evaluation consisted of:

* visual inspection/photography

* dye penetrant examination

* chemical analysis

* optical microscopy

* scanning electron microscopy/energy dispersive spectroscopy

* ferrite readings of the weld metal.

\subsubsection{Visual Inspection/Photography}

The two sections of radioactively-contaminated RWCU piping received at BNL were three inches in diameter and approximately six inches in length. Examination on the outside surface of the section of leaking piping disclosed a linear indication adjacent to a circumferential butt weld on the pipe. Inspection of the inside surface of the "leaker" disclosed a thermal sleeve which had been socket (fillet) welded $360^{\circ}$ around the inside circumference of the pipe. There appeared to be a linear indication approximately $11 / 4$ inches in length above the thermal sleeve.

Visual examination of the other (non-leaking) section of RWCU piping showed no evidence of cracking.

\subsubsection{Dye Penetrant}

A dye penetrant examination was performed on the second RWCU pipe in order to ascertain if there were present any cracks undetected by the visual examination. This examination encompassed the butt weld socket weld area and approximately 2 inches on the thermal sleeve. No evidence of cracking was noted during this examination.

\subsubsection{Chemical Analysis}

In order to more fully characterize the pipe's base metal, a section was chemically analyzed for constituents. The results of the analysis indicated that the section of pipe met the majority of Type 304 stainless steel alloying requirements except in that it contained a slight excess of carbon $(0.11 \mathrm{wt} . \%$ compared with the $0.08 \mathrm{wt} \%$ maximum of the requirement). 


\subsubsection{Optical Microscopy}

A cross section which included material from the butt weld (circumferential), the thermal sleeve and the fillet weld was cut from the leaking pipe. This cross section was ground and polished, then electrochemically etched using Practice A of ASTM A-262 ("Standard Recommended Practices for Detecting Susceptibility to Intergranular Attack in Stainless Steels"). The etchant used was a $10 \%$ solution of oxalic acid in demineralized water; the current density was $\sim 1 \mathrm{~A} / \mathrm{cm}^{2}$ for 1.5 minutes. The polished specimen served as the anode while a piece of platinum foil acted as the cathode.

Optical microscopy of the etched cross section revealed the existence of an intergranular type crack, initiating near the toe of the fillet weld and propagating into the crown of the butt weld. A second crack, very straight in appearance and with no branching evident, was noted in the thermal sleeve material. This second crack was categorized as transgranular, and its morphology and location indicated a probable fatigue (possibly thermal) origin.

The probable IGSCC crack appeared to originate near the toe of the fillet weld and propagate into the butt weld. The crack was entirely intergranular and had some branching evident. Examination at high magnification revealed a predominantly dual structure in the HAZ. The weld had an interdendritic appearance, normal for this type of weld. Although the crack had started to enter the butt weld, it apparently only penetrated the weld to a depth of only one or two grains. Although one or two grains were completely ditched (sensitized) after the ASTM A-262 Practice A etching, the microstructure near the crack initiation point had a more typically "dual" microstructure.

\subsubsection{Scanning Electron Microscopy/Energy Dispersive Spectroscopy}

Two fracture faces were examined by SEM/EDS for determination of fracture mode and possible detection of detrimental contaminants. The cracks. were opened for evaluation by dry cutting a counternotch below the cracks, immersing the specimen in liquid nitrogen, and then imposing a bending moment to the notch in order to open the crack.

The fracture surfaces of the thermal sleeve crack were predominantly transgranular in appearance (quasicleavage) and typical of that seen on fatigue type failures. No probable crack initiation point could be identified.

The fracture surfaces of the crack that initiated near the toe of the fillet weld indicated a predominantly intergranular fracture mode. This type of fracture is consistent with a intergranular stress corrosion cracking mode of failure.

Various EDS scans were performed on the fracture face of the intergranular crack. The majority indicated only the presence of $\mathrm{Cr}, \mathrm{Fe}, \mathrm{Ni}$, and $\mathrm{Mn}$, the normal constituents of a Type 304 stainless steel. Two of the scans, however, indicated the presence of a trace of chloride. One of these two scans also exhibited a trace of phosphorous.

\subsubsection{Ferrite Measurements}

Because the IGSCC crack had propagated slightly into the weld, ferrite measurements were performed on the welded sample. The requirement for ferrite control and content in austenitic stainless steel welds has been documented in at least two Regulatory Guides and is considered a first order defense against microfissuring and SCC prevention in the deposited weld metal. Additionally, the role of delta ferrite is thought to be quite important in reducing the susceptibility of austenitic materials to intergranular cracking.

The instrument used to make the ferrite readings on the specimens, a Ferritescope, was recalibrated after each specimen was set in order to assure accurate readings. 
Measurements were taken on both sides of the weld crown parallel to the pipe's outside surface, as well as one measurement perpendicular to the pipe's outside surface. These measurements were performed on the polished and etched specimen cross section in order to obtain representative readings of the "as deposited" metal. The results indicated that the ferrite numbers in the butt weld near the crack are low $(1.4-3.2)$, but that the outside surface measurements are somewhat higher, $3.7-6.0$.

Ferrite measurements were also made on the outside circumference of the butt weld on an uncracked section of RWCU pipe and supplementary measurements on the remaining material in the cracked section of RWCU pipe. The measurements on the uncracked section provided ferrite numbers in the range $6.4-8.9$, those from the cracked section in the range $2.4-7.1$. These significantly higher numbers would have the tendency to halt a crack propagating into the butt weld.

\subsubsection{Discussion/Conclusions}

In order for intergranular stress corrosion cracking to occur, three key conditions must exist: a susceptible microstructure, a corrosive environment, and tensile stress (applied or residual).

In the case of the austenitic stainless steels, the susceptible microstructure, termed "sensitized," can easily result from welding. In the present case, sensitization would be facilitated by the relatively high carbon content $(0.11$ wt.\%) of the material of the cracked pipe.

The second condition needed for IGSCC to occur is a corrosive environment. In light water reactors, the corrosive species responsible for the most instances of IGSCC has been oxygen. Other species identified as contributors to various instances of IGSCC failures are chloride and other halogens. This is particularly important for the present failure because traces of chlorides were found on two EDS scans.

The third condition required to induce IGSCC is tensile stress. Such stresses were probably present in the RWCU piping because of the residual tensile stresses induced by welding. The direction and amount of tensile stresses developed in piping are thought to be closely related to the pipe diameter. The small diameter RWCU pipe and the addition of a fillet/socket weld to a pre-existing butt weld probably contributed significant welding stresses to the cracking event.

An additional factor which should be considered is the increasing resistance of an austenitic stainless steel to IGSCC as the ferrite content of the material is increased.

From the above, it can be concluded that the leaking butt welded RWCU pipe from Big Rock Point resulted from a IGSCC crack. The crack appeared to originate near the toe of a fillet welded thermal sleeve. No definite corrosive species were identified by EDS but two scans indicated the presence of traces of chloride. In addition, a small transgranular crack was found in the thermal sleeve of the cracked RWCU pipe. Characteristics of the crack indicate that it was probably fatigue related.

\subsection{Evaluation of Cracked Cap Screws from the Control Rod Drive Mechanism of the Monticello Nuclear Power Plant}

Reference: $\quad$ Report MT-L1529-4

Author(s): $\quad$ C. J. Czajkowski

Date: October 1991 
Task:

FIN L-1529

Key words: $\quad$ low-alloy steel bolting; Monticello; pitting; slow strain rate testing; stress corrosion cracking

\subsubsection{Background}

Three instances of control rod drive capscrew cracking have occurred in U.S. boiling water reactors since late 1987. All of the cracks evaluated have been shallow in depth (maximum depth 0.036 inches). In 1991, the Monticello Nuclear Plant experienced cracking on $\sim 60 \%$ of their control rod drive capscrews which had been exposed to twenty years of service. The concerns about this instance revolve about the causes of the cracking. If the capscrews had been cracked as a result of original fabrication (defects and/or heat treatment) then the operating conditions for the screws may not be conducive to crack growth in service. If, however, the cracks had initiated and propagated as a result of service conditions, the operational life for the capscrews would have limitations. Subsequently, an evaluation of replacement and inspection options would be warranted.

BNL was requested by the NRC to metallurgically evaluate five capscrews from the Monticello Nuclear Plant, in order to determine the failure mode. This evaluation was to include the following:

* visual/photography/dye penetrant

* optical microscopy

* hardness testing/tensile tests

* $\quad$ scanning electron microscopy

* slow strain rate testing.

\subsubsection{Visual/Dye Penetrant Examinations}

A total of five capscrews (low alloy steel ASME SA-193 Grade B7 material) were delivered to BNL from the Monticello Nuclear Plant:- Three of the five had experienced approximately twenty years of service (original installation) while two of them were new (not been in service). The capscrews were 1.00 8UNC bolts approximately 7 inches in length. One of the three "used" capscrews had cracks clearly evident in the radius area of the bolt, directly below the capscrew head. This bolt had the most severe cracking (approximately 300 degrees of the bolt's circumference was cracked). Pitting was also evident in the vicinity of the cracks.

The two less severely degraded capscrews were dye penetrant tested. Cracking was evident in the radius area of one of the screws, as was pitting in the radius region of this bolt. The other screw had cracking which appeared to connect a line of corrosion pits at the shank-to-bolt head location. This suggests the possibility that a crevice corrosion mechanism was present during service of the bolts.

\subsubsection{Optical Microscopy}

Sections from the two less severely degraded capscrews were cut, mounted, metallurgically polished and examined using optical microscopy. All of the cracks examined were oxide filled and had blunted crack tips. The cracks appeared to have initiated at corrosion pits and occurred at multiple initiation sites. The cracks ranged in depth from 0.019 to 0.036 inches.

A number of crack starts and stops were seen in the cross-sections, indicating that a general corrosion process was competing with the cracking and also that the crack growth rate was relatively slow.

Two cross-sections normal to the bolts' long axes were examined after metallurgical etching. These showed that both microstructures were tempered martensite which is normal for this grade of bolting material. Evidence was also found of stringers (probably $\mathrm{MnS}$ ). 


\subsubsection{Hardness Testing/Tensile Testing}

Specimens were cut (perpendicular to the bolts' long axes) from one "new" (unexposed to service conditions) capscrew and the most severely cracked capscrew. These specimens were then hardness tested through their cross sections. There was no significant difference in average "core" hardnesses between the two capscrews, both being approximately HRC 31 . Such a hardness equates to a tensile strength of approximately $143 \mathrm{ksi}$, which would indicate that both the cracked and uncracked capscrews met the minimum tensile strength requirements for ASME SA-193 Grade B7 bolting material (125 ksi).

Both of the aforementioned capscrews were uniaxial tensile tested. The results of these tests confirmed that both capscrews met the minimum tensile strength requirement of $125 \mathrm{ksi}$. However, only the cracked capscrew met the minimum reduction of area requirement of $50 \%$. The new (uncracked) capscrew attained a reduction of area of $48.5 \%$ and thus failed to meet the minimum requirement.

\subsubsection{Scanning Electron Microscopy/Slow Strain Rate Testing}

Cracks on two of the "used" bolts were opened and examined by scanning electron microscopy. The fracture surfaces were found to be heavily attacked by general corrosion, thus obscuring the fractographic features. Pitting was evident at the crack initiation areas which was consistent with the optical microscopy observations.

In order to investigate further the environmental conditions under which the capscrew would fail, a flat tensile-type specimen was cut from the uncracked capscrew. This specimen was subjected to a slow strain rate test in a $300^{\circ} \mathrm{F}$ steam environment. The test method is basically the application of slow dynamic straining to a stress corrosion (tensile type) specimen while it is exposed to the environment. This particular mode of testing has the advantage of always resulting in a fracture at its completion and normally does so in a relatively short period of time (a few days). Another advantage of this type of testing is the ability to adjust the strain rate in the most probable range of stress corrosion crack velocities, namely, $10^{-6}$ to $10^{-9} \mathrm{sec}^{-1}$. This strain rate range is critical. Too high a strain rate would result in ductile failure by void coalescence prior to the development of the necessary corrosion reactions while too slow a rate could again fall out of the range for SCC failures to occur. For these reasons, it is important to realize that the absence of cracking in a given medium does not necessarily preclude the possibility of stress corrosion cracking until additional strain rate tests (both higher and lower values) have been completed.

In the present case, the specimen tested was loaded into a stainless steel autoclave and steamed with demineralized water at a temperature of $300^{\circ} \mathrm{F}$. The strain rate chosen was approximately $5.0 \times 10^{-7} \mathrm{sec}-1$. The sample broke after 99.2 hours of exposure at this strain rate and attained a tensile strength of $140.8 \mathrm{ksi}$. The resultant fracture surfaces were examined by SEM after testing. This revealed a number of apparent crack initiation sites on the fracture face and a general corrosion attack at the center of one of the initiation areas. The ductile nature of the fracture was evident at high magnification. The fractographs thus indicated the probable susceptibility of this material to stress corrosion attack under these conditions.

\subsubsection{Discussion/Conclusions}

The capscrew cracking was located in the shank-to-head juncture of the bolt and was circumferentially oriented. The cracks appeared to be associated with corrosion pitting which was also observed in the area. This pitting of the capscrews is thought to be indicative of crack initiation by crevice corrosion. The cracks themselves had blunted tips (partially rounded) and were oxide filled. This suggests that the corrosion process had slowed down or arrested crack growth. The deepest crack observed was 0.036 inch deep.

The microstructure of the capscrews was tempered martensite, normal for ASME SA-193 Grade B7 bolting material. The hardness and tensile strength of the capscrews examined (including the most severely degraded one) were found to be consistent with those expected of this material. 
Slow strain rate testing of a previously uncracked capscrew indicated the possible susceptibility of this material to SCC.

From the above, it was concluded that SCC appeared to be the failure mode of the capscrews. The cracking was observed at corrosion pits which aid in crack initiation. Although MnS stringers were observed in the microstructure, their significance to the cracking process was indeterminate.

\subsection{Metallurgical Evaluation of Weld Overlaid Pipe Sections from Brunswick Unit 2 Nuclear Power Station}

Reference: Report NUREG/CR-5885

Author(s): $\quad$ C. Czajkowski, B. Bowerman, M. Schuster, T. Roberts, L. Milian

Date: $\quad$ June 1992

Task: $\quad$ FIN L1438

Key words: $\quad$ Brunswick Unit 2; ferrite content; intergranular cracking; sensitization; Type 304 stainless steel; ultrasonic inspection; weld overlay

\subsubsection{Background}

Weld overlay repairs on piping degraded by IGSCC were initially considered as a short term repair and were accepted provided that no more than two additional fuel cycles were completed. The issuance of Generic Letter 88-01 allowed weld overlay repaired piping to continue to operate as long as the repaired piping was subjected to UT every other fuel cycle. This evaluation had to indicate that existing cracks had undergone no significant growth (propagation) and that no new cracks had initiated. Because many overlays had been applied in BWR plants, the NRC believed there to be a need to confirm the effectiveness of weld overlay repairs (in mitigating the IGSCC) by metallurgically examining several overlay-repaired welds and requested BNL to perform such an examination. Four stainless steel piping sections which had been in service for three refueling cycles were subsequently obtained from the Brunswick Unit 2 nuclear power station. All sections were from 12 inch diameter pipe, were approximately 12 inches long, and contained an overlaid weld. methods:

The evaluation included a review of the inspection data provided by the utility and the following examination

* visual inspection/dye penetrant/radiography

* residual strain measurements/ferrite measurements

* $\quad$ optical microscopy

* chemical analysis

* microhardness measurements

* scanning electron microscopy.

\subsubsection{Visual Inspection/Dye Penetrant Examination/Radiography}

The inside surfaces of all four pipes were covered with a heavy oxide coating which was removed before the dye penetrant examination was performed. This revealed that one section had three crack indications, two more had two indications, and the fourth one only one indication. Further characterization involved $x$-ray radiography (11 
radiographs per section) but the results of the latter could not be definitively correlated with the dye penetrant indications.

\subsubsection{Residual Strain Measurements/Ferrite Measurements}

Residual strains (stresses) of the welds in areas where cracks were measured using strain gages installed adjacent to and across selected cracks in the welds on the interior of the pipe sections and on the outer pipe circumference at locations corresponding to the interior surface strain gages. The gages were zeroed before the pipes were sectioned, then readings were taken after the pipes had been cut. The strain gage readings were, for the most part, consistent with what would be expected: compressive residual stresses in the inner diameter surface and tensile residual stresses in the outer diameters of the overlays. Using the strain readings, the inside surface residual compressive stresses were calculated to range from a low of $3.4 \mathrm{ksi}$ on one section to as high as $24.5 \mathrm{ksi}$ on another section. The highest residual tensile stress (on the outside diameter) was estimated to be $35.6 \mathrm{ksi}$, the lowest $5.1 \mathrm{ksi}$.

Ferrite measurements were done on all four pipes' outside surfaces (weld overlay area). The majority of the measurements indicated a ferrite number 8.0 or greater (the highest was 13.3). Of the approximately 480 readings, only four less than 8.0 (these were 7.3, 7.5, 7.9 and 7.9. All of the "as deposited" ferrite readings measured would be considered acceptable in making a weld overlay.

\subsubsection{Optical Microscopy}

The various samples cut for the strain gage measurements were sectioned into 21 smaller specimens suitable for metallography and optical microscopy. All 21 were removed from sections where the dye penetrant examination had indicated that a discontinuity was present. Only 11 of the 21 cross sections exhibited cracks when viewed in the optical microscope. In the case of one pipe section, none of the four small specimens examined revealed cracks. Those cracks that were visible were all intergranular in nature and many were associated with the HAZ of the original weld.

These small specimens were also subjected to oxalic acid etching according to Practice A of ASTM A-262. The microstructures made visible by the etching indicated that all the materials examined were sensitized and therefore susceptible to intergranular attack (IGA).

\subsubsection{Chemical Analysis}

Three specimens were cut from each of the four pipes and consisted of a sample from the individual overlay, the base metal, and the original weld metal. Chemical analysis using wavelength dispersive spectroscopy indicated that, for the most part, all the materials had compositions consistent with the values expected for Type 304 stainless steel and Type 308 weld metal.

\subsubsection{Microhardness Measurements}

A piece of one of the pipe sections was cut, metallurgically ground and polished, then tested for microhardness. With the exception of one hard spot near the outside edge of the overlay (overlay/pipe interface), the readings were reasonably consistent with those expected for Type 304 stainless steel and the Type 308 stainless steel overlay material.

\subsubsection{Scanning Electron Microscopy}

SEM of various crack (fracture) faces showed that the fractures were entirely intergranular with no evidence of beach marks or discontinuous crack growth. There were no signs that crack growth may have ceased due to overlay or that the cracks did or did not propagate during service after overlay application. 


\title{
8.13.8 Discussion/Conclusions
}

The chemical analyses performed on samples of the base metal, weld metal and overlay materials appeared normal for the alloys used (ASME SA-240 Type 304 stainless steel and ASME SFA 5.4 Type 308 weld metal). The hardness values were also consistent with those expected in this type of weldment. Oxalic acid etching revealed the microstructure of the material in the vicinity of the weld to be sensitized and hence susceptible to intergranular attack. Strain gage measurements showed the presence of residual stress in the pipe sections. The combination of a susceptible microstructure and residual stress in the presence of a corrosive medium (primary coolant water) provided conditions conducive to the occurrence of IGSCC.

The quality of the overlays was consistent with that expected in an ASME pressure boundary weld. There was no evidence of porosity, lack of fusion, lack of penetration, or weld metal cracking (other than intergranular cracking). The ferrite numbers (FNs) recorded (all greater than 7) for all of the overlaid welds were consistent with industry practice. One reading was below the recommended FN 7.5 minimum outlined in NRC Generic Letter 88-01. Considering the fact that the reading was FN 7.3 and that all other ferrite measurements on this pipe were above FN 7.5 , this was considered acceptable.

The evaluation of the UT data indicated that for certain overlay configurations, ultrasonic inspection may not provide an accurate picture of the top $25 \%$ (original pipe wall) of the pipe. Comparing the metallurgical sectioning of the four pipes to the dye penetrant results also gave rise to questions regarding overcalls and undercalls on intergranular cracking. Similarly, comparison of cracks to ultrasonic test data indicated that the sizing/locating of cracks (before overlay) is not an "exact science" and that the results of such inspections should be carefully evaluated.

The residual stress calculations (based upon the strain gage measurements) indicated that crack growth (propagation) after weld overlay is a distinct possibility. This conclusion was based on the low recorded residual compressive stresses observed on one of the pipe sections. However, it could not be positively determined from the metallurgical examination if crack growth occurred after application of the overlay.

\subsection{Palo Verde Unit 2 Steam Generator Tube Rupture Review}

\author{
Reference: Report MCE-E2089-02 \\ Author(s): $\quad$ C. J. Czajkowski \\ Date: $\quad$ August 1993 \\ Task: $\quad$ FIN E-2089
}

Key words: Alloy 600; crack detection uncertainty; eddy current testing; intergranular attack; intergranular stress corrosion cracking; Palo Verde Unit 2

\subsubsection{Background}

On March 14, 1993, Palo Verde Unit 2, one of three Combustion Engineering-designed System 80 pressurized water reactors at the site, experienced a steam generator tube rupture in one of the two steam generators. Subsequent investigation and examinations disclosed other tube defects, many of which were associated with deposits on the tube surfaces. The root cause investigation employed pulled tubes and additional eddy current inspections. Subsequently, BNL was requested to review of the licensee's (Arizona Public Service) submittals to the NRC in order to assist in analysis of the problem and in determining the safety adequacy of the licensee's corrective actions. 


\subsubsection{Licensee Submittals}

Evaluations by the utility and its contractors determined that the Alloy 600 tube had failed as a result of outside diameter initiated axial cracking. This cracking was determined to be the result of IGA/IGSCC at a tube-tube crevice. Subsequent eddy current testing (ECT) determined that axial crack indications at the free span and egg crate support locations were found on multiple tubes in the upper region of the tube bundle. The utility concluded that contributory factors to the cracking/failure included: increased sulfate levels due to resin intrusion; non-standard microstructure; and possible cold working of tubes. At the same time, the utility also concluded that loose parts did not play a role in the tube rupture event and that steam generator oscillations had no impact on the event.

\subsubsection{Specific Aspects}

\section{Flow-Induced Vibration}

Tube crack surfaces indicated that high cycle fatigue did not cause the failures. Both the instability flow regime of the unsteady momentum flux in the two-phase flow system and fluid-elastic instability were examined, mechanisms which had the potential to lead to large amplitude vibrations and result in tube-to-tube impacts, possibly even tube rupture at flow rates above a threshold value. It was determined that flow-induced vibration had the potential to contribute to the observed cracking but it was considered unlikely.

\section{Fabrication}

Following evaluation of items such as tube bundle fabrication, tubing manufacture, tube bending, and tubing operations, the utility concluded that no unusual fabrication problems could be associated with the failed unit.

Wear

An evaluation of wear indications by ECT above $20 \%$ through wall indicated that tube wear in the failed and unfailed steam generators were consistent (average wear was 10-11\%).

\section{Deposit Study}

Inspection results implied that some steam blanketing may have extended to the first vertical support, an observation supported by the presence of ECT-detected deposits in the region.

\section{Metallurgical Examination of Tubes}

A total of eight tubes, including the failed one, were removed for both destructive and nondestructive examination. Axial crack indications in the eggcrate supports and the free span areas were shown to be a combination IGA/IGSCC OD-initiated corrosion cracking. At least one tube (free span) indication had deep IGA. No transgranular cracking was noted.

Examination of free span ridge deposits showed the presence of the following species: $\mathrm{Fe}_{3} \mathrm{O}_{4}, \mathrm{Cu}, \mathrm{NiO}, \mathrm{SiO}_{2}$, $\mathrm{CaO}, \mathrm{MgO}, \mathrm{ZnO}, \mathrm{MnO}_{2}, \mathrm{Al}_{2} \mathrm{O}_{3}, \mathrm{PbO}$, sulfur species. It was determined that concentration of these species could have contributed to IGA and IGSCC in the Alloy 600 tubes.

\section{Oxide Analysis}

Analyses of tube surfaces and crack surfaces revealed areas of nickel depletion and chromium depletion at the crack tip. Depletion of nickel indicated that reduced sulfur and sulfates had contributed to IGA/IGSCC while the chromium depletion would only occur in an alkaline environment. There was no indication on the crack surfaces of 
a strong acid or alkaline environment. Thus it was determined that the crack environment was alkaline (mild caustic) with sulfate present.

In addition to the above, lead was detected in small amounts in the crack surface films and copper in high concentrations both in the deposits and on the crack surfaces associated with the upper tube bundle.

Surface Examination

Cracks were found on free surfaces of three tubes while a fourth had eggcrate defects. Scratches on one tube were associated with IGA.

\section{Microstructure}

The burst tube had a microstructure absent in intragranular carbide precipitation and slight intergranular carbide precipitates, indicating that it had lowered resistance to caustic IGSCC. Two other tubes examined had more IGSCC-resistant microstructures that contained intragranular and intergranular carbides and prior carbide grain boundaries. However, such a microstructure also suggested that the tubes did not receive a full solution anneal.

$\underline{\text { Wear }}$

Wear areas were noted on four tubes and had IGA, probably due to surface cold working.

\section{Eddy Current Testing}

Examination of tubes to field ECT data confirmed that no degradation was noted which was above field ECT thresholds.

\section{Material Testing}

Chemistry analysis and mechanical testing showed that the material met the specification requirements for Alloy 600 tubing. The utility concluded that the tube rupture experienced was caused by IGA/IGSCC at a tube-totube crevice formation. The crevice and subsequent increased heat flux across the tube led to an aggressive environment under the ridge deposit which initiated/propagated a long deep crack. The previously mentioned factors were also felt to be possibly contributory to the failure.

\subsubsection{Discussion/Conclusions}

Various ECT evaluations were carried out on both the Unit 2 steam generators using bobbin coil and motorized rotating pancake coil techniques, and axial cracks were identified in several locations. These areas were examined and the extent of the inspections appeared adequate to assure that structurally significant cracks had been located and repaired (i.e., the tubes had been plugged). However, the ECT techniques used appeared to incorporate large uncertainties concerning the detectability threshold for depth sizing. The rotating pancake coil technique could not detect three cracks with maximum depths less than $40 \%$ through-wall. At the same time, the bobbin coil inspections failed to detect two cracks later determined to have maximum crack depths of $57 \%$ and $61 \%$ through-wall. In fact, the bobbin coil inspections detected only one of the nine observed cracks with maximum crack depths of less than $50 \%$ through-wall. These results thus indicate that considerable uncertainty exists concerning the probability of crack detection in field inspections.

The ECT results were used by the utility to estimate potential crack growth rates for the steam generator tubes. In view of the amount of discrepancy in probable detection thresholds for the techniques involved, the 
uncertainty of location of additional (susceptible) mill annealed tubing and definitive failure root cause, it was recommended that a more conservative approach be taken to the estimation of crack growth rates.

\subsection{Palisades Nuclear Plant Safe-End to Pipe Cracking}

Reference: $\quad$ Report MCE-E2087-02

Author(s): $\quad$ C. J. Czajkowski

Date: $\quad$ January 1994

Task: $\quad$ FIN E-2089

Key words: $\quad$ Alloy 182 weld; Alloy 600; interdendritic cracking; intergranular cracking; Palisades; safe-end transition joint; stress corrosion cracking; Type 316 stainless steel

\subsubsection{Background}

On September 16, 1993, through wall cracking was discovered in the pressurizer power operated relief valve nozzle safe-end of the Palisades Nuclear Plant. This cracking was detected early in the outage and preliminary analysis by the licensee determined the cause of the cracking to be primary water stress corrosion cracking (PWSCC) of the Alloy 600 safe-end welded to stainless steel piping.

BNL was requested to perform a failure analysis of the root cause of the cracking and received several contaminated and activated samples of the aforementioned piping. The evaluation was to consist of:

* scanning electron microscopy/energy dispersive spectroscopy

* dye penetrant examination

* microhardness measurements

* optical microscopy.

\subsubsection{Scanning Electron Microscopy/Energy Dispersive Spectroscopy}

Of the sections received, two had half of the fracture face from the "through wall" crack. The crack was entirely intergranular in appearance with an extremely coarsened grain size (ASTM 0-00). EDS scans of one area revealed traces of $\mathrm{Mg}, \mathrm{Si}, \mathrm{Ca}$, and $\mathrm{Ti}$ with $\mathrm{Cr}, \mathrm{Fe}$, and $\mathrm{Ni}$. These scans, containing $\mathrm{Cr}, \mathrm{Fe}$ and $\mathrm{Ni}$, were more typical of stainless steel than Alloy 600 . EDS scans of other areas showed traces of $\mathrm{Na}, \mathrm{Al}, \mathrm{Si}, \mathrm{P}, \mathrm{Cl}, \mathrm{Ca}, \mathrm{K}, \mathrm{Ti}$, and Vith $\mathrm{Mn}, \mathrm{Cr}, \mathrm{Fe}$, and $\mathrm{Ni}$ also present. These scans characteristically had much higher concentrations of $\mathrm{Mn}$ than would be expected for either Alloy 182 or Alloy 600 . Although some scans showed $\mathrm{P}, \mathrm{S}$, or $\mathrm{Cl}$, none of the contaminants could be confirmed in sufficient concentration to have contributed to the cracking.

Qualitative analysis (EDS) of a polished cross-section was also performed and indicated that the materials of construction were Alloy 600 , Alloy 182, and Type 316 stainless steel.

\subsubsection{Microhardness}

Microhardness measurements were performed on two cross-sections, one of which was taken from an area of apparent weld repair. The readings indicated that the material was in a hardened condition which would make it more susceptible to SCC. 


\subsubsection{Dye Penetrant Testing}

Dye penetrant testing was performed on the inside surface and cut sides of the specimens received. A possible indication was noted on one sample and a possible "end of crack" was seen on an extremely rough cut area of another. Additional sections were removed from these areas for cross-section/optical microscopy.

\subsubsection{Optical Microscopy}

Three sections of the valve received at BNL were cut, ground, metallurgically polished, and etched electrolytically using phosphoric acid and water (to reveal carbides).

Of the three sections examined, one revealed no abnormalities other than a rather large weld root gap. A second section showed evidence of lack of fusion at the fusion line between weld passes and a lack of penetration/porosity in the weld. Possible carbide segregation was also seen after etching. The third section included the small dye penetrant indication originally seen. This revealed that the crack on the Alloy 600 side of the weld metal deposit was confined to the heat affected zone. There was an unusually large weld pass deposit at the weld root, the characteristics of which indicated a probable weld repair made from the inside surface of the pipe.

These observations, coupled with the visual observations of possible weld repairs/bad fit up, indicated that the welded joint was substantially reworked, an observation partly substantiated by the extremely large grain sizes seen on the fracture surfaces. This amount of rework/repair was a good indication that relatively high tensile stresses were present in this weld configuration.

\subsubsection{Discussion/Conclusions}

The conditions necessary for stress corrosion cracking to occur are: a susceptible material; a corrosive environment; and tensile stress (applied or residual). In the present case, the susceptible material was the high hardness Alloy 600 material. The corrosive environment at work was primary coolant water, possibly made more aggressive by the presence of oxygen and/or hydrogen in the area of the nozzles. The final component needed for SCC to occur, tensile stress (residual or applied), was probably present in the areas of weld rework/repair on the inside surface of the pipe.

The large grain sizes noted on the fracture surfaces were not necessarily the result of repair welding, but may have been the result of overheating the forging. Such large grains would not be conducive to a crack-free weldment.

Consequently, the following conclusions were drawn:

* the cracking was intergranular with some interdendritic cracking where the crack entered the weld metal;

* there appeared to be areas of poor fit-uplweld repair which would subject the weld to thermal cycles and relatively high stresses;

* the corrosive species was considered to be primary water;

* traces of possible detrimental elements were found $(\mathrm{S}, \mathrm{Cl})$ but their contribution to the cracking was not clear;

* the large grain sizes seen were indicative of an overheating phenomenon which, coupled with the relatively high hardness of the material, would make the Alloy 600 material potentially susceptible to IGSCC; 
* the potentially susceptible material coupled with high residual stresses in a primary water environment led to the conclusion that the cracking was a result of PWSCC. 


\title{
9 TEMPER BRITTLENESS
}

\subsection{Investigation of Cracking on a Main Steam Isolation Valve Shaft from the Farley Unit \#1 Nuclear Power Plant}

\author{
Reference: $\quad$ Report BNL-NUREG-36717 \\ Author(s): $\quad$ C. J. Czajkowski \\ Date: $\quad$ August 1984 \\ Task: $\quad$ FIN A-3500
}

Key words: $\quad$ Farley Unit 1; high hardness susceptible material; intergranular stress corrosion cracking; Type 410 stainless steel

\subsubsection{Background}

In February 1984, during a refueling outage at the Joseph M. Farley Unit 1 Nuclear Power Station, linear indications were discovered on three of six main steam isolation valve (MSIV) shafts. The indications, ranging in length from 1 inch to 13 inches, were found during cleanup of the shafts prior to reassembly of the valves. All indications were in the operator side packing gland area. Two of the shafts had only longitudinal indications, while the third shaft had both longitudinal and circumferential indications. The three cracked shafts were made of Type 410 stainless steel.

In order to more fully characterize the failure mode of these indications, BNL was requested to perform a failure analysis on one of the shafts (with only longitudinal indications). The analysis was to consist of:

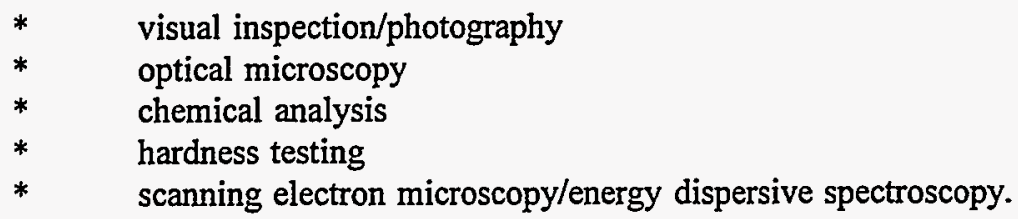

The subject MSIV shaft (\#69C) was 77 inches long by 3.5 inches diameter and weighed approximately 400 lbs. The linear indications were located at the approximate halfway point on the shaft. The indications (cracks) encompassed a total length of approximately 6.6 inches axially along the shaft.

Seven discs were cut from the shaft in the area of the cracks. All cuts were made dry in order to keep contamination to a minimum. After the initial cutting, the three discs that were to be used for SEM/EDS examination had counter notches cut in them (also cut dry), were soaked in liquid nitrogen, and then were broken open by applying a bending moment to them.

\subsubsection{Visual/Photography}

Visually, it was evident that fracture surfaces had thumbnail-like shapes and were granular in appearance. Surfaces were covered by a heavy oxide film which appeared black near the crack initiation areas and was lighter in appearance the greater the distance traversed from the initiation surface. This sort of appearance is typical of cracks which have been pre-existing for a good deal of time prior to propagation. It was learnt that the shafts had 
been dye penetrant inspected prior to installation, which precluded the possibility of pre-existing quenching cracks in the material. There was no gross evidence of fatigue contribution (beach marks, etc.).

\subsubsection{Chemical Analysis/Hardness Testing/Optical Microscopy}

The results of the chemical analysis showed that the shaft material met the chemical requirements for AISI Type 410 stainless steel, with the carbon content measured at 0.030 weight percent.

Both hardness (Rockwell " $\mathrm{C}$ ") and microhardness (Knoop, 500g load) measurements were made on a crosssection of the shaft. The hardness tests gave an average of HRC 41.25 while the average of the microhardness measurements was $444 \mathrm{HK}$ (this equates to HRC 43.4). It was learnt that the shaft's heat treatment comprised of quenching from $1775^{\circ} \mathrm{F} \pm 25^{\circ} \mathrm{F}$ ) in either air or oil, then tempering at $950^{\circ} \mathrm{F}$ to a Brinell hardness of $345-370$ (equivalent to HRC 37-39.8). This was significantly lower than the current hardness readings.

Specimens from the shaft were ground, metallographically polished, and then etched in Vilella's reagent. It was determined that the crack was intergranular in nature, along prior austenite grain boundaries in a basically tempered martensite matrix, and with very little branching in evidence.

\subsubsection{Scanning Electron Microscopy/Energy Dispersive Spectroscopy}

SEM of the fracture face of the crack revealed a "thumbnail-like" appearance, granular and covered with oxide scale, the latter varying from crystalline to powdery in appearance. All the EDS scans indicated the presence of $\mathrm{Fe}$ and $\mathrm{Cr}$, while many also displayed a $\mathrm{Zn}$ peak. One scan also had $\mathrm{Al}$ and $\mathrm{Si}$ peaks present. No known corrodent species were identified by the EDS scans. The appearance of $\mathrm{Zn}$ on the fracture face could not be explained, unless a $\mathrm{Zn}$-based lubricant was used somewhere on the valve near the packing gland area. It appeared that the further the scan moved away from the initiation surface, the lower the $\mathrm{Zn}$ peak, until near the leading edge of the crack no $\mathrm{Zn}$ was detected.

After the EDS evaluation, the fracture faces were deoxidized with endox-214. The resultant appearance confirmed that the fracture was predominantly intergranular with no indications of fatigue interaction.

\subsubsection{Discussion/Conclusions}

Type 410 stainless steel has been shown to be susceptible to SCC in the presence of sulfides, chlorides, acids, and even in pure water environments. In many cases, the cause of SCC can be attributed to the heat-treatment received by the material prior to service. The effect of heat treatment is so pronounced that tempering of the 400 Series stainless steels in the range of 700 to $1050^{\circ} \mathrm{F}$ is not recommended because it results in low and erratic impact properties and poor resistance to corrosion and stress corrosion. The use of AISI Type 410 stainless steel in PWRs is recommended only if it has been tempered above $1100^{\circ} \mathrm{F}$.

Three elements are essential if SCC is to occur: tensile stress (either applied or residual), a susceptible microstructure, and a corrosive environment. If any of these is absent, SCC will not occur. In the particular instance of the MSIV shaft at Farley Unit \#1, the tensile stress could simply have been residual quenching stresses still present after the tempering operation. The susceptible material condition was martensite tempered at too low a temperature (the MSIV shaft had been tempered at $950^{\circ} \mathrm{F}$ ). PWR operating conditions provided the environment in which this material is susceptible to SCC.

From the above analysis, it was concluded that the cracking observed in the MSIV shaft resulted from intergranular stress corrosion cracking of a high hardness-susceptible material under pressurized water reactor conditions. The environmental causative agent was assumed to be clean steam, in the absence of any positive evidence of species known to cause this type of failure. 


\subsection{Investigation of Failed Type 410 Stainless Steel Shafts from Main Steam Isolation Valves at Two Operating Plants}

Reference: Paper Number 97, Corrosion/87, The International Corrosion Forum Sponsored by the National Association of Corrosion Engineers, San Francisco, CA.

Author(s): $\quad$ C. J. Czajkowski

Date: $\quad$ March 1987

Task: $\quad$ FIN A-3500

Key words: $\quad$ Farley Unit 1; high hardness susceptible material; intergranular stress corrosion cracking; R.E. Ginna; Type 410 stainless steel

\subsubsection{Background}

During refueling outages at the Joseph M. Farley Unit 1 and R.E. Ginna nuclear power plants, linear indications were observed on MSIV shafts. Dye penetrant examinations indications ranging in length from 1 inch to 33 inches. A second MSIV shaft at Ginna was also dye penetrant tested but showed no evidence of linear indications.

In order to evaluate more fully the failure characteristics of the cracked shafts, the NRC had the affected shafts (plus the apparently uncracked shaft from Ginna) sent to BNL for examination consisting of:

* visual inspection/photography

* optical microscopy

* chemical analysis

* hardness testing

* scanning electron microscopy/energy dispersive spectroscopy.

The evaluation conducted on the Farley shafts is summarized in the previous item (item 9.1). That of the Ginna shafts is summarized below.

\subsubsection{Visual Inspection/Photography}

The shafts, which were constructed from ASTM A-276 Type 410 stainless steel in the quenched and tempered condition, contained no visible marks except for one greyish smear on the cracked shaft. The smear tumed out to be an iron-epoxy filler material used to fill in the area where a crack indication had been ground out.

\subsubsection{Optical Microscopy}

Cross-sections through the linear indication revealed the existence of intergranular cracking with very little branching. Etching disclosed the martensitic microstructure with little evidence of tempering. It also became apparent that the cracking had occurred on prior austenite grain boundaries.

\subsubsection{Chemical Analysis}

Chemical analysis confirmed the material to be within the specifications for Type 410 stainless steel. 


\subsubsection{Hardness Testing}

The average hardness value for the cracked shaft was $44.8 \mathrm{HRC}$, that for the uncracked shaft $44 \mathrm{HRC}$. Such values are much higher than the 37-39.5 HRC that would be expected for Type 410 stainless steel quenched and tempered to specification.

\subsubsection{Scanning Electron Microscopy/Energy Dispersive Spectroscopy}

Three fracture faces were examined by SEM; all were intergranular in appearance, with no evidence of a fatigue component. EDS scans typically showed peaks from the expected $\mathrm{Fe}, \mathrm{Cr}$, and $\mathrm{Ni}$, plus one from $\mathrm{Si}$.

\subsubsection{Discussion/Conclusions}

It was apparent from the analysis that R.E. Ginna MSIV shafts met the chemical composition requirements of a Type 410 stainless steel. However, the microstructure of the base material was martensitic in nature with very little evidence of tempering. The corresponding hardness measurements were exceptionally high, with the cracked shaft having values in the range 42.9-45.0 HRC. Such high hardness values cast doubt that the tempering operations were performed at a sufficiently high temperature for adequate service life.

The cracking was intergranular in nature and occurred along prior austenite grain boundaries. There were no definite corrosive species observed nor was there any evidence of fatigue contribution. It was concluded that most probably the failure mode was IGSCC brought about by the material being in a high hardness/susceptible condition due to improper tempering.

\subsection{Evaluation of a Failed River Water Pump Shaft Coupling from the Beaver Valley Power Plant}

$\begin{array}{ll}\text { Reference: } & \text { Report MT L-1529-6 } \\ \text { Author(s): } & \text { C.J. Czajkowski } \\ \text { Date: } & \text { April } 1992 \\ \text { Task: } & \text { FIN L-1592 }\end{array}$

Key words: Beaver Valley; improper heat treatment; intergranular cracking; temper embrittlement; Type 410 stainless steel

\subsubsection{Background}

In October 1991 a coupling of a river water pump shaft at the Beaver Valley Nuclear Power Plant failed during operation. The coupling was used to join two shafts of a Byron Jackson Vertical Circulator river water pump. The pump rotates at $1170 \mathrm{rpm}$ in river water of $32-90^{\circ} \mathrm{F}$ and produces a discharge pressure of $68 \mathrm{psi}$. The coupling was provided by Byron Jackson as part of an order containing 12 identical couplings.

A utility-sponsored preliminary root cause analysis concluded that the failure occurred due to an improper heat treatment being applied to the Type 410 stainless steel couplings which resulted in a temper embrittled condition, making the component susceptible to cracking. BNL was requested to perform an independent analysis and subsequently received six pieces sectioned from the coupling. The BNL investigation consisted of: 
* visual examination/chemical analysis

* optical microscopy

* $\quad$ scanning electron microscopy

* hardness/tensile/Charpy impact testing.

\subsubsection{Visual Examination/Chemical Analysis}

Visual inspection showed an oxide coating on the fractures and the appearance of worn threads on the inside surface of the coupling. There was no sign of heat tinting or of the presence of high-temperature oxides, both of which would have been indicators of heat treatment cracking. The chemical analysis was consistent with that expected for a typical heat of Type 410 stainless steel.

\subsubsection{Optical Microscopy}

Optical microscopy revealed the cracking to be intergranular and the microstructure to be tempered martensite, typical of that of a Type 410 stainless steel.

\subsubsection{Scanning Electron Microscopy}

SEM examination of the fracture surfaces indicated that the mode of failure was solely intergranular. There were signs of fatigue interactions.

\subsubsection{Hardness/Tensile/Charpy Impact Testing}

The average hardness was determined to be equivalent to $32 \mathrm{HRC}$, representative of that of Type 410 stainless steel tempered at about $1000^{\circ} \mathrm{F}$.

Tensile tests produced an average tensile strength of $141.1 \mathrm{ksi}$, comparable to the $145 \mathrm{ksi}$ of a typical Type 410 stainless steel tempered at $1000^{\circ} \mathrm{F}$. However, the yield strength of $88.6 \mathrm{ksi}$ was considerably less than the typical value of $115 \mathrm{ksi}$. The elongation, at $15 \%$, was lower than the typical $20 \%$. This indication of a degree of embrittlement was confirmed by examination of the fracture surfaces of the tensile specimens.

Charpy impact tests were performed on specimens in various conditions: "as received," after vacuum degassing for 48 hours, and after heat treating at $1300^{\circ} \mathrm{F}$ for one hour and oil quenching. The as-received and the vacuum degassed specimens had low absorbed energy values, in the range 8 to $15 \mathrm{ft}-\mathrm{lb}$ and the fracture surfaces appeared virtually completely intergranular. However, the heat treated material showed an eight-fold increase, to 120 $\mathrm{ft}-\mathrm{lb}$, and exhibited predominantly a shear fracture mode. Sections of these specimens were then examined metallographically using an ethereal picric etch and confirmation was obtained that the as-received material was in a temper-embrittled condition whereas the heat-treated/oil quenched material was not.

\subsubsection{Discussion/Conclusions}

The chemical analysis of the failed Beaver Valley river water coupling verified that the coupling was made from Type 410 stainless steel and that the tensile strength was reasonably consistent with that expected for this type of material tempered at $1000^{\circ} \mathrm{F}$. However, there was a reduction in ductility and yield strength from expected values, and the impact energy was extremely low (8-15 ft-lb). The latter was markedly increased (to $120 \mathrm{ft}-\mathrm{lb}$ ) after a corrective heat treatment was performed.

The observed cracking in the failed coupling was intergranular and appeared to follow prior austenite grain boundaries in the tempered martensitic alloy matrix. There was no evidence of heat tinting and no high temperature 
oxides present on the fractures, precluding the possibility of heat treatment cracking. The results obtained using an ethereal picric etching technique indicated that the material was in a temper embrittled condition.

Based on the observations made during the evaluation and a literature review of all the possible failure mechanisms, it was concluded that the root cause of the failure was temper embrittlement of the Type 410 stainless steel coupling brought about by improper heat treatment of the coupling during manufacture.

\subsection{Thermal Embrittlement Test Method Development for Type 410 Stainless Steel}

Reference:

Report MCE-E2087-01

Author(s): $\quad$ C. Czajkowski, E. Edwards, K. Warburton, M. Dascoli

Date: $\quad$ December 1993

Task: $\quad$ FIN E-2087

Key words: ethereal picral etchant; non-destructive test; thermal embrittlement; Type 410 stainless steel

\subsubsection{Background}

There had been several instances of cracking of Type 410 stainless steel in nuclear plant applications. Three such have been described in items 9.1, 9.2 and 9.3, and other occurrences took place at Oconee, Brunswick Unit 2 and Brown's Ferry. The failures were related to improper heat treatment of the material and resulted in thermal embrittlement and subsequent stress corrosion cracking of Type 410 stainless steel components. Temper embrittlement occurs when specific steels are cooled slowly through (or are held at) temperatures in a defined range and is generally only detectable via notched-bar impact tests. This led the NRC to place a contract with BNL for the development of a non-destructive etch for the determination of possible thermal embrittlement, in order that components in such a condition could be identified before being placed in service. The program consisted of:

* identifying a prospective etchant

* $\quad$ selecting Type 410 stainless steel specimens and performing heat treatments on them

* microhardness testing, to verify material condition

* Charpy impact testing

* applying etchant to specimens and recording the microstructural observations.

\subsubsection{Etchant}

The etchant selected for testing was the ethereal picral etch. This etch is known to be extremely sensitive to phosphorus, one of the impurities in steel that segregate to the prior austenite grain boundaries when the steel is held within a certain range of temperatures dependent on its composition. The ethereal picral etch contains picric acid $(50 \mathrm{~g})$, purified ethyl ether $(250 \mathrm{ml})$, Zephiren chloride $(10 \mathrm{ml}$ of a $12.8 \%$ solution), and $240 \mathrm{ml}$ water.

\subsubsection{Materials/Heat Treatments/Hardness Testing}

Type 410 stainless steel was taken from two past programs (see items 9.1 and 9.3 ), each differing in composition and prior treatments. Eleven samples were taken from each program and cut to similar dimensions. After austenitization at $1700^{\circ} \mathrm{F}$, samples were oil quenched then those to be tempered were heat treated for one hour 
at one of several temperatures $\left(200^{\circ} \mathrm{F}, 400^{\circ} \mathrm{F}, 600^{\circ} \mathrm{F}, 800^{\circ} \mathrm{F}, 850^{\circ} \mathrm{F}, 900^{\circ} \mathrm{F}, 950^{\circ} \mathrm{F}, 1000^{\circ} \mathrm{F}, 1100^{\circ} \mathrm{F}, 1200^{\circ} \mathrm{F} 1400^{\circ} \mathrm{F}\right)$. Following the tempering, all except one of the samples were water quenched. The exception was furnace cooled after tempering at $1200^{\circ} \mathrm{F}$.

The hardness remained relatively constant and independent of tempering temperature up to about $900^{\circ} \mathrm{F}$, after which it began to drop as the specimen passed through the critical range. The recorded hardness values were in line with those that would be expected from this type of material after being subjected to the various tempering conditions.

\subsubsection{Charpy Impact Testing}

Charpy impact tests were performed on samples tempered at $850^{\circ} \mathrm{F}, 900^{\circ} \mathrm{F}, 950^{\circ} \mathrm{F}$, and $1000^{\circ} \mathrm{F}$. The results showed much reduced absorbed energy values (around $15 \mathrm{ft}-\mathrm{lb}$ ) for the tempered samples when compared with the as-received sample ( $45 \mathrm{ft}-\mathrm{lb})$.

\subsubsection{Microstructural Observations}

For those specimens simply austenitized and those tempered in the range of $200-850^{\circ} \mathrm{F}$, and at $1400^{\circ} \mathrm{F}$ there appeared to be no effect on the specimens from the etchant. The only observation was that small pits appeared on the surface. As the tempering temperature reached $900^{\circ} \mathrm{F}$, there was obvious etching, indicating a change in microstructural condition. Thus the point at which this particular heat of Type 410 stainless steel became embrittled appeared to be in the $850-900^{\circ} \mathrm{F}$ range. Those specimens tempered within the range of $950^{\circ}-1200^{\circ} \mathrm{F}$ appeared to have their microstructure highly defined by the etchant. The prior austenite grain boundaries were defined in addition to the martensitic structure. After a slight repolishing, the prior austenite grain boundaries became more evident. Comparison of the two sets of samples tempered at $1200^{\circ} \mathrm{F}$ showed that the furnace cooled specimen had darker highlights created by the etchant than those water quenched.

\subsubsection{Discussion/Conclusions}

It is believed that for each steel there is some range of temperatures at which, if the steel is tempered or cooled slowly enough, it will be susceptible to temper embrittlement. The specific temperature ranges for the tested Type 410 stainless steels were unknown, so a variety of tempering temperatures were tested. There was a vast difference in the effects of the ethereal picral etch on the differently treated specimens. Those tempered between $900^{\circ}-1200^{\circ} \mathrm{F}$ showed a significant amount of etching, whereas the others showed no apparent etching. The measured hardness values were as would be expected for this type of material and indicated that a change in properties occurred between $850^{\circ} \mathrm{F}$ and $900^{\circ} \mathrm{F}$. Charpy impact tests confirmed this change, which manifested itself in a significant loss of ductility.

The conclusion was that the ethereal picral etchant had proved to be an effective determinant of temper embrittlement in Type 410 stainless steel. The etch delineated microstructures of temper-embrittled material while performing no apparent etching on Type 410 stainless steel that is not embrittled. Thus the etch was non-destructive in nature and lent itself to field applications and receiving inspection of critical components. 
\begin{tabular}{|} 
\\
\\
\\
\\
\\
\\
\\
\\
\end{tabular} 


\title{
10 THERMAL SHOCK
}

\subsection{Evaluation of the Vent Header Crack at Edwin I. Hatch Unit \#2}

\author{
Reference: $\quad$ Report BNL-NUREG-34709 \\ Author(s): $\quad$ C. J. Czajkowski \\ Date: $\quad$ April 1984 \\ Task: $\quad$ FIN A-3500
}

Key words: $\quad$ carbon steel; brittle fracture; Edwin I. Hatch Unit 2; nil ductility transition temperature; thermal shock

\subsubsection{Background}

On February 3, 1984 Georgia Power Company informed the NRC that a crack had been discovered in the vent header of the Edwin I. Hatch Nuclear Plant Unit 2. The NRC subsequently issued IE Bulletin No. 84-01 "CRACKS IN BOILING WATER REACTOR MARK I CONTAINMENT VENT HEADERS" (February 3, 1984), informing Mark I containment owners of the problem and requesting visual inspections on any plants which were in cold shut down at the time. Information notice No. 84-17, "PROBLEMS WITH LIQUID NITROGEN COOLING COMPONENTS BELOW THE NIL DUCTILITY TEMPERATURE," followed (March 5, 1984), documenting the results of the investigations required by bulletin No. 84-01 and giving a more detailed summary of the observations to date.

Preliminary inspections revealed that the crack was a brittle fracture which had resulted from cooling the vent header material to a temperature below the nil ductility transition temperature (NDTT) by the uncontrolled release of liquid nitrogen. The nitrogen discharge system, needed to evolve an inert environment in the torus, was designed to maintain the nitrogen temperature leaving the system at approximately $100^{\circ} \mathrm{F}$.

As a result of the original notification by the utility, the NRC initiated an independent failure analysis of some sections of the vent header at the Brookhaven National Laboratory. The analysis, designed to evaluate the failure mechanism and verify the vent header's mechanical/chemical and impact properties, employed several test methods:

$\begin{array}{ll}* & \text { visual inspection/photography } \\ * & \text { optical microscopy/metallography } \\ * & \text { chemical analysis } \\ * & \text { tensile and hardness testing } \\ * & \text { scanning electron microscopy } \\ * & \text { impact testing. }\end{array}$

\subsubsection{Visual Inspection/Photography}

Three pieces of the Hatch $\# 2$ vent header were received for evaluation: NRC-1 (a piece with an approx. 15 inches long crack), and NRC-2R and NRC-2L (opposing pieces separated by a "through wall" crack). Visual observation of the fracture face of NRC-1 indicated that the fracture was brittle. There were no indications of ductility nor of fatigue (no beach marks, etc.). There were some marks (rachet-type) on the fracture surface, but these would be typical of a fast fracture. 


\subsubsection{Optical Microscopy/Metallography}

A metallurgical cross-section of the vent header pipe and seam weld was cut, mounted and polished, and the specimen etched in a $10 \%$ Nital solution. The weld appeared to have been made using a single weld pass from each side. The microstructures of the base metal, weld metal and HAZ were all consistent with that of a $0.2 \%$ carbon steel welded in this manner.

\subsubsection{Chemical Analysis/Tensile Testing/Hardness Testing}

A chemical analysis was performed on the base metal from the vent header and it was determined that it met all of the chemical requirements of an ASTM A-516 Gr. 70 steel, with the exception that the carbon content was $0.01 \%$ greater than the maximum allowed. This very slight deviation was considered to be acceptable.

Four subsize tensile specimens were pulled, two having been cut longitudinal to the rolling direction of the original plate and two transverse to it. All four tensile strength values recorded fell within the requirements of the specification.

Microhardness testing produced average values of $180 \mathrm{HK}$ for the base metal, $181 \mathrm{HK}$ for the HAZ and 197 HK for the weld metal, values which are consistent for this type and grade of steel.

\subsubsection{Scanning Electron Microscopy/Impact Testing}

A total of 10 fracture face specimens from both NRC-1 and NRC-2 and examined by SEM in order to determine if the failure mode could be ascertained by fractography. In all cases the fracture faces exhibited a quasicleavage type fracture, indicative of brittle failure. This type of fracture would be expected if the steel was at or below its NDTT. There was no evidence of fatigue marks on any of the fracture faces.

Because the fracture morphology suggested a rapid, brittle failure of the material, a series of 18 Charpy "V" notch impact tests were performed on the vent header material. These tests were conducted on subsize specimens at varying temperatures from $-270^{\circ} \mathrm{F}$ liquid nitrogen) to $+100^{\circ} \mathrm{F}$, and included the operating conditions supposedly seen by the vent header $\left(0^{\circ} \mathrm{F}\right.$ to $\left.100^{\circ} \mathrm{F}\right)$.

The material's impact resistance is relatively good in the range of $100^{\circ} \mathrm{F}$ down to $0^{\circ} \mathrm{F}$ for the longitudinallycut specimens. Longitudinal specimens also had reasonable impact resistance at the lower temperatures, with the lowest energy appearing at $-270^{\circ} \mathrm{F}$. The fracture faces for these specimens showed some ductility in all but the $270^{\circ} \mathrm{F}$ test. The transition temperature of a material is normally defined as the temperature at which an impact specimen's fracture surface shows a 50\% ductile and 50\% cleavage structure. By this definition, the transition temperature for this material is approximately $-60^{\circ} \mathrm{F}$.

All of the nine transverse specimens tested had values of absorbed energy significantly lower (by a factor of approximately 3 ) than the longitudinally-cut specimens. This difference is not unexceptional and is in line with observations recorded in the literature for $0.12 \% \mathrm{C}$ steel plate. The fracture faces for these specimens show the tremendous amount of directionality associated with the rolling direction of this plate. However, as with the longitudinal specimens, all the fracture surfaces with the exception of the $-270^{\circ} \mathrm{F}$ test showed some ductility.

\subsubsection{Discussion/Conclusions}

The results from the analyses and tests performed indicated that the material of the Hatch $\# 2$ vent header met all the chemical and mechanical properties of ASTM A-516 Grade 70 material. The hardness and microstructure of the base metal, weld metal and HAZ in the area of the seam weld were similarly consistent with those expected for ASTM A-516 Grade 70 material. All of the fracture surfaces examined on the cracks were quasi-cleavage (brittle) 
in nature and there was no evidence of a fatigue contribution. The cracking was characteristic of very low temperature cracking. The NDTT for this material is considered to be about $-60^{\circ} \mathrm{F}$, based on impact test results and fracture face examinations. The transition temperature for this material is significantly outside the normal operating conditions for the vent header, thus it is considered likely that the failure occurred at or below the transition temperature. This inordinate cooling probably caused a thermal shock to the pipe resulting in a fast brittle fracture of the vent header.

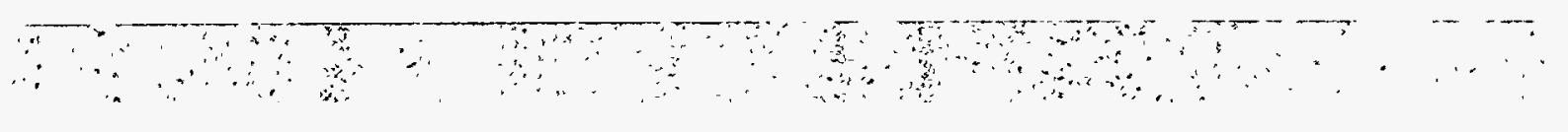





\title{
11 WEAR
}

\subsection{Investigation of Failed Tubes from "B" Steam Generator of the R.E. Ginna Nuclear Power Plant}

\author{
Reference: Report BNL-NUREG-31283 \\ Author(s): $\quad$ C.J. Czajkowski \\ Date: $\quad$ May 1982 \\ Task: $\quad$ NA
}

Key words: ductile overload; R.E. Ginna; steam generator tubing; wear damage

\subsubsection{Background}

In 1982 the R.E. Ginna nuclear power plant experienced a loss-of-coolant accident (LOCA) involving a steam generator tube rupture. Visual and video inspections had developed a "fishmouth" type crack. Additional inspections determined that various surrounding tubes had been severely degraded. It was suggested the failure was of a mechanical type, caused by an adjacent tube rubbing the outer surface of failed tube until the tube cross-section was worn to a thickness insufficient to withstand the pressure differential between the primary and secondary pressure boundary.

As part of a subsequent failure analysis program, seven tube sections were sent to BNL and subjected to an evaluation consisting of:

* visual inspection/photography

* dye penetrant examination

* optical metallography

* scanning electron microscopy/energy dispersive spectroscopy.

\subsubsection{Visual Inspection/Photography}

Visual inspection of the seven tubes, a mix of inner tubes and outer periphery tubes, revealed basically two types of damage, abrasion and impact, sometimes acting in conjunction. The former were characterized by longitudinal wear patterns, consistent with two tubes rubbing together for an extended period of time. In one case, this had led to a "fishmouth" type of fissure in the tube. The impact damage ranged from severe deformation to complete collapse of the tube.

\subsubsection{Dye Penetrant Examination}

Dye penetrant examination of the inside surfaces of the seven tubes found no indications of defects.

\subsubsection{Optical Microscopy}

Cross-sectional metallography disclosed the existence of varying degrees of cold working in some tubes, it being particularly significant in the one that had undergone collapse. However, none was detected in the tube with 
the "fishmouth" fracture. A slight amount of grain boundary "etching" was observed at the inside surface of one of the tubes.

\subsubsection{Scanning Electron Microscopy/Energy Dispersive Spectroscopy}

SEM of the "fishmouth" fracture surface showed it to be typical of that expected from a ductile overload failure mechanism. No evidence could be found of fatigue contributions. However, examination of a tube which had been collapsed and broken at the tube sheet did reveal fatigue striations. Another observation made was that the inside surface of one of the tubes had what initially appeared to be an intergranular crack. Later examination of this and other tubes indicated that this was the result of an etched microstructure resulting from a pickling operation. Metal smears, the consequence of impact damage, were also detected on the outside surface of some tubes.

EDS scans provided only limited information because the prior decontamination process apparently removed loose particles, thereby displacing evidence of the impacting material. Two locations with metal smears in evidence showed extremely high Fe peaks relative to those of $\mathrm{Cr}$ and $\mathrm{Ni}$. This was thought consistent with the impact of a carbon steel foreign object.

\subsubsection{Discussion/Conclusions}

It was determined that all the failures examined were caused by mechanical damage, either through wear/abrasion or an impact mechanism These had resulted in ductile overload fatigue type failures or mechanical collapse. The fact that inner tubes displayed a fretting type wear with no significant areas of cold work while outer periphery tubes displayed significant cold work, would be consistent with the hypothesis that damage occurred on the outer periphery tubes by impact with one or more foreign objects. This theory was substantiated by the discovery of iron smears on the outer surface of an outer periphery tube.

The grain boundary etching found on the inside surface of one tube was probably the result of an incomplete pickling operation done prior to its installation. It did not appear to have adversely affected the tubing or contributed in any way to the LOCA.

The final conclusion was that the initial tube rupture leading to the LOCA occurred as a result of the synergistic degradation of previously plugged steam generator tubes initially caused by impact and final severance of the outer periphery tubes by one or more foreign objects.

\subsection{Investigation of Reactor Coolant Pump Seal from Indian Point No. 2}

Reference: Intl. Journal of Pressure Vessels \& Piping, Vol. 27, pp. 325-334

Author(s): Carl J. Czajkowski

Date: $\quad 1987$

Task: $\quad$ NA

Key words: $\quad$ Indian Point Unit 2; rubber seal; wear damage

\subsubsection{Background}

BNL was requested to examine a RCP seal from the Indian Point Unit 2 in order to determine the cause of the leaking which had been observed. The analysis comprised:

NUREG/CR-6489 
* visual examination/photography

* scanning electron microscopy/energy dispersive spectroscopy.

The examination concentrated on a single seal element (the stationary portion of a first stage seal) and, in particular, on the 'double-delta' and 'O'-ring seals within that element. Both seals are made of rubber.

\subsubsection{Visual Examination/Photography}

Visual examination disclosed significant areas of degradation but no evidence of metallic wear or abrasion.

\subsubsection{Scanning Electron Microscopy/Energy Dispersive Spectroscopy}

SEM revealed a continuous wear line on the double-delta seal, such that it was virtually abraded in half. There was apparent cracking but no indication of foreign matter present. The ' $O$ '-ring seal showed signs of abrasion and a large area of material had been torn away. There was also an area of obvious cracking.

Two samples of debris from the inside surface of the seal were found by EDS to contain Fe and Mn. EDS scans of the double-delta and ' $O$ '-ring seals also revealed the presence of $\mathrm{Fe}$ and $\mathrm{Mn}$, together with traces of other elements (Cd, $\mathrm{Cr}, \mathrm{S}, \mathrm{Ca})$.

\subsubsection{Discussion/Conclusions}

The examination revealed no evidence that metal abrasion was a major factor in the wear of the seals, indicating that the degradation only occurred on the rubber sealing surfaces. It was postulated that wear damage could be reduced by minimizing or eliminating dry starts on the seals (thereby reducing heat buildup and wear). 



\section{OTHER FAILURE-RELATED REPORTS}

\subsection{Evaluation of Cracks Found in Indian Point Steam Generators Phase II}

Reference: $\quad$ Report MT-3851-3

Author(s): $\quad$ M. H. Schuster and C. J. Czajkowski

Date: July 1988

Task: $\quad$ FIN A-3851

Key words: $\quad$ impact testing; low-alloy steel; Indian Point Unit 2; nil ductility transition temperature; quasicleavage fracture

\subsubsection{Background}

A metallurgical investigation had been performed by BNL on cracked weld specimens removed from the Indian Point 2 Nuclear Power Station (see item 4.4). These specimens had been removed from the shell closure weld of the steam generators and during the examination a narrow hardened band (HRC 39-41) was observed adjacent to the weld fusion line. The closure weld specimens' microstructure was composed of weld metal (of typical columnar appearance), base material (a pearlitic-ferritic structure typical of the kind found in ASTM A-302 Grade $\mathrm{B}$ material) and a heat-affected zone. The latter contained a hardened band composed of martensite (slightly tempered), the hardness of which could not be reduced through stress relief at $1000^{\circ} \mathrm{F}$. Because utility predictions on crack growth rates had assumed the normal properties of ASTM A-302 Grade B material, the NRC funded a program at BNL to perform Charpy impact tests on material that simulated the atypical condition found in the cracked closure weld specimens. The subsequent program consisted of the following steps:

* hardness measurements/heat treatment

* Charpy impact tests

* optical microscopy

* $\quad$ scanning electron microscopy.

\subsubsection{Materials}

The material used in the investigation was a 6 inches $x 12$ inches piece of one-inch thick plate of ASME SA-302 Grade B. This material, a manganese-molybdenum alloy steel manufactured for boiler and pressure vessel applications, had been specified in the fabrication of the steam generator shells for the Indian Point 2 Nuclear Power Station.

\subsubsection{Hardness Measurements/Heat Treatment}

Ten sections (9/16" $\times 1$ " $\mathrm{x}$ approximately 6") were machined from the plate, then quenched and tempered (heated to $1500^{\circ} \mathrm{F}$, held at $1500^{\circ} \mathrm{F}$ for 1 hour, quenched in a $10 \%$ salt brine solution, tempered at $800^{\circ} \mathrm{F}$ for 1 hour, removed from the furnace, then air-cooled). Samples were cut from each section and Rockwell hardness readings taken. All the heat-treated samples fell within the hardness requirement of 35-40 HRC. 


\subsubsection{Metallography}

A section of the as-received material was sectioned, mounted, ground, polished, then etched in $10 \%$ nital solution. Optical microscopy of the section revealed that material's microstructure was pearlite and ferrite, typical of tempered martensite, and with the direction of rolling indicated by the grain and inclusion configuration.

\subsubsection{Impact Testing}

After completing the heat treatment and hardness verification, the ten sections were machined into standard Charpy V notch (CVN) impact specimens. The requirements of ASTM A-370, 1981 Edition, Simple Beam Impact Test Specimen Fig. 11 Type A and ASTM-E23, 1981 Edition, were utilized for all machining and impact testing requirements. Impact testing was completed as described in ASTM E 23 using a u-type pendulum machine with direct absorbed impact energy readout.

A total of 9 specimens were impact tested at three temperatures $\left(32,100\right.$ and $\left.200^{\circ} \mathrm{F}\right)$. Minimum absorbed energies measured were $19.5 \mathrm{ft}-1 \mathrm{~b}\left(32^{\circ} \mathrm{F}\right), 33 \mathrm{ft}-1 \mathrm{~b}\left(100^{\circ} \mathrm{F}\right)$, and $32 \mathrm{ft}-1 \mathrm{~b}\left(200^{\circ} \mathrm{F}\right)$.

\subsubsection{Scanning Electron Microscopy}

After impact testing, the specimens' fracture faces were examined by SEM in order to verify the fracture mode. The fracture surfaces exhibited a predominately shear fracture mode at all three temperatures. However, examination at high magnification indicated that the specimen with the highest absorbed energy $(31 \mathrm{ft}-1 \mathrm{~b})$ at $32^{\circ} \mathrm{F}$ indicated areas of ductile rupture characterized by numerous cup-shaped fracture sites, in some areas with a flatter fracture surface. This type of fracture surface, sometimes called quasi-cleavage, was observed over approximately $70 \%$ of the fracture face.

\subsubsection{Discussion/Conclusions}

Heat treating then Charpy impact testing $\left(32^{\circ} \mathrm{F}\right.$ to $\left.200^{\circ} \mathrm{F}\right)$ SA 302 Grade B Material provided evidence that the material will withstand impact energies of at least $19.5 \mathrm{ft}-1 \mathrm{~b}$ at $32^{\circ} \mathrm{F}$. This value is above the minimum specified in Appendix X2 of ASME SA-20 for carbon and low alloy steels of the strength of Grade B material.

Examination of the fracture surface of a sample tested at $32^{\circ} \mathrm{F}$ indicated quasi-cleavage over approximately $70 \%$ of the fracture surface. This would indicate a probable ductile-to-brittle transition temperature range of $32^{\circ} \mathrm{F}$ to $100^{\circ} \mathrm{F}$. The actual transition temperature cannot be determined more precisely without additional testing.

\subsection{Examination of Failed Controlled Closure Check Valve Bolts from the Seabrook Nuclear Power Plant}

Reference: $\quad$ Report MT-L1529-2

Author(s): $\quad$ C. J. Czajkowski

Date: $\quad$ August 1991

Task: $\quad$ FIN L-1529

Key words: $\quad$ bolting; ductile failure; low-alloy steel; Seabrook; tensile overload 


\subsubsection{Background}

Three 3/8" x 16" cracked bolts (hex headed capscrews) from a Controlled Closure Check Valve in the secondary side main feedwater line at the Seabrook Nuclear Power Plant were received at BNL. The valves had been manufactured by Edward Valves, Inc. (formerly Rockwell International) and the bolting (capscrew) material was specified as SAE A-193 Grade B7 with a minimum yield strength of $108 \mathrm{ksi}$. The valve company had determined that the bolts failed as a result of tensile overload. BNL was requested to evaluate the three cracked bolts to confirm the failure mode and to assess the probability of other check valves being susceptible to stress corrosion cracking. The subsequent investigation consisted of:

$\begin{array}{ll}* & \text { visual/photography } \\ * & \text { scanning electron microscopy } \\ * & \text { hardness measurements/optical microscopy. }\end{array}$

\subsubsection{Visual/Photography}

The specimens received from Seabrook consisted of two capscrews (bolts) with hexagonal heads and one bolt with no head. Markings on the head of two of the bolts indicated that they were manufactured from B-7 material. The three bolts (identified as numbers 1,2 and 3 for ease of reference) appeared (visually) to have failed in a ductile manner with distortion of the threaded area quite evident.

\subsubsection{Scanning Electron Microscopy}

Initial examination of the fracture faces disclosed that the surfaces were covered by a tight and adherent oxide film. In order to characterize more fully the fractographic features of the cracks, the bolts were then subjected to electrolytic cleaning.

Examination of the cleaned fracture faces from all three bolts disclosed ductile failure in all areas examined. There were no indications of brittle failure (IGSCC, etc.) on any of the three fracture faces examined. All three areas examined had indications of progressive crack growth prior to failure, suggesting the possibility that, after one bolt broke, the others proceeded to crack at their own rate based on preload conditions. This concept is consistent failures of bolts on flanges. There were no definitive indications of fatigue on any of the three fracture faces.

\subsubsection{Hardness Measurements/Optical Microscopy}

Rockwell "C" scale hardness measurements were performed on the shoulders of the two bolts received with their heads intact. Both bolts averaged above HRC 28. This equates to a tensile strength of approximately $132 \mathrm{ksi}$, consistent with the manufacturer's certification for these bolts.

All three bolts were longitudinally sectioned, mounted in epoxy and metallurgically polished. Secondary cracking was evident at the thread root of many of the visible threads. These cracks were not branched and appeared to turn in the direction of the fracture face (along the line of axial tensile stress). This is a strong indicator of ductile overload with high stresses being applied more than once prior to final failure. At high magnification, one thread tip showed a distinct "crack-like" separation, indicating that these threads were probably rolled.

\subsubsection{Discussion/Conclusions}

The hardness testing confirmed that the tensile strengths of two of the capscrew/bolts met the specification standards for SAE A-193 Grade B-7 bolts. There was no evidence of brittle failure, the entire fracture surface having the appearance of ductile fracture. This observation, coupled with the thread deformation and secondary cracks, 
indicated that a ductile overload (either preload or operating stresses) caused the failures. The probable mode of failure was a cascade effect of bolt failures after the first bolt had broken.

\title{
12.3 Millstone Bolt Evaluation
}

\author{
Reference: Report MCE-E2089-01 \\ Author(s): $\quad$ C. J. Czajkowski \\ Date: $\quad$ January 1994 \\ Task: $\quad$ FIN E-2089
}

Key words: $\quad$ bolting; discontinuities; low-alloy steel; Millstone; pitting; tensile properties

\subsubsection{Background}

BNL was requested to independently evaluate ten bolts removed from the Millstone Nuclear Power Station in order to verify results previously reported by the licensee.' The evaluation was to include the following subtasks:

* determine and record the dimensional characteristics (including threads) of each bolt per ANSI B.18.2.1;

* identify and photograph any defects or deficiencies noted in the bolts;

* $\quad$ perform tensile tests per ASTM A-193 Grade B7 on two selected bolts (up to two additional tests would be performed if any of the bolts did not meet specific requirements);

* determine the chemistry of the tensile tested bolts (minus the plating) using the method described in ASTM A 193 B7;

* document the results in a technical letter report.

The evaluation involved a total of ten 5/16-inch diameter bolts, comprised of two each of five different lengths from 1.5 to 4.5 inches. Pitting of the shank area was evident on all of the bolts, in addition to which there was a distinct "bending" of a 4.5 inch long bolt.

\subsubsection{Dimensional Characteristics}

The dimensional characteristics evaluation (to ANSI B.18.2.1) revealed that five of the ten bolts (two 4.5 inch, two 4.0 inch and one 2.5 inch) had oversized heads. In addition, one of the 4.5 inch bolts had a double bend.

\subsubsection{Discontinuities}

Seven of the ten bolts had discontinuities, the most prevalent of which was disruption of the protective coating on the bolts and subsequent pitting. The pitting was categorized as significant to severe on two 1.5 inch, one 2.5 inch, and both 3.0 inch bolts. Possible arc strikes were also seen on both 1.5 inch bolts. One of the 4.0 inch bolts had the head markings stamped dramatically off center on the bolt head.

\subsubsection{Tensile Testing}

Two bolts (4.0 inch and $4.5 \mathrm{inch}$ ) that were considered relatively straight had their shoulders machined and then were tensile tested. Both specimens met the ultimate tensile requirements for ASTM A-193 B7 bolts, but the 
4.5 inch bolt failed the yield strength requirement. Two additional 4.0 inch and 4.5 inch bolts were subsequently tested and both found to pass the mechanical test requirements.

\subsubsection{Chemical Testing}

Chemical analysis of the first two bolts tested indicated that both met the specifications with the exception that the bolt that failed the yield strength requirement also did not meet the minimum carbon content. This would be consistent with the low yield strength results.

\subsubsection{Discussion/Conclusions}

The findings from the evaluation were summarized as follows:

* five of the ten bolts examined had oversized heads and one other had the head stamping significantly off-center;

* pitting, ranging from moderate to severe, was noted on five of the bolts, two of which had evidence of arc strikes;

* three of the four bolts tested passed the mechanical test requirements but the fourth one failed to meet yield strength minimum;

* one of the two bolts tested met all the chemical composition requirements but the bolt that did not meet the yield strength minimum was also found not to meet the carbon content minimum.

\subsection{Millstone Bolt Evaluation - 2}

Reference: $\quad$ Report MCE-E2089-04

Author(s): $\quad$ C. J. Czajkowski

Date: $\quad$ April 1994

Task: $\quad$ FIN E-2089

Key words: bolting; dimensional characteristics; hardness; low-alloy steel; Millstone; tensile properties

\subsubsection{Background}

BNL was requested to independently evaluate thirty bolts removed from the Millstone Nuclear Power Station in order to verify results previously reported by the licensee. The evaluation included the following subtasks:

* identify, visually inspect and photograph any defects or deficiencies noted in the bolts;

* determine and record the dimensional characteristics (including threads) of each bolt per ANSI B.18.2.1.

* perform tensile tests on three selected bolts using the method described in the appropriate ASTM or ASME specification (up to two additional tests would be performed if any of the bolts did not meet specific requirements); perform hardness tests on all thirty bolts; determine the chemistry of the tensile tested bolts; document the results in a technical letter report. 
The thirty bolts encompassed 10 different sizes, with diameters ranging from 5/16-inch to 1 inch and lengths from 3.5 inches to 5.0 inches. Various ASME and ASTM specifications were involved: SA-193 Grade B6, SA-453 Grade 660A, A-193 Grade B7, A-193 Grade B8, A-193 Grade B8M.

\subsubsection{Visual Inspection/Photography}

Visual inspection of the bolts revealed no noticeable defects in any area. Those bolts that were plated had no voids or pits. There was no bend in the body of any of the bolts and all the markings were clear.

\subsubsection{Dimensional Characteristics}

The results of the dimensional characteristics evaluation indicated that all thirty bolts met the dimensional requirements of ANSI B.18.2.1. All but four of the bolts passed the screw thread acceptability requirements of ANSI/ASME B1.3.

\subsubsection{Tensile Testing} requirements.

All the ten bolts that were tensile tested met or exceeded the applicable specification tensile property

\subsubsection{Hardness Testing} requirements.

All thirty bolts were hardness tested using a Rockwell hardness tester. All values fell within the specification

\subsubsection{Chemical Analyses}

Chemical analyses were performed on ten of the bolts. All ten met the applicable specification requirement for chemical constituents.

\subsubsection{Discussion/Conclusions}

In general, the bolts were found to be of high to very high quality with no obviously discernible defects. The only detected imperfections were the failure of four bolts to pass the thread fit inspection.

\subsection{Evaluation of Stainless Steel Tubes from TVA}

Reference: Report MCE-E2089-03

Author(s): $\quad$ Carl J. Czajkowski

Date: $\quad$ April 1994

Task: $\quad$ FIN E-2089

Key words: $\quad$ flattening testing; hardness; tensile testing; type 304 stainless steel 


\subsubsection{Background}

BNL was requested to independently evaluate four heavy wall stainless steel tubes received from TVA, in order to verify that the materials met ASME requirements (SA-213). The evaluation included the following subtasks:

* visually inspect and photograph all tubes;

* determine the hardness of each tube;

* conduct a tensile test on a sample from each tube;

* conduct flaring/flattening tests on a sample from each tube;

* determine the chemistry of each tube;

* determine and record the dimensional characteristics

* examine the microstructures for the presence of carbides;

* document the results in a technical letter report.

\subsubsection{Visual Inspection/Photography}

No visual defects were observed on any of the tubes.

\subsubsection{Hardness Testing}

All tubes met the specification requirement for a maximum hardness of $85 R_{b}$.

\subsubsection{Tensile Testing}

All tubes met the minimum specification requirements for mechanical properties.

\subsubsection{Flaring/Flattening Tests}

No cracks or gross imperfections were noted on the flare edges and inside surface following flaring tests according to ASTM A-450.

\subsubsection{Chemical Analysis}

The results of the analyses indicated that all tubes met the chemical requirements of the specification.

\subsubsection{Dimensional Characteristics}

All four tubes were determined to have wall thicknesses and outside diameters within specification.

\subsubsection{Microstructural Examination}

Samples from each tube were subjected to testing according to Practice A of ASTM A-262, in order to determine the degree of sensitization present. Metallographic evaluations of specimens following the oxalic acid etch test indicated that the tubes were not sensitized.

\subsubsection{Discussion/Conclusions}

It was established that the four pieces of tubing examined met the mechanical, chemical and dimensional requirements of ASME SA-213. 


\title{
12.6 Verification of False UT Indications in Cooper Closure Studs
}

\author{
Reference: Technical Letter Report attached to letter from Biays S. Bowerman to James Davis \\ (NRR/DE/EMC), dated September 27, 1995 \\ Author(s): $\quad$ Carl J. Czajkowski, Biays S. Bowerman, Thomas C. Roberts \\ Date: $\quad$ September 1995 \\ Task: $\quad$ FIN E-2089
}

Key words: $\quad$ bolting; Cooper; corrosion; magnetic particle testing; ultrasonic testing

\subsubsection{Background}

During a 1991 refueling outage at the Cooper Nuclear Power Station, the reactor vessel closure studs were examined using end shot ultrasonic inspection and bore probe UT. 'Of the 52 studs examined, 51 showed crack-like indications that ranged from 1/8 to $11 / 8$ inches deep, according to the UT data. General Electric (GE) Nuclear examined the stud with the deepest indication but could find no crack. Nevertheless, all 52 studs were replaced with new closure studs. The NRC then requested BNL to verify independently that vessel closure studs can be examined with UT to detect reliably cracks and other imperfections. A reactor pressure vessel closure stud was subsequently provided by Cooper and BNL performed the following subtasks:

* reviewed documents describing non-destructive tests on Cooper studs

* conducted magnetic particle tests, and confirmatory end shot and $60^{\circ}$ bore probe UT examinations of a closure stud provided by Cooper

* conducted destructive examinations to verify any UT indications found in the stud.

\subsubsection{Document Review}

The documents provided for review were five data sheets, two UT procedures and a GE report on the nondestructive examination of closure studs at Cooper. The findings of the GE study showed that false indications taken using a single UT technique could be resolved with other UT methods. Simulated cracks (electric discharge machining (EDM) notches) of at least 0.060 inch depth and 0.025 inch width were detected in the presence of false indications. The GE report demonstrated that one source of false indications in closure studs was corrosion in the threads. Another potential source of false indications was found to be the end shot technique, with false indications arising from too high a pulse repetition rate.

\subsubsection{Magnetic Particle/Confirmatory UT Tests}

The reactor pressure vessel closure stud provided by Cooper initially had a small amount of surface contamination, as well as surface corrosion, particularly in the threads. EDM notches, cut to simulate circumferential cracks, were clearly visible. The stud developed more corrosion on its smooth surfaces as well as the threads during subsequent months as delays were experienced acquiring equipment. Prior to the testing, the threads were cleaned with a wire brush to reduce the potential for phantom cracks.

With the magnetic particle technique, no indications were found other than the EDM notches and surface gouges, presumably from tools. The end shot UT method identified the EDM notches as the only reportable indications. The $60^{\circ}$ bore probe UT examination revealed two reportable indications, in addition to the EDM notches. These indications were located in threads characterized by pitting and corrosion, one in the lower threaded region, and one in the upper, each within two inches of the smooth bore. 


\subsubsection{Destructive Examination}

After the indications had been located and marked, the stud was sectioned and the two sections examined using dye penetrant. No indications of cracks were found in either piece. Optical microscopy of the cross-sections revealed that the thread root at both indication points was packed with corrosion.

\subsubsection{Discussion/Conclusions}

The accuracy of UT inspections is a significant concern in nuclear power plants, since the technique is widely used. Undetected material flaws may lead to component and system failures but false indications may lead to economic burdens because of the replacement of serviceable components and increased worker exposures.

A GE report on tests conducted on some Cooper studs concluded that the false indications could be explained technically. The detection of phantom cracks was said to be conservative, because detection of simulated cracks (EDM notches) was still possible even though the corrosion product "phantoms" were present.

The magnetic particle and metallurgical sectioning examination conducted at BNL confirmed that corrosion in thread roots was a source of false indications. The false indications were obtained with a $60^{\circ}$ bore probe but not with the end shot method. The end shot method detected the same simulated cracks as the GE study. 


\section{APPENDIX \\ CHRONOLOGICAL LIST OF DOCUMENTS}

Brijesh Vyas, "Metallurgical examination of steam generator feedwater pipe cracks," BNL-NUREG-28146, July 1980.

C. J. Czajkowski, "Intergranular stress corrosion cracking of Type 304 stainless steel in the spent fuel pool piping of Three Mile Island Unit 1," BNL-NUREG-28879, October 1980.

C. Czajkowski, "Examination of failed turbine discs from Yankee-Rowe Nuclear Power Station," BNL-NUREG29964, March 1981.

C. Czajkowski, J. R. Weeks, and S. R. Protter, "Corrosion of structural and poison material in spent fuel storage pools," Paper Number 163, Corrosion/81, The International Corrosion Forum Sponsored by the National Association of Corrosion Engineers, Toronto, Canada, April 6-10, 1981.

Brijesh Vyas, Carl J. Czajkowski, and John R. Weeks, "Metallurgical examination of cracked feedwater pipes from nine pressurized water reactors," Nuclear Technology 55:525-537 (November 1981).

C.J. Czajkowski, "Investigation of failed tubes from "B" steam generator of the R.E. Ginna Nuclear Power Plant," BNL-NUREG-31283, May 1982.

C. J. Czajkowski, "Boric acid corrosion of ferritic reactor components," NUREG/CR-2827 (BNL-NUREG-51561), July 1982.

C. Czajkowski, "Failure analysis of a bolt from "B" reactor coolant pump at the H.B. Robinson Unit 2 Nuclear Power Station," BNL-NUREG-31530, July 1982.

Carl J. Czajkowski, "Evaluation of failed reactor coolant pumps internal bolts from the H.B. Robinson Nuclear Power Station," BNL-NUREG-31743, October 1982.

C.J. Czajkowski, "Evaluation of the transgranular cracking phenomenon on the Indian Point No. 3 steam generator vessels," NUREG/CR-3281, June 1983.

C. J. Czajkowski, "Constant extension rate testing of SA 302 Grade B material in neutral and chloride solutions," NUREG/CR-3614, February 1984.

Carl J. Czajkowski, "Testing of nuclear grade lubricants and their effect on A540 B24 and A193 B7 bolting materials," NUREG/CR-3766 (BNL-NUREG-51767) (also Paper 112 at Corrosion/85, Boston, MA, March 1985), March 1984.

C. J. Czajkowski, "Evaluation of the vent header crack at Edwin I. Hatch Unit \#2," BNL-NUREG-34709, April 1984.

C. J. Czajkowski, "Investigation of cracking on a main steam isolation valve shaft from the Farley Unit \#1 Nuclear Power Plant," BNL-NUREG-36717, August 1984.

C. J. Czajkowski, "Evaluation of the Pilgrim Inconel 182 cracking," Report A-3763 5-8-85, May 1985.

C.J. Czajkowski, "Investigation of corrosion and stress corrosion cracking in bolting materials on light water reactors," Intl. J. Pressure Vessels \& Piping 26:87-96 (1986). 
C. J. Czajkowski, "Metallurgical evaluation of an 18-inch feedwater line failure at the Surry Unit 2 Power Station," NUREG/CR-4868 (also BNL-NUREG-52057), March 1987.

C. J. Czajkowski, "Investigation of failed Type 410 stainless steel shafts from main steam isolation valves at two operating plants," Paper Number 97, Corrosion/87, The International Corrosion Forum Sponsored by the National Association of Corrosion Engineers, San Francisco, CA, March 1987.

C. Czajkowski, "Evaluation of boat samples from the steam generators at Indian Point No. 2," MT A-3851-1, December 1987.

C.J. Czajkowski, "Evaluation of core spray line cracks from Nine Mile Point Unit No. 1 and isolation condenser cracks at Oyster Creek Unit No. 1," Intl. J. Pressure Vessels \& Piping 27:1-15 (1987).

Carl J. Czajkowski, "Investigation of reactor coolant pump seal from Indian Point No. 2," Intl. J. Pressure Vessels \& Piping 27:325-334 (1987).

Carl J. Czajkowski, "Evaluation of intergranular cracks on the ring header cross at Grand Gulf Unit No.1," Intl. J. Pressure Vessels \& Piping 27:353-365 (1987).

C. Czajkowski, "Evaluation of a cracked RHR pump impeller from the Vermont Yankee Power Plant," MT-3851-2, February 1988.

G. Cragnolino and C. J. Czajkowski, "Erosion-corrosion in nuclear power plants," MT-3305-1, March 1988.

C. Czajkowski and M.H. Schuster, "Investigation of a reactor head bolt from Turkey Point No. 3," MT-3305-2, March 1988.

C. J. Czajkowski, M. H. Schuster and J. Clinton, "BWR pipe cracking evaluation," MT-3739-1, March 1988.

C. J. Czajkowski, "Failure investigation of 3M Series 900 static eliminators," NUREG/CR-5145, July 1988.

M. H. Schuster and C. J. Czajkowski, "Evaluation of cracks found in Indian Point steam generators Phase II," MT3851-3, July 1988.

C. J. Czajkowski, "Examination of a cracked reducer from the Trojan Nuclear Plant," MT-3851-5, October 1988.

C. J. Czajkowski, "Evaluation of dealloying in aluminum bronze components at the South Texas Project," MT-3851-4, November 1988.

C. J. Czajkowski, M. H. Schuster, and M. G. Cowgill, "Evaluation of pipe samples from the Trojan Nuclear Power Station," MT-3871-1, January 1989.

C. J. Czajkowski, "Examination of two 3M Type 902F static eliminators," NUREG/CR-5266, January 1989.

C.J. Czajkowski, "Survey of boric acid corrosion of carbon steel components in nuclear plants," NUREG/CR-5576, June 1990.

C. J. Czajkowski, "Evaluation of cracked pipe from Big Rock Point," MT-L1529-1, November 1990.

C. J. Czajkowski, "Examination of failed controlled closure check valve bolts from the Seabrook Nuclear Power Plant," MT-L1529-2, August 1991.

NUREG/CR-6489 
C. J. Czajkowski, "Evaluation of cracks found in Stellite valve guides at Vermont Yankee Nuclear Power Station," MT-L1529-3, September 1991.

C. J. Czajkowski, "Evaluation of cracked cap screws from the control rod drive mechanism of the Monticello Nuclear Power Plant," MT-L1529-4, October 1991.

C. J. Czajkowski, "Corrosion testing of thermal shield support system - San Onofre Nuclear Generating Station," MTL1529-5, December 1991.

C.J. Czajkowski, "Evaluation of a failed river water pump shaft coupling from the Beaver Valley Power Plant," MT L-1529-6, April 1992.

C. Czajkowski, B. Bowerman, M. Schuster, T. Roberts, and L. Milian, "Metallurgical evaluation of weld overlaid pipe sections from Brunswick Unit 2 Nuclear Power Station," NUREG/CR-5885, June 1992.

C. J. Czajkowski, "Palo Verde Unit 2 steam generator tube rupture review," MCE-E2089-02, August 1993.

C. Czajkowski, E. Edwards, K. Warburton and M. Dascoli, "Thermal embrittlement test method development for Type 410 stainless steel," MCE-E2087-01, December 1993.

C. J. Czajkowski, "Palisades Nuclear Plant safe-end to pipe cracking," MCE-E2087-02, January 1994.

C. J. Czajkowski, "Millstone bolt evaluation," MCE-E2089-01, January 1994.

C. J. Czajkowski, "Millstone bolt evaluation - 2," MCE-E2089-04, April 1994.

Carl J. Czajkowski, "Evaluation of stainless steel tubes from TVA," MCE-E2089-03, April 1994.

Biays S. Bowerman, Carl J. Czajkowski, and Thomas C. Roberts, "Examination of a bolt with boric acid attack from Three Mile Island Nuclear Generating Station," MCIT-E2089-01, February 1995.

Carl J. Czajkowski, Biays S. Bowerman and Thomas C. Roberts, "Verification of false UT indications in Cooper closure studs," Technical Letter Report attached to letter from Biays S. Bowerman to James Davis (NRR/DE/EMC), dated September 27, 1995. 
Summary of Failure Analysis Activities at

Brookhaven National Laboratory

3. DATE REPORT PUBLISHED

\begin{tabular}{l|l} 
MONTH & YEAR \\
tober & 1996
\end{tabular}

October

4. FIN OR GRANT NUMBER

E2089

5. AUTHOR(S)

6. TYPE OF REPORT

Technical

M.G. Cowgill, C.J. Czajkowski, and E.M. Franz

7. PERIOD COVERED (Inclusive Oates)

1980-1995

8. PERFORMING ORGANIZATION - NAME AND ADDRESS UI NRC, provide Division, Office or Region, U.S. Nuclear Regulatory Commission, and mailing address; if contractor, provide name and mailing addresst

Brcokhaven National Laboratory

P.O. Box 500

Upton, New York $1197 \hat{\jmath}$

9. SPONSORING ORGANIZATION - NAME AND ADDRESS IIf NRC, Iype "Same as above"; if contractor, provide NRC Division, Office or Region, U.S. Nuclear Regulatory Commission, and malling address,

Division of Engineering

Office of Nuclear Reactor Regulation

U. S. Nuclear Regulatory Commission

Washington, D. C. 20555-0001

10, SUPPLEMENTARY NOTES

\section{ABSTRACT (200 words or less)}

Brookhaven National Laboratory has for many years conducted examinations related to the failures of nuclear materials and components. These examinations include the confirmation of root cause analyses, the determination of the causes of failure, identification of the species that accelerate corrosion, and comparison of the results of nondestructive examinations with those obtained by destructive examination. The results of those examinations, which had previously appeared in various formats (formal and informal reports, journal articles, etc.), have been collected together and sumarized in the present report.. The report is divided into sections according to the general subject matter (for example, corrosion, fatigue, etc.). Each section presents sumaries of the information contained in specific reports and publications, all of which are fully identified as to title, authors, report number, or journal reference, date of publication; and FIN number under which the work was performed.

12. KEY WORDS/DESCR!PTOAS (List words or phrases that will assist researchers in locating the report.)

CORROSION-TESTING, FATIUURE MODE ANALYSIS-REACTOR COMPONENTS, NUCTEAR POWER PLANT-FAIIURES, REACTOR COMPONEENTS-CORROSION, Bibliographies, BNL, Boric Acid, Corrosion Fatigue, Cracking, Destructive Testing, Erosion, Evaluation, Fatigue, Intergranular Corrosion, Mechanical Properties, Nondestructive Testing, Physical Properties, Reviews, Stress Corrosion, wear

\begin{tabular}{l} 
13. AVAILABILITY STATEMENT \\
Unil imited \\
14. SECURITY CLASSIFICATION \\
(This Pogel \\
Unclassified \\
(This RePOrt) \\
Unclassified \\
15. NUMBER OF PAGES \\
\hline 16. PRICE
\end{tabular}




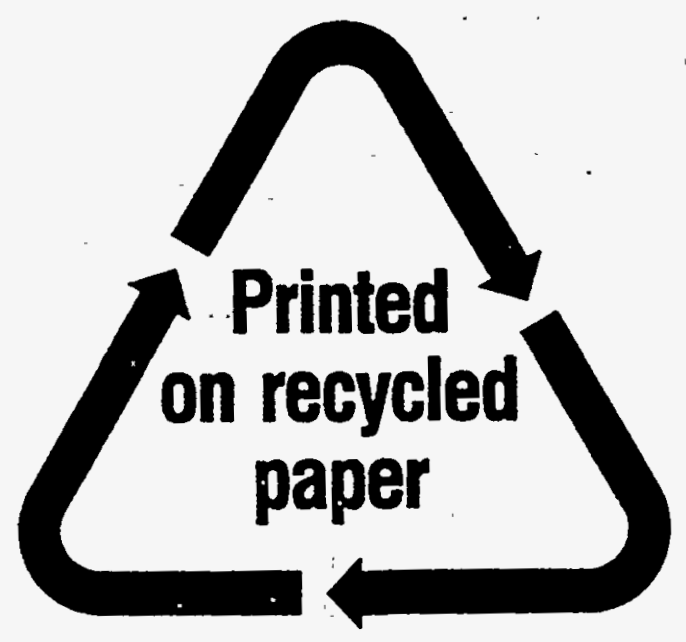

Federal Recycling Program 